\title{
WestVirginiaUniversity
}

THE RESEARCH REPOSITORY @ WVU

Graduate Theses, Dissertations, and Problem Reports

2010

\section{Virtual programs and their impact on Appalachian Ohio high schools}

Wendy Hanasky

West Virginia University

Follow this and additional works at: https://researchrepository.wvu.edu/etd

\section{Recommended Citation}

Hanasky, Wendy, "Virtual programs and their impact on Appalachian Ohio high schools" (2010). Graduate Theses, Dissertations, and Problem Reports. 2947.

https://researchrepository.wvu.edu/etd/2947

This Dissertation is protected by copyright and/or related rights. It has been brought to you by the The Research Repository @ WVU with permission from the rights-holder(s). You are free to use this Dissertation in any way that is permitted by the copyright and related rights legislation that applies to your use. For other uses you must obtain permission from the rights-holder(s) directly, unless additional rights are indicated by a Creative Commons license in the record and/ or on the work itself. This Dissertation has been accepted for inclusion in WVU Graduate Theses, Dissertations, and Problem Reports collection by an authorized administrator of The Research Repository @ WVU.

For more information, please contact researchrepository@mail.wvu.edu. 
Virtual Programs and Their Impact on Appalachian Ohio High Schools

\author{
Wendy Hanasky
}
Dissertation submitted to the College of Human Resources and Education at West Virginia University in partial fulfillment of the requirements
for the degree of

\author{
Doctor of Education \\ in \\ Technology Education
}

\author{
Terence C. Ahern, Ph.D., Chair \\ Paul Chapman, Ph.D. \\ Sebastián Díaz, Ph.D., J.D. \\ Denetta Dowler, Ph.D. \\ Pamela Whitehouse, Ph.D.
}

Department of Technology, Learning, and Culture

\author{
Morgantown, West Virginia \\ 2010
}

Keywords: virtual programs, fully online courses, blended courses, modified Delphi 


\section{Abstract \\ Virtual Programs and Their Impact on Appalachian Ohio High Schools \\ Wendy Hanasky}

Online learning has grown so much in recent years that researchers have struggled to keep up with its evolution. Practitioners are interested not only in how many schools are using online courses, but also how these courses are being delivered and how programs are being implemented.

The purpose of this exploratory study was to examine the impact of virtual programs on Appalachian Ohio school districts including: which Appalachian Ohio High Schools are using virtual programs, what programs are being used, and why these programs are in place. Rural school districts have added hardships because they are usually limited in course offerings due to budget constraints and geographic location. This study will specifically look at The Appalachian Ohio region and determine how the use of virtual programs is being implemented.

The outcomes of this study will help educators make more informed decisions on the educational infrastructure they create, as well as the support mechanisms in place for students. It is important that educational institutions understand how to best support their students throughout their educational career and provide the best training to prepare a $21^{\text {st }}$ century workforce. 


\section{Acknowledgments}

I have often said that if I ever won the lottery, I would give a portion of my winnings to the people who have inspired me throughout my life. Since I do not believe a windfall is coming my way any time soon, I would like to thank the following individuals for their contribution to making me who I am today and allowing me (in their own ways) to achieve this lifelong goal.

Husband Larry Hanasky

To my loving husband whose love and support enabled me to complete this lifelong goal. Because of you and your dedication to our family, I was able to spend the time needed to complete my dissertation. I am forever indebted to your graciousness. I Love You!

Daughter Sloan Hanasky

To my beautiful 3 year old daughter. I love you so much and I hope your Mommy's degree serves as an inspiration to you someday. You are such a joy to me and I wish you all that life has to offer. I Love You!

Son Landen Hanasky

To my handsome 6 month old son. Although this degree was done when you were very young, I hope someday you will come to know what it means to me. Thank you for taking three hour naps during those early months that allowed Mommy to work on her dissertation. You are such a good baby and I am so lucky to have you. I Love You!

\section{Dad Ken Fogle}

To the strongest man I know (and most stubborn!). You have always been my role model. Your work ethic, loyalty to family and friends, and strong values has made me what I am today. I feel so blessed that God allowed me to be raised by two extraordinary parents. You are a wonderful man who I am so grateful to have as a father!

Mom Sandy Fogle

To my soul mate in female form. Because you are truly the best Mom that ever was, I was able to complete this degree. You tirelessly supported me while I worked, watching my children and offering pep talks when needed. I could not have done this without you. You are such a great person and I am the luckiest daughter on Earth. Thank you for being you and being such an inspiration to me.

\section{Sister Karen Fogle}

To my sister, the hardest working, single Mom I know. You too are completing a degree this year, your Master's. Congratulations! You have a lot to be proud of, including your beautiful 11 year old daughter, Madison. Thank you for always supporting everything I do. Whether you are listening to me, babysitting my children, or helping me run errands, I truly appreciate having a sister like you who is close to me. There are many things in my life that I could not have done without you. Thank you for being so great! 
Brother K.C. Fogle

To the best brother! You have shown me what it is like to have true passion for your work. Helping others has been your life motto and it is inspiring to watch. When we are out together, I am still amazed at how many people know you and want to come and talk to you. With LaShawnda, Taylor (10), and Kyle (8), you have a beautiful family and much to be proud of. Thank you for always being there when I need you.

\section{Grandma June Frohnapfel}

To the woman who introduced me to shrimp by taking me on my first trip to Long John Silvers. When I was pregnant, that restaurant saw a lot of me! With the loss of Pap this year and moving to a new house, your strength has impressed me. You are a strong woman, with strong ideas, and that is great. Thank you for always checking in on me and for being so great with my kids. You are the best Grandma!

Grandpap Ray Frohnapfel

To the man with the tough reputation, but a teddy bear at heart. Your presence is extremely missed. I know our loss is heaven's gain, but I continue to think about you and look for you from time to time. I will never forget how good you were with Sloan. She loved you and you loved her - that was evident! Pap - I love you and I miss you!

Uncle Bruce Shane

To the best uncle! Brad Paisley sings a song about a Dad who "didn't have to be". When I hear that song, I substitute "Uncle" instead of "Dad". You didn't have to be, but you were. You have taken an interest in my life as far back as I can remember. In high school, you repeatedly told me to enjoy this time of my life and I will always remember that. As an adult, you still continue to support me and my family. I appreciate what you bring to our entire family and the giving person that you are.

Aunt Penny Shane

To the best aunt! You have always been my "go to" person from an early age. Whether it was to talk about my boyfriends, take my friends and I to park dances (that we weren't suppose to go to), or to borrow your "I have to be seen driving this car" sports car! I don't think you ever told me "No". Thank you for always encouraging and supporting me. I value you as my aunt.

Stephanie Sauvageot

To my best friend since kindergarten. There are no words for my appreciation for you. You have been there for me my entire life and I am so appreciative of the closeness we still share. You are such an inspiration of goodness. With three boys, a husband, and a full time job....you have your hands full; yet, you always find time to fit in your friends. I cherish you and our friendship.

Kari Roth

To my other best friend since $8^{\text {th }}$ grade. You are such a kind and giving person who has served as an inspiration to me for many years. I have always appreciated our friendship. You have intelligence, beauty, and compassion for others... a rare combination. Thank 
you for always being willing to listen and give support. I appreciate all of our years together and look forward to many more.

Patti Crunelle

To my high school sweetheart's Mom who became so much more. You were so much of an inspiration to me during my high school years. You showed me how good Christian people view the world, from your weekly church attendance, to your holiday traditions. I enjoyed my time with you and your family and you will always be someone I adore.

\section{Peggy Jenkins}

To my Cooperating Teacher that I was assigned to while student teaching. You are such a great teacher and I learned so much from you. Practices that I used while I taught high school were ones that I learned while under your charge. Your combination of teaching skill and true compassion for your students impressed me so much. I want you to know you made an impression on me that I still carry today.

\section{Craig Closser}

To one of the smartest men I have ever met. Singlehandedly, you have facilitated my professional growth more than any other person. I have grown so much, and learned so much from you. Thank you for teaching me that the Nike slogan is a motto we should all live by. Looking for every way possible in order to make something happen is the difference between those that succeed and those that accept the status quo. You are a great inspiration and I couldn't be more grateful for having the opportunity to work for you.

Joy Howell

To one of the kindest women I have ever met. You have an ability to lead with a caring hand. I can't thank you enough for your generosity while I was away from work. You never made me feel guilty about time off and always encouraged me to keep going. I appreciate your interest in me, my personal life, and my professional growth. You are a gem of a person who I enjoy working for.

Maribeth Arlia

To the best coworker I have ever worked with. From the beginning of your employment, we were able to just "click". At this point, we can just about finish each other's sentences.... and sometimes we know what each other is thinking without even speaking. Our working relationship has turned into a personal friendship that I cherish. Thank you so much for carrying my heavy load while I was out working on my dissertation. You are a great person and so fun to be around.

\section{Shaye Casper}

To a quality young lady who has so much going for her. You are good at everything you do. As a office mate, I couldn't ask for anything more. You are organized, thorough, and kind-hearted. It has been a pleasure watching you grow professionally. Thank you for your extra hard work while I was absent. I could leave the office knowing that our work was in good hands. 


\section{Dr. Ahern}

To my great Committee Chair that helped me through this entire process. I appreciate your guidance as I worked through my dissertation. Your firm, but caring, feedback allowed me to complete a quality research project that will hopefully help many stakeholders in the virtual program industry. Thank you for always making time for me and for coaching me through this lifelong dream experience.

\section{Ann Crabtree}

I can't thank you enough for all of your assistance throughout this process. I knew, without a doubt, that whatever I asked of you would be done. It took such a load off of my mind knowing that you were in the background coordinating the necessary paperwork, meeting times, etc. that allowed this ball to keep rolling. Your dedication to your job, your thoroughness, and your timeliness combines to make you a valued part of the WVU team. Thanks again for everything you did for me. 


\section{Table of Contents}

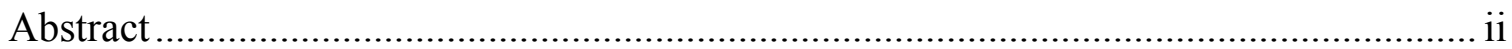

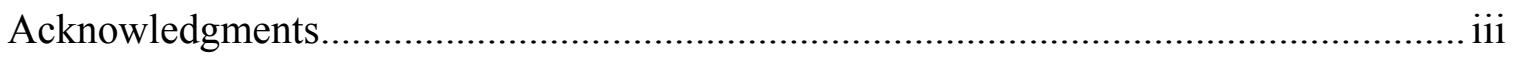

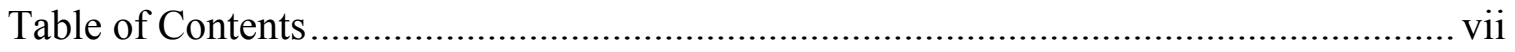

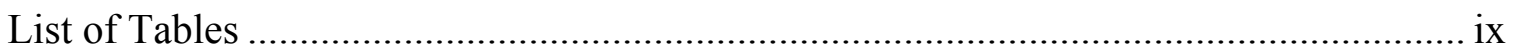

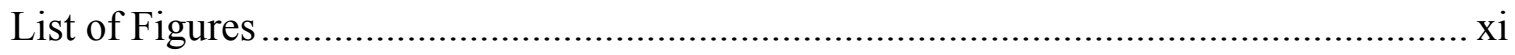

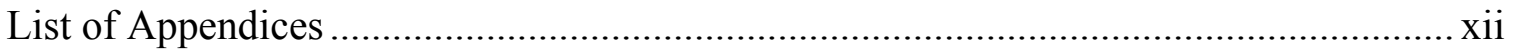

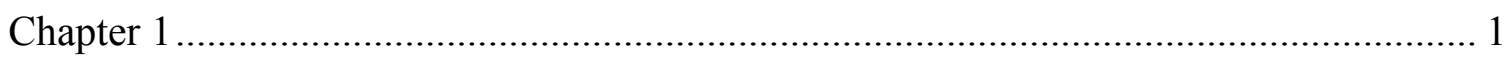

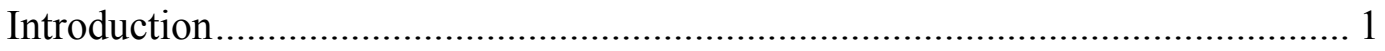

Significance and Purpose of the Study …………….......................................... 7

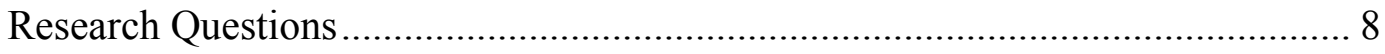

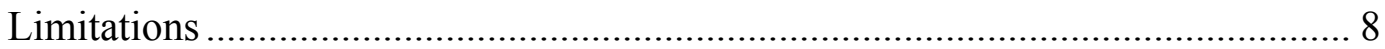

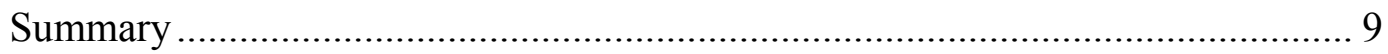

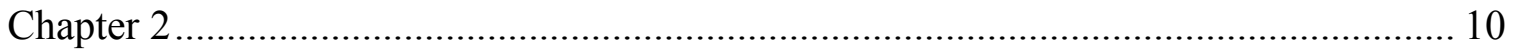

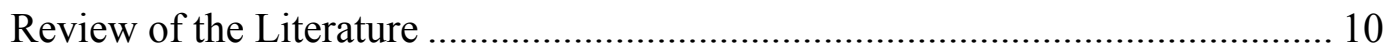

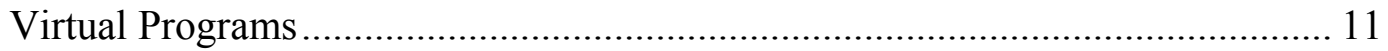

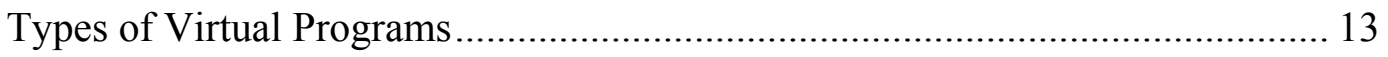

Virtual Programs - Policy Issues............................................................... 16

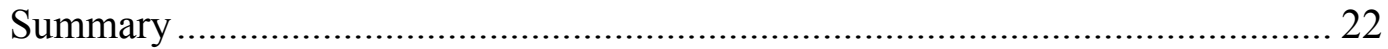

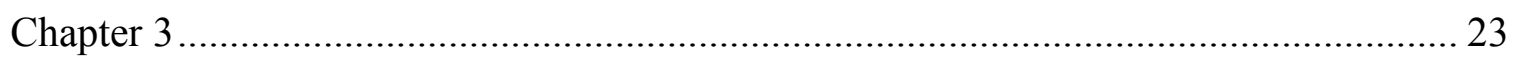

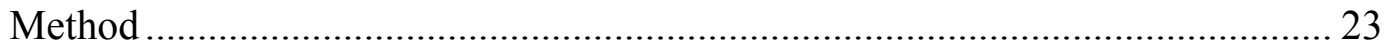

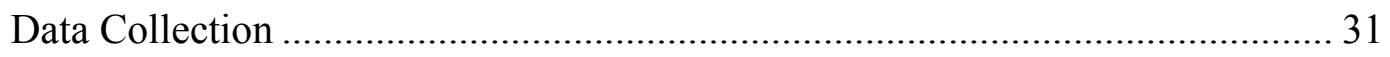

Guarantee of Anonymity and Confidentiality................................................... 41 
Summary

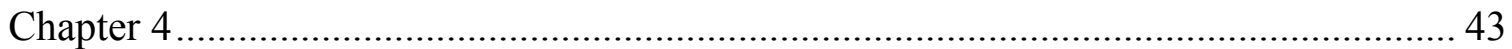

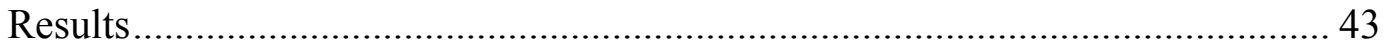

Principals and School Characteristics ................................................................... 43

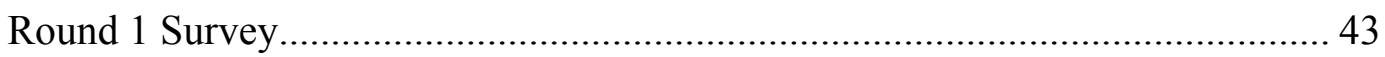

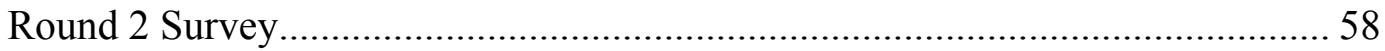

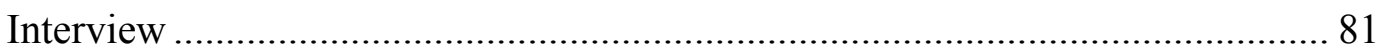

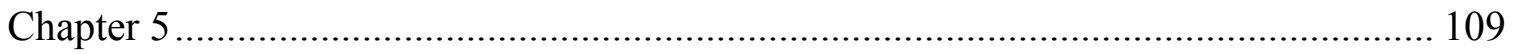

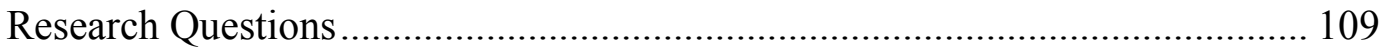

Research Question 1 .................................................................................... 111

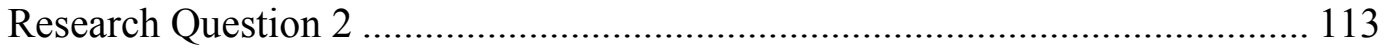

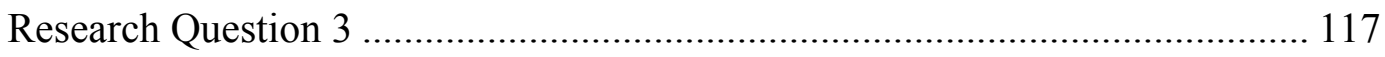

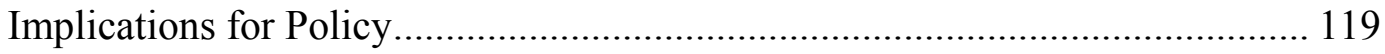

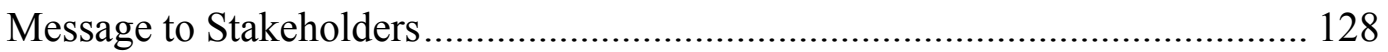

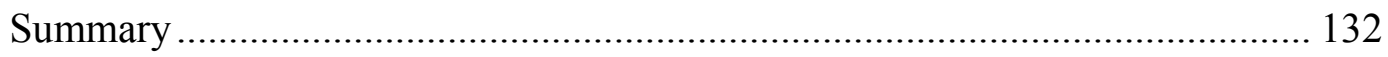

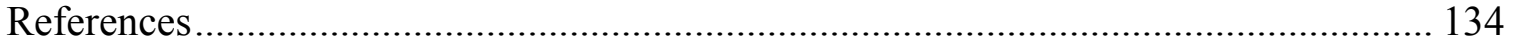

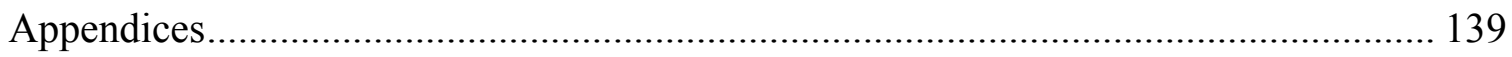




\section{List of Tables}

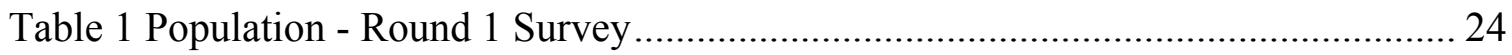

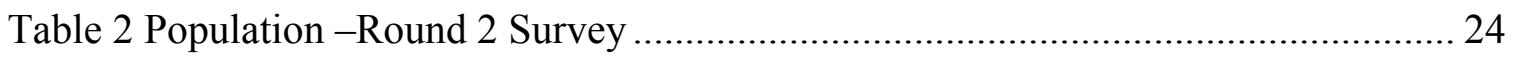

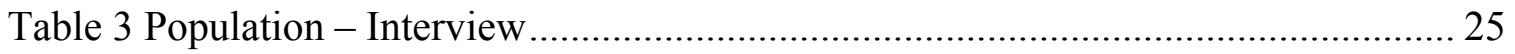

Table 4 Speculated Growth of Fully Online Courses - Answers Given ........................... 55

Table 5 Speculated Growth of Blended Courses - Answered Given ............................... 56

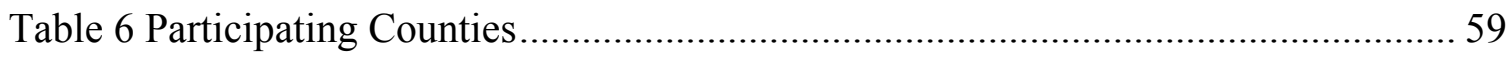

Table 7 Position of Participants ...................................................................................... 59

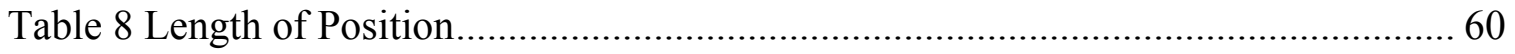

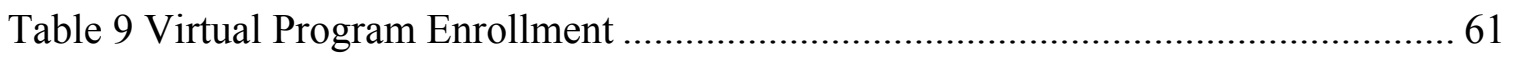

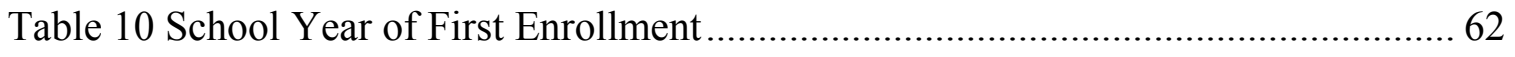

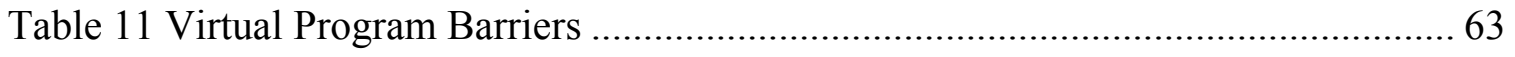

Table 12 Virtual Program Enrollment Reasons ............................................................... 65

Table 13 Pedagogical Feelings of Agreement/Disagreement............................................ 69

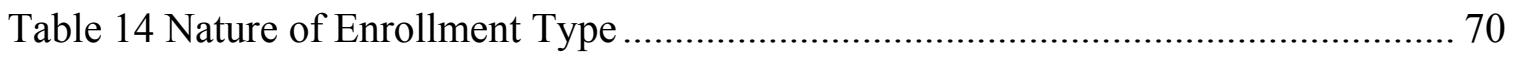

Table 15 Growth of Virtual Programs ....................................................................... 72

Table 16 Speculated Growth Percentage of Fully Online Courses -Answers Given....... 72

Table 17 Growth of Fully Online Courses................................................................. 73

Table 18 Speculated Growth of Blended Courses - Answered Given .............................. 76

Table 19 Growth of Blended Courses......................................................................... 76

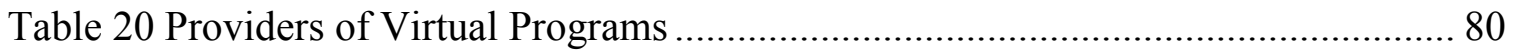

Table 21 Participating Counties.............................................................................. 82

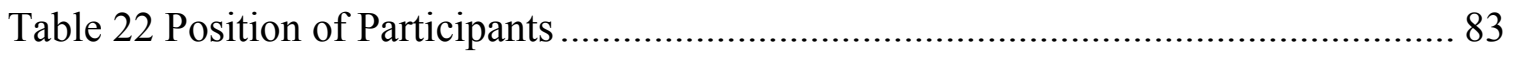




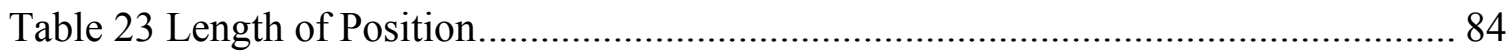

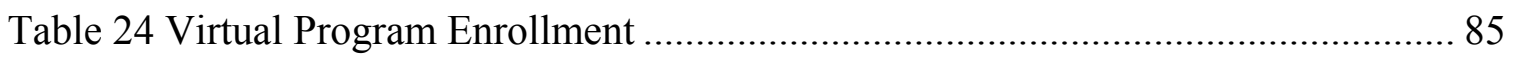

Table 25 School Year of First Enrollment.................................................................... 86

Table 26 Virtual Program Barriers ……………………............................................... 87

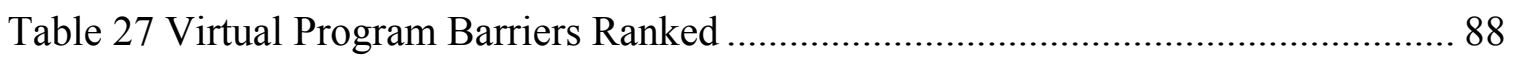

Table 28 Virtual Program Enrollment Reasons ........................................................... 90

Table 29 Virtual Program Enrollment Reasons Ranked.................................................. 91

Table 30 Pedagogical Feelings - Alternative Uses of Virtual Programs.......................... 93

Table 31 Pedagogical Feelings - Alternative Uses of Virtual Programs Ranked ............ 94

Table 32 Pedagogical Feelings - Apprehensions ............................................................. 95

Table 33 Pedagogical Feelings - Apprehensions Ranked ............................................ 96

Table 34 Pedagogical Feelings of Agreement/Disagreement............................................ 97

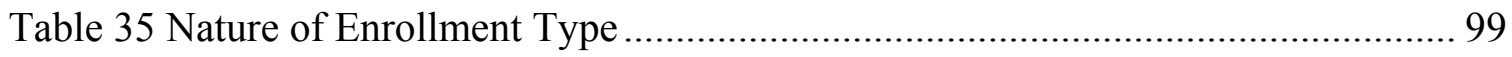

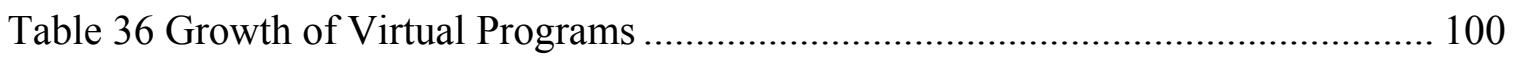

Table 37 Speculated Growth Percentage of Fully Online Courses - Answers Given.... 101

Table 38 Growth of Fully Online Courses................................................................... 101

Table 39 Speculated Growth of Blended Courses - Answers Given ............................. 102

Table 40 Growth of Blended Courses........................................................................ 102

Table 41 Qualitative Responses - Factors that Allow Virtual Program Growth............ 105

Table 42 Providers of Virtual Programs ..................................................................... 106

Table 43 Summary of Commonalities to each Interview Question ................................. 108

Table 44 Research Questions Separated by Survey/Interview Questions ...................... 110 


\section{List of Figures}

Figure 1. United States Appalachian Region ............................................................... 4

Figure 2. Appalachian Ohio Counties....................................................................... 4

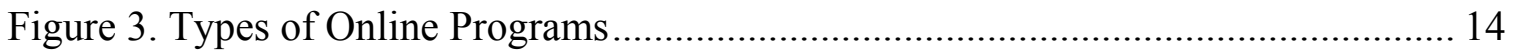

Figure Q1. Participating Counties......................................................................... 170

Figure R1. Participating Counties............................................................................ 177

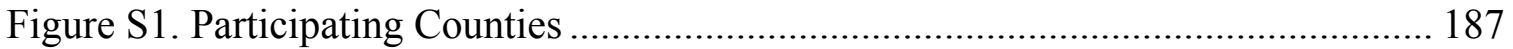




\section{List of Appendices}

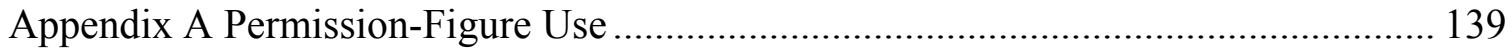

Appendix B Sloan Consortium Survey Instrument/Round 1 Survey ............................. 140

Appendix C Round 1 Survey - Initial Email to Population............................................. 144

Appendix D Round 1 Survey - Initial Email Letter Attachment.................................... 145

Appendix E Round 1 Survey - Initial Email Attachment, CORAS Support Letter ....... 147

Appendix F Round 1 Survey - Second Request Email ................................................... 148

Appendix G Round 1 Survey - Thank You Email ....................................................... 149

Appendix H Round 2 Survey - Initial Email to Population .......................................... 150

Appendix I Round 2 Survey - Survey ................................................................. 151

Appendix J Round 2 Survey - Second Request Email ................................................. 160

Appendix K Round 2 Survey - Third Request Email.................................................... 161

Appendix L Round 2 Survey - Thank You Email......................................................... 162

Appendix M Interview - Initial Email to Population ...................................................... 163

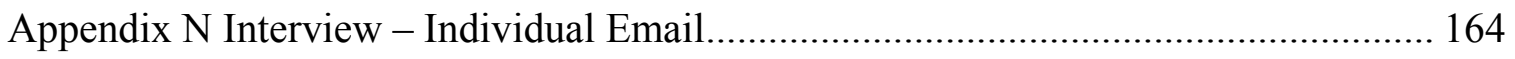

Appendix O Interview - Email with Interview Questions Email Attachment ................ 165

Appendix P Interview - Interview Questions............................................................. 166

Appendix Q Round 1 Survey Questions .................................................................... 170

Appendix R Round 2 Survey Questions ………………......................................... 177

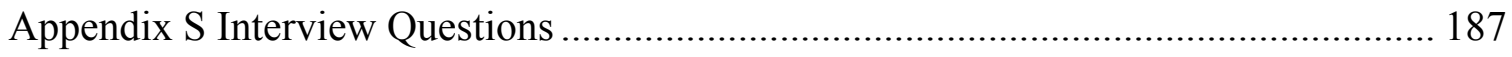




\section{Chapter 1}

\section{Introduction}

The landscape of American school districts changed on September 15, 2004, when President Bush signed into law the No Child Left Behind (NCLB) Act of 2001. This law requires states to hold districts and schools accountable for the achievement of each student group, including racial and ethnic groups, low income students, limited English proficient students and students with disabilities.

NCLB established Adequate Yearly Progress (AYP) which measures the extent to which each student group is meeting benchmarks for proficiency. These measures indicate whether districts and schools have achievement gaps between student subgroups. Districts and schools are required to meet annual AYP goals, with the intent that all students will reach proficient levels in reading and mathematics by the 2013-2014 school year.

In response to NCLB, many school district administrators have been forced to reexamine the strategies used to educate students in their districts because NCLB regulations hold school districts accountable for showing increased yearly progress for all students. When this mandate is not met, school districts are labeled "in need of improvement." If this designation is assigned two years in a row, school districts are forced to give their students an option to attend a higher performing school district. If this designation occurs three years in a row, Superintendents may lose their jobs (D'Orio, 2004). NCLB places school administrators under tremendous pressure to ensure all students succeed. 
Ohio uses a Report Card system in which the Ohio Department of Education requires each school district to send community members a status report on how well they have met the required four measures of achievement. These four measures include: 30 performance indicators, performance index, value-added measure, and adequate yearly progress (AYP).

The 30 performance indicators include: 18 results from the Ohio Achievement Tests: reading and mathematics in the 3 rd through $8^{\text {th }}$ grades; science and social studies in the 5th and 8th grades; and writing in the 4th and 7th grades. They also include the results from the Ohio Graduation Tests at the 10th-grade level and cumulative results for 11 th-graders. Measures for the attendance and graduation rates complete the 30 statewide indicators (Ohio Department of Education, 2009).

The performance index is a weighted range between 0 and 120 . The weights are 1.2 for Advanced, 1.1 for Accelerated, 1.0 for Proficient, 0.6 for Basic, 0.3 for Below Basic, and 0.0 for untested (PSK12.com, 2009).

The value-added measure assesses student progress and how each district and school contributed to students' performance over time. This differs from traditional test scores, as they only measure proficiency at one point in time. In Ohio, value-added results are calculated for grades 4 through 8 in reading and mathematics, and a composite result is also available for most school buildings in each district. The results show whether a district or school meets, exceeds, or is below its expected growth standard (Ohio Department of Education, 2009).

Ohio is one of eight states that received approval from the U.S. Department of Education to provide schools and districts with an additional way to meet AYP. Growth 
models utilize projections to determine whether an individual student will be proficient. A student projected to be proficient is considered proficient for AYP purposes. Use of the growth model enables Ohio to focus on the schools and districts where performance is of greatest concern - those in which proficiency rates are low and in which students are in jeopardy of reaching proficiency.

Many school districts face inherent challenges while trying to ensure their students learn, but one region in particular has continually struggled with educational system equality. Appalachian designation, first created in the mid 1960s at the urging of President Kennedy and President Johnson, was created to address the persistent poverty and growing economic despair of the region. This region, which spans from southern New York to northern Alabama, Mississippi, and Georgia, as shown in Figure 1, has enjoyed an abundance of natural resources, but nonetheless, has still struggled with poverty (Appalachian Regional Commission, 2009). A few statistics tell the story:

- 1 of every 3 Appalachians lived in poverty

- Per capita income was $23 \%$ lower than the U.S. average

- High unemployment and harsh living conditions had, in the 1950s, forced more than 2 million Appalachians to leave their homes and seek work in other regions. (Appalachian Regional Commission, 2009).

In Ohio, the Appalachian region has been recognized as an area in southeastern Ohio consisting of 32 counties (see Figure 2). According to the Coalition of Rural and Appalachian Schools (CORAS) (2009), there are considerable differences between school districts in Ohio Appalachian counties and the state as a whole. In fact, the following statistics are worth mentioning (CORAS, 2009): 


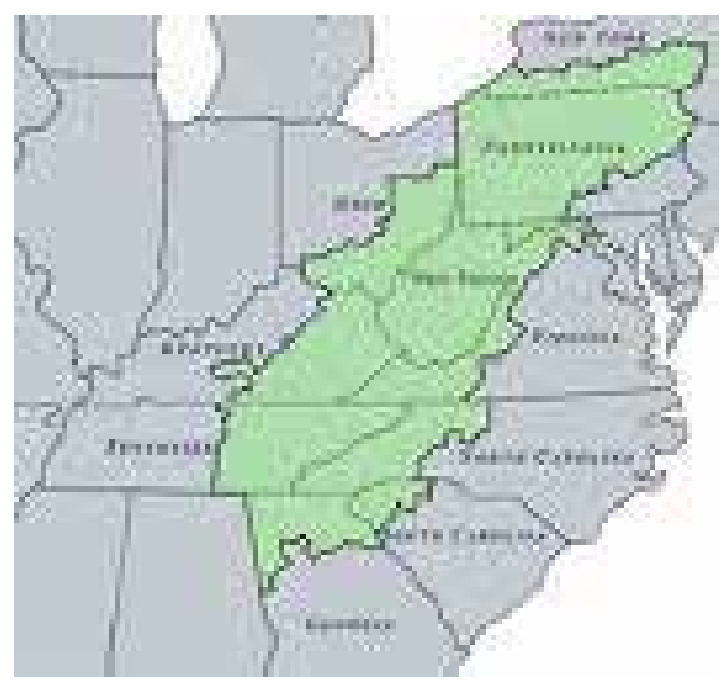

Figure 1. United States Appalachian Region

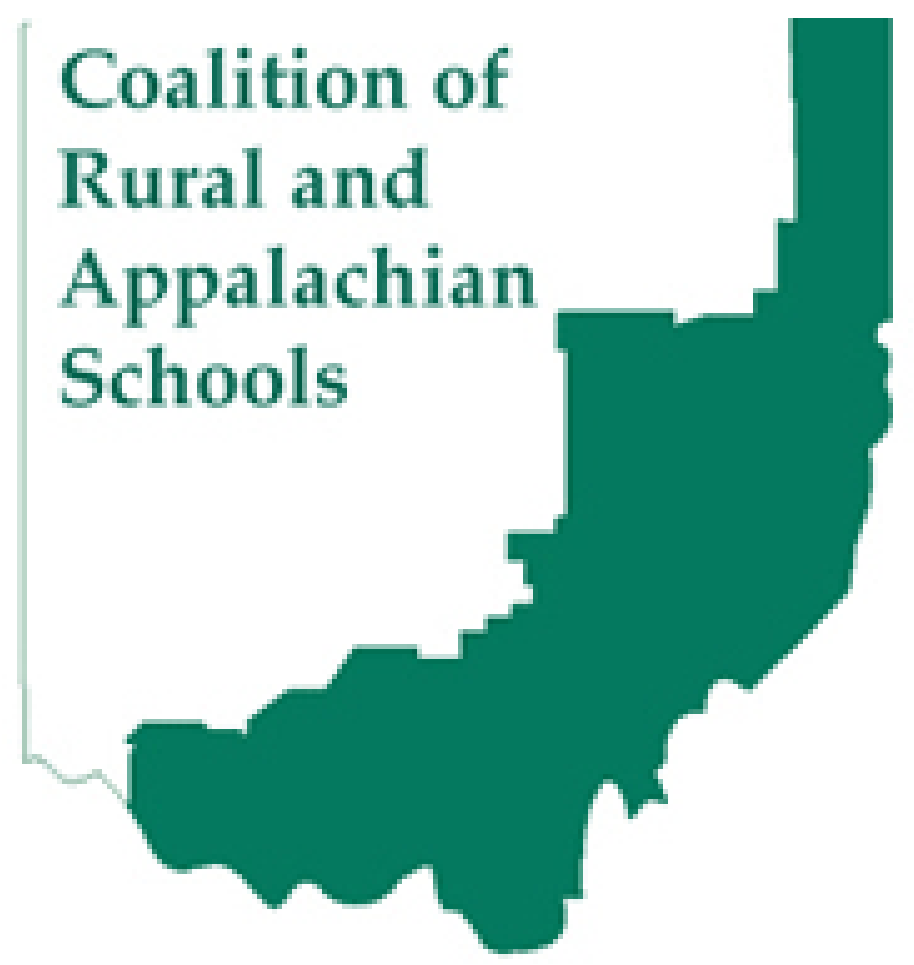

Figure 2. Appalachian Ohio Counties 
- There are school children in Ohio's rural Appalachian region receiving a \$7,056 per pupil allocation, while the state average per pupil expenditure is $\$ 9,216$. The $\$ 2250$ shortfall translates into $\$ 45,000$ less annually per classroom of 20 students, or over $\$ 2.25$ million less annually for a school district with 1000 students, than the state average.

- There are school districts in Ohio’s rural Appalachian region with local property valuation per pupil as low as $\$ 38,229$, while the state average is $\$ 134,211$. These numbers illustrate the lack of ability for some local communities to raise revenue to support education for their school children.

- There are school districts in Ohio's rural Appalachian region with average annual teacher salaries as low as $\$ 31,431$, while the state average teachers salary is $\$ 50,661$. The $\$ 19,230$ less annually translates into $\$ 576,900$ in less income for those teachers over a 30-year career. It makes it much more difficult for Ohio Appalachian school districts to recruit and retain teachers.

Appalachian Ohio school districts are under enormous pressure to compete with their more urban counterparts because of the increased accountability of NCLB and the public pressure to show improvement. Given their intrinsic challenges, many Appalachian Ohio school districts are researching alternative educational models to service their student's wide variety of needs including: credit reclamation, Advanced Placement (AP) offerings, and enrichment courses.

One alternative that Appalachian school districts are exploring is the use of virtual programs. For the purpose of this study, a virtual program is a combination of online courses including both fully online courses and/or blended courses. An online course is defined as a course delivered over the Internet, using a learning management system (LMS). Typically, student and teacher are separated by time, location, or both. Online courses can be synchronous or asynchronous (Tallent-Runnels et al., 2006). Blended courses consist of both a fully online component partnered with a traditional face-to-face component. Virtual programs can have more than one provider of online courses. 
Virtual programs have many benefits and have even been described in literature as a "life line" to Appalachian school districts because of the increased accessibility to a larger number of courses (Picciano \& Seaman, 2009). Some Appalachian Ohio school districts are also attracted to virtual programs because of the cost savings. Districts can offer students a wider variety of course offerings without having to hire a full time teacher. In addition, because these courses are delivered over the Internet, building costs are minimized.

Another benefit of virtual programs is that they provide a means to serve students in need of credit reclamation. Appalachian Ohio High Schools already incur obstacles, and without staff and time, many students fall short of their credit obligations which in turn, decrease the school district's overall achievement rating on the state's accountability system (CORAS, 2009).

Appalachian Ohio school districts are not the only types of school districts that are experiencing growing use of virtual programs. According to a recent report by International Association of K-12 Online Learning (iNACOL) (2009), the number of K12 students enrolled in online courses during the 2007-2008 school year was 1,030,000. This represents a 47\% increase since the 2005-2006 school year. Virtual programs, or more commonly referred to as online learning, have grown so much in recent years that it is not a question of how many schools are using online courses, but how these programs are being delivered and what best practices govern their use.

As many as 45 states now operate significant online learning opportunities for students, which in turn mean 45 different implementation models. Research has been slow to conclude which model is most effective and what best practices need to be in 
place when implementing virtual programs, especially in the K-12 arena. With the increasing accountability of today's school districts however, it is imperative that more research be conducted. This study will facilitate a deeper understanding of virtual program use in Appalachian Ohio High Schools.

\section{Significance and Purpose of the Study}

Understanding the significance of virtual programs and how they can aid school districts in servicing their students is critical to a number of stakeholders. First, school administrators can benefit by increasing course offerings, which could in turn increase student achievement due to the larger exposure of coursework and concepts. Virtual programs can also be offered at a fraction of traditional course delivery. (U.S.

Department of Education, 2009). Students and parents can benefit from virtual programs because they allow continuous access to coursework that may not otherwise be available. Finally, school districts as a whole can increase their ability to show continued student performance, a must according to the NCLB standards.

It is important that educators understand how to use every tool available in order to increase student performance. Virtual programs are closing the accessibility gap as well as the achievement gap in today's students because they allow the playing field to be leveled (Picciano \& Seaman, 2007). With the rise of the Internet, the "have's" and the "have not's" classifications are starting to diminish. Narrowing the digital divide is a concept that is becoming more and more of a reality with the rise of technology and its capabilities.

Data needs to be collected in order to aid school administrators with decisions if virtual programs will best serve their student population. With the increasing number of vendors, state-led virtual programs, and charter/community schools, many building 
principals are left with the daunting task of navigating through "sales pitches" to determine the most educationally sound products. Research is needed to allow administrators access to data which will increase their knowledge in this ever-growing field of course delivery.

The purpose of this study was to examine Appalachian Ohio High Schools and their use of virtual programs to supplement traditional course offerings. This exploratory study investigated which school districts were using virtual programs, what attributes were important when choosing to use virtual programs, why certain students were chosen to enroll in virtual programs, and what best practices govern the use of virtual programs once they were implemented. The conclusions of this study will provide all stakeholders additional research to base policy decisions in regards to virtual programs.

\section{Research Questions}

The following questions will guide the research of this exploratory study:

- RQ1 In the opinion of Appalachian Ohio High Schools Principals, what reasons are considered when using virtual programs as an alternative to traditional course offerings? What factors need to be in place to facilitate continued growth of virtual program use?

- RQ2 In the opinion of Appalachian Ohio High Schools Principals, what apprehensions of virtual programs impede their use? What factors need to be in place to overcome those apprehensions?

- RQ3 In the opinion of Appalachian Ohio High Schools Principals, what best practices and/or policies need to be in place to implement a successful virtual program?

\section{Limitations}

A possible bias exists because of the researcher's current position as a director of a virtual program. The potential for bias will be limited by the use of an established survey instrument. The study is also limited in that it is exploratory of a particular 
geographic area located in one state, whose findings may only be useful in other Appalachian regions or states.

\section{Summary}

Student achievement is the standard by which all educators are measured today. In the past, a teacher may be heard saying, "Johnny failed Math." Today, however, with continued attention placed on school districts and their ability to educate students, some may argue that Johnny did not fail, the system failed to educate Johnny. Because of higher accountability towards student achievement, educational administrators are forced to make a shift towards alternative delivery methods other than the traditional brick and mortar model. Regions such as Appalachian Ohio must consider alternative delivery methods when servicing students if they wish to compete in an ever-growing, competitive, educational marketplace. 


\section{Chapter 2}

\section{Review of the Literature}

The development of the first personal computer in 1971 lead to an evolution of computer use in the classroom. In those early days, computers were large, expensive, and not very practical for classroom use. Today, however, with growing communication technologies and an increased need for a global education, providers are striving to create computers that are affordable and adaptable to a classroom setting. The rise of personal laptops and netbooks has made the idea of replacing textbooks with computers a reality. Modern curricula are available to students, teachers, administrators, and community members with a few clicks of a mouse. School districts across the globe are searching for innovative strategies to utilize these technologies while maintaining high curriculum standards. The converging forces of high stakes tests, NCLB, the need for AP courses, and higher accountability standards of school administrators have combined to demand an alternative education model that will reform the way instruction is delivered.

Today, technology is quickly advancing all aspects of life. From work to home to school to play, humans are able to access information on demand. Because of the Internet, high speed networking, and wifi, students are able to connect to data, friends, and the outside world in a way that even futurists could not have predicted.

Schools have struggled to remain current with technology as constrained budgets, lack of understanding, and resistance to change have strangled progressive educational leaders to adapt to a new global standard. Yet, because of NCLB, accountability has risen greatly and schools are now forced to examine how to teach a $21^{\text {st }}$ century workforce by transitioning from $20^{\text {th }}$ century teaching methodologies. 


\section{Virtual Programs}

Virtual program growth has been tremendous. According to Clark (2001), in 2000, there were 40,000-50,000 enrollments in K-12 online education. During the 20072008 school year, over one million K-12 enrollments were reported (iNACOL, 2009). A staggering statistic even suggests that in six years $10 \%$ of all courses will be computer based, and by 2019 50\% of courses will be delivered online (U.S. Department of Education, 2009; Christensen, 2008 ). According to a recent report by Evergreen Consulting (2009), 45 of the 50 states, plus Washington, D.C., have a state virtual school or online initiative, full-time online schools, or both.

Virtual programs, commonly referred to as online learning, are often defined by a variety of descriptors. For the purpose of this study, virtual programs will be classified into two categories: fully online and blended. A fully online course is defined as a course where most or all of the content is delivered online, in both synchronous and asynchronous time, and typically has no face-to-face meetings. A blended course is one that blends online and face-to-face delivery. Blended courses have a substantial proportion of the content delivered online, sometimes use online discussions, and typically have few face-to-face meetings.

One reason virtual programs have become so popular is that they allow more flexible access to content and instruction at any time, any place (U.S. Department of Education, 2009). Additional advantages include: increasing the availability of learning experiences for learners who cannot or choose not to attend traditional face-to-face offerings; assembling and disseminating instructional content more cost-efficiently; and enabling instructors to handle more students while maintaining learning outcome quality 
that is equivalent to that of traditional face-to-face interactions (U.S. Department of Education, 2009).

School districts chose to implement virtual programs for a variety of reasons and to serve a variety of students. Some of these include: increasing course offerings, especially in rural and inner-city school districts; providing highly qualified teachers in areas that are hard to hire; providing flexible scheduling; and giving opportunity to at-risk students, dropouts, pregnant students, homebound, or military family students. Many types of students mentioned above would not succeed if they did not have a virtual program option.

Virtual programs provide an opportunity for students who do not fit in the traditional brick and mortar school environment. They provide much needed flexibility which allows students to fit all of their responsibilities into the daily grind. Without them, many students would simply not graduate.

There are different technology models that support online learning (U.S. Department of Education, 2009). One model of virtual programs uses asynchronous communication tools such as email, threaded discussion boards, and newsgroups. This allows users the flexibility to participate at their convenience. Another model uses synchronous technologies such as webcasting, chat rooms, and desktop audio/visual technologies. Earlier virtual programs used one model or the other; however, recent applications are combining multiple forms of synchronous and asynchronous interactions (U.S. Department of Education, 2009).

In addition, virtual program offerings are being designed to enhance the quality of learning experiences and outcomes (U.S. Department of Education, 2009). Some 
researchers suggest learning a body of knowledge requires a community of learners (Riel \& Polin, 2004; Schwen \& Hara, 2004; Vrasidas \& Glass, 2004), and online technologies can be used to expand and support such communities. Other scholars suggest that asynchronous learning is inherently self-reflective and therefore conducive to deeper learning than synchronous learning that is traditionally offered in a classroom setting (Harlen \& Doubler, 2004; Hiltz \& Goldman, 2005; Jaffee, Moir, Swanson, \& Wheeler, 2006).

\section{Types of Virtual Programs}

According to Watson, Winograd, and Kalmon (2004), there are five types of virtual programs. As shown in Figure 3, these include:

- statewide supplemental programs,

- $\quad$ single-district supplemental programs,

- single-district cyberschools,

- multidistrict cyberschools, and

- cyber charters.

Students can enroll in these types of virtual programs either on a full time or part time basis.

Statewide supplemental programs provide virtual courses to students who are enrolled in a brick and mortar school. Students enroll in an online course as a supplement to their traditional course load taken in a physical school building. These types of programs are governed by a state agency and operate on a state-wide basis. 


\section{Part-Time Enrollment}

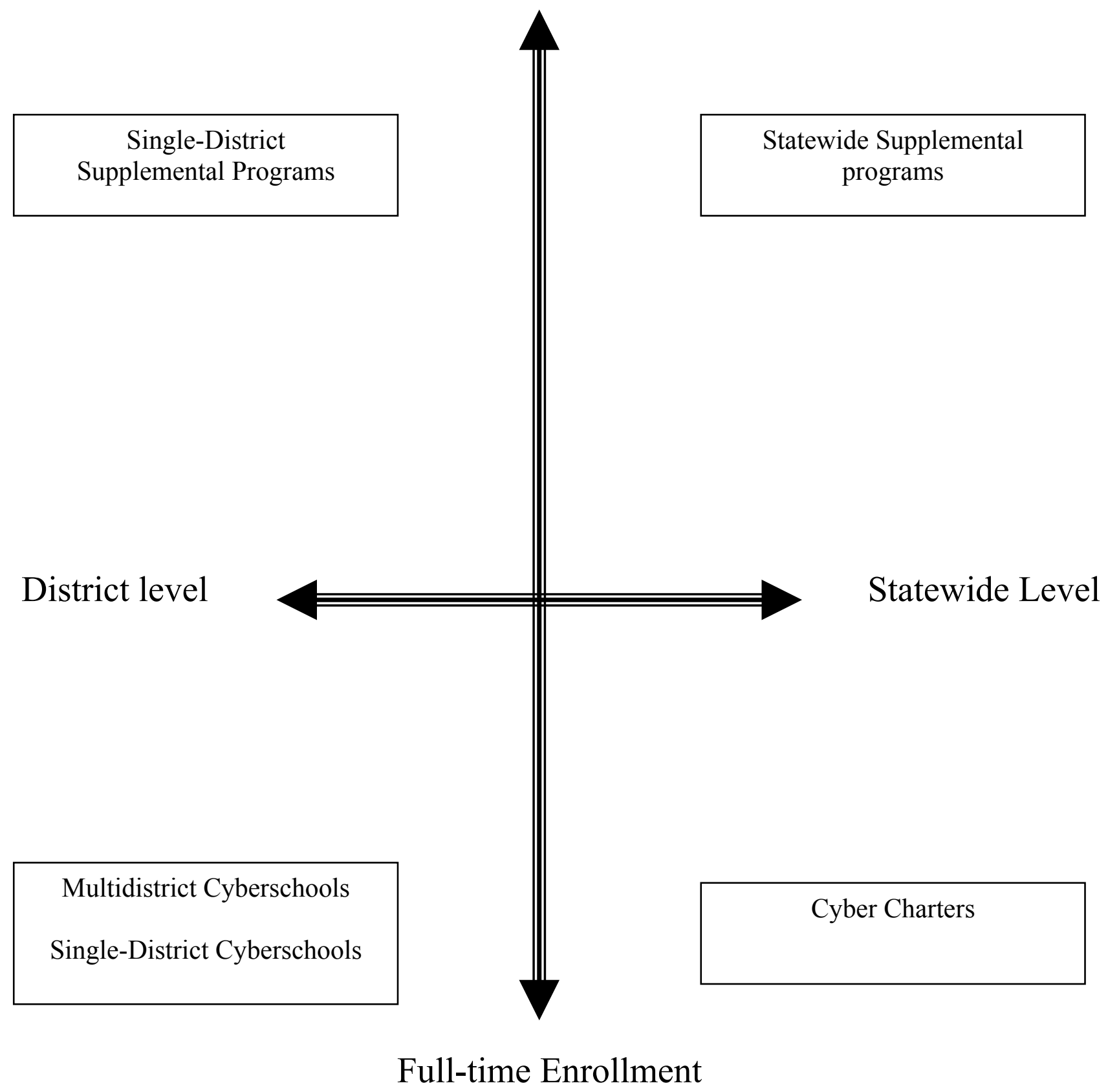

Figure 3. Types of Online Programs

Note: Recreated with permission by John Watson (see Appendix A). 
Single-district supplemental programs are operated under the administration of the school district. Students enroll in online courses to supplement their classroom course load. Typically, little data is reported to the state level regarding these programs since districts mark courses as part of their own curriculum offerings.

Single-district cyberschools exist in many states. Most students enrolled in this type of school work from a location other than the physical school building. Programs are run by individual districts to serve students and families who are looking for an alternative to the traditional brick and mortar environment (Watson et al., 2004).

Multi-district cyberschools are governed by charters within individual school districts; however, enrollment covers students from across the state. Most students work from a location other than the physical school building. These cyberschools are the largest growing sector of virtual programs, but much work is still needed in policy guidance.

Cyber charters exist in states that allow charter schools. In Ohio, these schools are named Community Schools. They compete with traditional school districts because they take the average daily membership (ADM) dollar amount directly from the Ohio Department of Education. As one can imagine, public school districts are not in favor of these types of virtual programs because they compete for student enrollment. In addition, most public school administrators believe that tougher policies are needed to govern cyber schools since most states do not hold these schools to the same standards as traditional public schools.

As explained above, many different virtual programs exist and are governed by different agencies. Much more work is needed in the form of policy and data reporting. 
A tremendous growth in virtual programs has occurred and there is no indication that it is likely to slow down. It is imperative that some standard of accountability be enacted. NCLB has outlined learner outcomes that need to be achieved in a traditional classroom delivery model, however very few policies guide virtual program delivery models.

In some states, funding opportunities, rather than student educational needs, drive enrollment. In other states, virtual programs are created to offer an opportunity for at-risk students who may not otherwise graduate (Picciano \& Seaman, 2009). Whatever the case, individual school districts as well as states as a whole, need to examine policy regulations so that each student is awarded the same opportunities (Watson et al., 2004). It is important to determine if school districts are using virtual programs to create a model of quality, a response to need, or to take advantage of a financial opportunity.

\section{Virtual Programs - Policy Issues}

Watson et al. (2004) named five policy issue domains that need to be examined when determining whether to adopt and enroll students in virtual programs. These include:

- quality (program, course, teacher, and student support),

- funding,

- access and equity,

- accountability and oversight, and

- research and evaluation data.

The survey instrument used for this study sought to further the existing research of these five domains. Outlined below is the historical perspective of the five policy issue domains and their importance for K-12 virtual program research. 
The first domain is quality. Quality of virtual programs is often deferred from the state level to the individual school district level. "Local control" often determines the effectiveness of virtual programs. As a result, little is known about the quality of virtual programs as a whole. In an effort to correct this, state level policies need to be written specifically for virtual programs in which individual districts are responsible for establishing goals, meeting those goals, and reporting the results to the state, district, or other governing body.

According to a recent report by the U.S. Department of Education (2009), virtual programs were found to be as effective as instruction delivered traditionally in a brick and mortar building. This was a landmark conclusion because it is the first stance made by the Department towards their position on virtual program quality. Advocates of virtual programs have debated this point for many years, but now have the backing of the U.S. Department of Education.

Course quality is also important because it directly affects what the student is learning. Many states require course content be aligned with academic content standards; however no state has created standards specifically for virtual programs (Watson et al., 2004).

Teacher quality is also important. Most states and school districts require teachers to be licensed in the area they teach. Some states such as Pennsylvania, however, only require $75 \%$ of their teaching staff be licensed (Watson et al., 2004). Other states such as Michigan require teachers to be licensed in some state, but it does not have to be Michigan. The justification is that this allows marketing of great teachers from outside the state. Either way, teaching virtual programs have been shown to also 
increase a teacher's effectiveness in a face-to-face setting. According to Smith, Clark, and Blomeyer (2005), three out of four teachers who were teaching through virtual programs reported a positive impact in their face-to-face teaching.

Student support is another issue that deserves policy awareness. According to a study conducted by Park (2007), lower dropout rates can be achieved if online program developers, instructors, and school administrators find ways to enhance learner satisfaction by organizing content efficiently and effectively and by increasing interaction among students or between students and instructors. Learner satisfaction is a major factor relating to a student's decision to drop out of online courses (Levy, 2007), and is highly correlated to various course related issues such as instructional design, organization of the online courses, instructors' facilitation, and interaction. School district administrators must realize this is an important component of a successful virtual program.

The second domain of virtual program policy is funding. Funding often drives conversations regarding virtual programs. Many feel that funding is one of the biggest barriers to the growth of online learning. According to Watson, Gemin, and Ryan (2008), 66 percent of program administrators would like to see faster growth in virtual program funding from their state. Connecticut and Delaware, for example, established online programs in 2007, but because of funding cuts, these programs did not flourish. In contrast, Idaho Learning Academy saw appropriations grow from $\$ 450,000$ during the 2003-2004 school year from \$3.2 million during the 2007-2008 school year which equated into an enormous growth rate of virtual program enrollees (Watson et al., 2008). 
Many states, including Ohio, use full time equivalent (FTE) dollars to transfer from traditional public schools to cyber schools. Appalachian Ohio school districts often suffer financially when students who live within their district choose to enroll in outside cyberschools.

In addition, there is much concern that the home school population is being targeted by cyber charters, which would increase the state's education costs. One vendor, $\mathrm{K} 12$, Inc., is specifically known for marketing to home school families, which has caused state legislatures to take notice. Texas, for example, specifically denied K12, Inc. the ability to operate within their state. However, since its inception in 1999, K12, Inc. has grown by 50 percent every year (Van Dusen, 2009). Ron Packard, K12 founder, states that as time passes, more and more educators understand virtual programs are a partner to traditional brick and mortar schools and by offering these types of courses, districts have the benefits of complimenting curriculum options.

The third domain of virtual program policy is access and equity. A key question exists in what a state's role is to ensure equal access and equity of all students in regards to virtual programs and online courses. All states are required to comply with federal and state laws such as the Americans with Disabilities Act; however, few policies truly outline specifics. Many states allow student enrollment decisions to be local decisions. Towards that end, some districts choose to provide hardware equipment and Internet access to students enrolled in virtual programs. There is a breakdown, however, with students living in rural areas because of the slow Internet access that most rural communities experience. Some virtual programs such as Florida Virtual School actually give priority enrollment status to students in rural or low-performing school districts. 
Michigan Virtual High School has also created a program to help underserved students in Detroit Public Schools (Watson et al., 2004). Illinois Virtual High School was created specifically to address equity of access to curriculum across the state (Watson et al., 2004). However, even with some states best efforts, the question of access and equity remain, especially in rural and underserved communities.

Moe and Chubb (2009) believe that technology is the answer to today's access and equity problem in American's schools. They argue that online education holds dramatic academic benefits. Virtual programs simply improve education, especially in inner cities and rural areas, because they allow remote locations access to high quality instruction and learning. In 1990, these same two authors release a report entitled, "Politics, Markets and America's Schools", which identified political groups, specifically teachers' unions, as the culprit to strangling educational institutions innovation. This report cited that many states prohibit policy regulations or data gathering techniques that tie teachers to their student's test scores. The authors point out that virtual programs tear down the jurisdiction lines of teacher unions because of the varying geographic locations in which online teachers are located. Moe and Chubb (2009) are quick to point out that virtual programs, through instant messaging, voice and interactive whiteboards, and continued communication with teachers also provide access and equity to students in hard to serve geographic areas.

The fourth domain of virtual program policy is accountability and oversight. Some state agencies have collaborated to create policy, either through task forces or commissions, which help to set standards for virtual programs. For example, both Hawaii and Wyoming established task forces to research virtual program options and 
report to their state legislature. Because of this, in 2008, Wyoming created the Wyoming Switchboard Network to create and oversee online and other distance learning courses, and Hawaii's legislation is now supporting both state-led supplemental programs and full-time online schools (Watson et al., 2008).

Ohio's community schools are required to provide physical space for students enrolled in virtual programs to take state assessments. They are also required to comply with the NCLB provisions, where students must make adequate yearly progress toward their academic achievement goals.

Without oversight, the quality of virtual programs can differ greatly from school district to school district (Watson et al., 2004). Many states transfer control to the local school district which makes consistency even harder to attain. With many different standards in place and differences in operations, it is difficult for students and families to gauge which program is truly best at matching their needs.

The fifth domain of virtual program policy is research and evaluation. Virtual programs are still an area of little research, especially in the K-12 arena. States can do their part, however, to record accurate data regarding students who are enrolled in virtual programs, demographic data, and course completion data (Cavanaugh, Gillan, Kromrey, Hess, \& Blomeyer, 2004).

Virtual program growth has exploded over the last decade and much research is still needed to determine how best to implement the many models that have been adopted by various providers. State legislatures and state departments of education should institute policy guidelines to govern the varying standards that exist today. In addition, individual school districts should track pertinent data so that accurate conclusions can be 
drawn regarding the types of students that virtual programs serve. Finally, many students benefit from virtual programs and would not succeed without them. Hence, today's educator's role is to determine how best to continue the growing trend of virtual schools and their benefits.

\section{Summary}

The role of virtual programs in rural and Appalachian Ohio is significant. These 193 identified school districts face inherent challenges because they are small and are located in remote geographic areas. Students in these districts need to be awarded the same opportunities as students in more urban areas. Virtual programs are the arm that extends to these students in an effort to provide the same opportunities to all.

Virtual programs can provide courses to school districts that may not be able to offer those courses otherwise. They can provide at-risk students an alternative modality so that a more flexible approach to their schooling can be obtained. Virtual programs can provide students and families a means to achieve credits that cannot fit in traditional schedules. Whatever the reason, there are many benefits to virtual programs and what they can offer school districts and students. 


\section{Chapter 3}

The purpose of this study was to examine Appalachian Ohio High Schools and their use of virtual programs to supplement traditional course offerings. The field of K12 virtual programs is relatively new and little research has been conducted to assess its impact. In addition, few state and/or federal policies outline best practice models for this type of course delivery. This exploratory study sought to answer how Appalachian Ohio High Schools are using virtual programs by investigating which school districts were using virtual programs, what attributes were important when choosing specific virtual programs, why certain students were chosen to enroll in virtual programs, and what best

practices governed the use of virtual programs once they are implemented. The results of this study have benefits to stakeholders because they will allow additional research into the vast abyss of virtual program use, but little evidence of effectiveness.

\section{Method}

\section{Participants}

The participants for this study were each principal in the 193 Appalachian Ohio school districts (see Table 1). The Ohio Department of Education was used as a source to identify Appalachian Ohio school districts. In addition, CORAS was also used to cross reference school districts that fell under the Appalachian Ohio category. Using these two sources, 193 school districts were identified as Appalachian Ohio. Each of these school districts was sent the Round 1 Survey.

Using a modified Delphi Method approach, two rounds of surveys were conducted, followed by a phone interview to selected individual principals. Round 1 Survey identified school districts using virtual programs, as well as some key 
demographic information about the principal and the school district. The survey not only identified key barriers, but also key facilitators affecting the use of virtual programs in their high schools. Finally, Round 1 Survey identified the types of students enrolled in virtual programs and the policies that govern their use.

Table 1

Population - Round 1 Survey

\begin{tabular}{ccc}
\hline Appalachian Ohio HS & Appalachian Ohio HS Principals & Participated \\
193 & 214 & $77(35 \%)$ \\
\hline
\end{tabular}

Round 2 Survey was constructed after analysis of Round 1 Survey. Based on the results of Round 1 Survey, the Round 2 Survey was sent to 62 principals whose high schools were currently using virtual programs (see Table 2$)$. Thirty-three $(\mathrm{N}=33)$ principals participated.

Table 2

Population-Round 2 Survey

\begin{tabular}{ccc}
\hline Appalachian Ohio HS & Appalachian Ohio HS Principals & Participated \\
60 & 62 & $33(53 \%)$ \\
\hline
\end{tabular}

Once both survey rounds were conducted and analyzed, a focus group of seven principals was chosen to participate in an interview. The principals were chosen based on the following criteria:

- are currently using a virtual program and have done so for the past three years;

- have been employed as the principal in the high school for the past three years; and, 
- have at least ten high school students enrolled in at least one virtual course.

Ten students were chosen as a criterion because the mean number of enrolled students in Round 1 Survey and Round 2 Survey was 11 and 6.5, respectively. Having ten students enrolled in virtual courses showed the principal had experience with virtual programs. Because of this experience, their insights were richer.

Seven principals, as shown in Table 3, matched this predetermined criteria and all were invited to participate in the interview; however, only five $(\mathrm{N}=5)$ principals agreed to participate. Interview questions were constructed using the findings from the first two rounds of the survey and were used to answer the three research questions.

Table 3

Population - Interview

Appalachian Ohio HS Appalachian Ohio HS Principals Participated

7

7

$5(71 \%)$

\section{Instrumentation}

This study used a modified Delphi Method approach in the form of a 2-round survey, with a focus group interview follow up. The survey instrument used was the Sloan Consortium Survey Instrument (Appendix B), used in a 2007 national study entitled, K-12 Online Learning. A Survey of U.S. School District Administrators. This report was one of the first studies to collect data on and compare fully online and blended learning in K-12 schools. The survey instrument was created specifically for that study was demonstrated to be reliable and valid by the BABSON Survey Research Group (Picciano \& Seaman, 2007). 
The Sloan Consortium is an institutional and professional leadership organization dedicated to integrating online education into the mainstream of higher education, helping institutions and individual educators improve the quality, scale, and breadth of online education. The Sloan Consortium supports the collaborative sharing of knowledge and effective practices to improve online education in learning effectiveness, access, affordability for learners and providers, and student and faculty satisfaction (The Sloan Consortium, 2009).

In addition to the aforementioned study, the survey instrument was also used in a follow up national study titled, K-12 Online Learning. A 2008 Follow-up of the Survey of U.S. School District Administrators in which the following conclusions were made: $75 \%$ of all public school districts offer online or blended virtual courses; $66 \%$ of school districts with students enrolled in an online or blended virtual course expect their online enrollments to grow; school districts typically depend on multiple online learning providers; and that rural American schools view virtual programs as a lifeline that enables them to provide students with course choices (Picciano \& Seaman, 2009).

Creation of the Sloan Consortium Survey Instrument evolved from many previous national studies. Beginning in 2002, the instrument was used to survey over 3000 Chief Academic Officers in American colleges and universities regarding different aspects of virtual programs. The objective was to seek answers to relatively simple questions such as if students, teachers, and institutions would embrace online education as a delivery model. The survey also sought to discover if online learning matched the quality of faceto-face instruction. The results concluded that both students and institutions would embrace online education, but teachers were more reluctant (Allen \& Seaman, 2006). 
Each year, the Sloan Consortium would "tweak" the questions from the previous year's national study based upon the conclusions of the results. By 2005/2006, the Sloan Consortium released their $4^{\text {th }}$ annual study results, entitled, Making the Grade, Online Education in the United States. It concluded that over three million students were registered for fully online courses in colleges and universities (Allen \& Seaman, 2006).

About this same time, Penn State University hosted the Sloan K-12 Higher Education Collaboration in Online Learning, a meeting that was organized to discuss issues related to online learning between K-12 schools and colleges and universities. It became clear that more K-12 online learning data was needed. The participants in this meeting pointed to the lack of data, as the last study done by the U.S. Department of Education focused on generic distance education and was based on data that were more than four years old (Picciano \& Seaman, 2007).

There are a number of reasons why data are not available. First, there are minimal requirements in many states to collect data on online students (Picciano \& Seaman, 2007). A number of states do not have specific guidelines or data collection process for online students. Watson (2005) conducted a study of state policy on online learning in 2005, and found that state policymakers have moved slowly.

Second, there is some confusion related to definitions of online learning and distance education. Distance education is not the same as online learning (Picciano \& Seaman, 2007). Items such as video conferencing and televised courses woud be considered distance education, but not online learning (Picciano \& Seaman, 2007).

Third, the lack of data collection can be attributed to the significant growth of online learning providers. As previously outlined, charter schools, state supported 
schools, other school districts offering online schools, etc. all cloud the field of student data because many of these schools allow enrollment across state lines (Picciano \& Seaman, 2007).

Fourth, the home school population is growing their use of virtual courses, either as a supplement to their course offerings or as the entire curriculum. Many of these families do not report to any school district and therefore, this population is perhaps the least known in the K-12 population (Picciano \& Seaman, 2007).

Because of this lack of data, in 2007, the Sloan Consortium opted to transition from colleges and universities, and conduct their first report on K-12 schools. This report entitled, K-12 Online Learning: A Survey of U.S. School District Administrators was one of the first studies to collect data on and compare fully online and blended courses. The lead researchers, Picciano and Seaman, modified the survey used in the previous annual reports so that the questions were more appropriate for the K-12 school districts. As a result, the survey was sent to 16,000 school districts. The survey was meant to collect data on main themes such as: those currently using virtual programs, perceived importance of online and blended courses; barriers; lessons learned; providers; and overall feelings regarding virtual programs.

According to the authors, the voices heard most clearly in this survey were those of respondents representing small rural school districts (Picciano \& Seaman, 2007). For them, the availability of online learning is important to provide students with choice and to compete with more urban school districts. Teacher shortages in high demand content areas, such as math and science, are inherent barriers to rural schools. In addition, most rural schools have low property tax bases, which mean low per pupil expenditures 
making every financial decision an important one. Virtual programs can provide courses that may not otherwise be available.

The authors of this study wanted to explore the nature of online learning in K-12 schools and establish base data for future studies. They claimed that in a field that was relatively new and ever-changing, their research could add a bit more to what is known about this course delivery mechanism.

In 2009, the Sloan Consortium released another report entitled, K-12 Online Learning: A 2008 Follow-up of the Survey of U.S. School District Administrators. This report was conducted to replicate the original study in order to substantiate its findings and to examine what if any changes occurred in online learning in K-12 school districts. (Picciano \& Seaman, 2009). Major findings from this study included:

- $\quad 75 \%$ of public school districts offer online or blended courses;

- $66 \%$ of school districts with students enrolled believe their online enrollments will grow;

- the overall number of students enrolled in online courses during the 2007-2008 school year was 1,030,000;

- respondents reported that online learning is meeting the specific needs of a range of students, such as credit recovery and advanced placement courses;

- school district rely on multiple providers; and,

- perhaps the most clearly heard voices were from small rural school districts who have listed online learning as a lifeline that enables them to provide students with course choices and in some cases, the basic course that should be part of every curriculum (Picciano \& Seaman, 2009).

The survey instrument used for this study was an extension of the 2007 and 2008 instrument used by the Sloan Consortium. It contained the same survey questions, with some additional demographic questions added. Just like the study conducted by the 
Sloan Consortium in 2007 and 2009, this survey aimed at furthering research in the five policy aspects of virtual programs. These five policy aspects include: quality (program, teacher, course, and student support), funding, access and equity, accountability and oversight, and research \& evaluation data were used. These five domains were born from the years of annual reports conducted by the Sloan Consortium.

The survey instrument used for this study was proven reliable and valid by the BABSON Survey Research Group. (Picciano \& Seaman, 2007). It begins with demographic questions regarding the district and the principal and is then divided into the following sections:

- Section 1 does the district use virtual programs;

- Section 2 barriers of enrolling students in virtual programs;

- Section 3 reasons school districts enroll students in virtual programs;

- Section 4 pedagogical feelings towards using virtual programs to service the district's students;

- Section 5 the types of students who are enrolled in virtual programs;

- Section 6 expected growth of the virtual programs in their districts; and

- Section 7 types of virtual programs and providers that are being used in the district.

The outcomes of this study will help educators make more informed decisions on the educational infrastructure they create, as well as the support mechanisms in place to ensure student success. 


\section{Data Collection}

\section{Delphi Method}

A modified Delphi Method for data collection was used for this study. The Delphi Method is a group facilitation technique used to transform raw data into group consensus or to find commonalities. Using a modified Delphi Method approach, commonalities of responses regarding reasons why these programs are so important to Appalachian Ohio High School Principals, as well as how they are being used, were sought.

Each survey and interview question was rated on levels of commonalities. In literature, the Delphi Method uses the term "consensus." For the purpose of this study, "consensus" is not the goal. With the intrinsic differences in school districts and student populations, it would be difficult for all principals to agree on the uses of virtual programs. Instead, the researcher is looking for commonalities of uses.

According to Loughlin and Moore (1979), a Delphi Study requires 51\% agreement to reach consensus/commonalities; however, Sumsion (1998) and Green, Jones, Hughes, \& Williams (1999) and Webb (1999) believe 70\% and 80\% are needed, respectively. Alternatively, Crisp, Pelletier, Duffield, Adams, and Nagy (1997) questioned the idea of using percentages claiming that stability of response over the series of rounds are more reliable for reaching consensus. Because there is no clear guideline for an acceptable agreement percentage, this study defined commonalities as $41 \%$ agreement among participant responses on the surveys and interview questions. Forty-one percent was chosen because a true majority $(51 \%)$ is not necessary to identify trends of commonalities. Forty-one percent commonalities show agreement among responses, but does not necessitate a majority. 
The Delphi Method was originally developed by the Rand Corporation for technological forecasting, but has since been established as a flexible approach that can significantly broaden knowledge within a given field (Hasson et al., 2000). It seeks to obtain consensus or to find commonalities from a field of experts by using a series of structured questionnaires, known as rounds. These questionnaires, usually in the form of surveys, are completed anonymously and the data is reviewed. Typically, the first round collects qualitative data, which drives the content of the second round. The second round survey typically collects quantitative data. Finally, focus groups can then be established to gather additional qualitative data in the form of interviews (Hasson et al., 2000).

Researchers using the Delphi Method must be aware of when to stop collecting data and what the definition of consensus/commonalities are in relation to the study's findings (Williams \& Web, 1994). When creating each subsequent round survey, the researcher must ensure that a fair representation of the participants' opinions is included. If only $50 \%$ of the first round opinions are listed in the second round survey, a true collection of all data may not be represented (Haason et al., 2000).

The data used in the second round survey of this study represented $66 \%$ of the opinions given to the quantitative section of the survey, and $100 \%$ of the opinions given in the qualitative section in the survey. In addition, to reduce the chance of eliminating a potential commonality, $100 \%$ of the opinions given in Round 2 Survey were used for the interviews.

Another item of caution when using the Delphi Method is sample size. A balance must occur between too large a sample vs. too small a sample. If the sample size is too large, a risk occurs in handling the data as well as its true analysis. If the sample size is 
too small, a risk is run that the conclusions are not fully representative of the field (Hasson et al., 2000). Alexander and Kroposki (1999) believed to provide representative information, 60 subjects are needed. Others, such as Burns (1998) believed as few as 15 participants can be used.

The sample size for this study was $77(\mathrm{~N}=77)$ Appalachian Ohio High Schools Principals for Round 1 Survey, 33 (N=33) Appalachian Ohio High School Principals for Round 2 Survey, and 5 (N=5) Appalachian Ohio High Schools Principals for the interview. This is a relatively large sample and is appropriate for this type of exploratory study.

Once the sample size is decided, researchers must choose experts who will be invited to participate. Unlike other data collection methods, participants in a Delphi study must agree to a continued effort throughout the process. Some researchers feel it is best to use an interview setting first in order to create a relationship with the participant and to ensure higher participation rates (McKenna, 1994).

The participants in this study were sent an email (Appendix C) with a letter attachment (Appendix D) outlining the aspects of a Delphi Research Project and the protocol for data collection. Those who participated in Round 1 Survey understood they may be asked to participate in Round 2 Survey, and then possibly be asked to participate in the interview. In attempts to keep the field large, the only criteria for Round 2 Survey participants was being identified as currently using virtual programs. In addition, the subjects chosen for the interview were done so because they currently use virtual programs, have at least 10 students enrolled in a virtual course, and have been a principal 
in that school district for three or more years. Because of this, these subjects are appropriate sources of data as they have considerable experience in this field.

Once the experts agree to participate, the researcher must inform them of his/her expectations. The participants need to know exactly what is going to be asked of them. Verbal or written instructions can be used to explain the necessary information. The subjects of this study were sent an email that introduced the researcher and asked for their participation in the study.

Once data collection and analysis begins, three main issues guide this stage: the discovery of opinions, the process of determining issues, and data analysis (Hasson et al., 2000). The discovery of opinions will help determine how many rounds it will take to reach consensus/commonalities. The literature states that the classic Delphi Method has four rounds (Young \& Hogben, 1978); however, more recent evidence appears to show that either two or three rounds are preferred (Proctor \& Hunt, 1994; Beech, 1997; Green, Jones, Hughes, \& Williams, 1999). This study used two rounds of surveys and one follow-up focus group interview.

The process of determining issues begins with round one. Usually, round one contains open-ended questions that allow the researcher to gather over-arching themes of responses. These themes allow the construction of the Round 2 Survey questions.

Schmidt (1997) recommends that participants be asked for at least six opinions, as several participants are likely to raise the same issue using different terms. Some studies revised this approach. Duffield (1993) and Jerkins and Smith (1994), claimed that round one should provide pre-existing information for ranking and response. This study adopted that approach as most questions required participants to use a Likert scale to rank pre- 
existing responses. Duffield and Jerkins and Smith did recognize this approach could bias the response or limit the available options. In attempts to negate this, Round 1 Survey also asked open-ended qualitative questions.

The third step in the series is data analysis. Data collected from each round can be both qualitative and quantitative in nature. Qualitative data can be analyzed using content analysis techniques. Common ideas are grouped together and minor editing should be conducted only if absolutely necessary. Some researchers believe that infrequent themes can be eliminated, however others believe this could jeopardize the results because the experts should be determining consensus, not the researcher (Haason, Keeney, \& McKenna, 2004).

This study used the constant comparative method, as described by Patton (1990), to analyze the qualitative questions in Round 1 Survey. This method is an inductive process for data analysis and is conducted by placing raw data into categories to uncover emerging themes. The major themes of Round 1 Survey were identified, summarized, and then feed back to the participants in Round 2 Survey.

Haason et al. (2004) believes that standard deviation does not apply to ordinal or nominal data, therefore these statistics were not used. This study used descriptive statistics for each quantitative question asked in Round 1 Survey. These results were then provided to the participants of Round 2 Survey and the interview. Each participant was asked to review the findings from Round 1 Survey before answering each question in Round 2 Survey. This process was then repeated as results of each round were reported separately to give clear indication of why the following round's content was chosen. 
According to Goodman (1987), Delphi Method guidelines do not require participants to meet face to face. He believes the participants can present and react to ideas unbiased by the identities and pressures of others. Anonymity is one of the features that characterize Delphi from other consensus methods. For this study, the focus group interviewees were interviewed individually. In addition to the time constraint barriers that seemed impossible to overcome, individual interviews allowed each participant to fully answer questions.

\section{Data Collection}

The population sample was sent an email including a link to the Round 1 Survey (see Appendix B). The email asked each participant to click on the link which would redirect to the online survey sponsored by Survey Monkey. Survey Monkey (www.surveymonkey.com) is a survey software program that will gather all responses and send a summary to the creator. Because of this, the participants did not have to email the researcher. They simply had to answer the survey questions online.

The email also contained an attachment letter outlining the study and the use of a modified Delphi Method. This letter, on WVU letterhead and approved by IRB, explained to the participants that they may be asked to participate in a follow up survey and interview.

A letter (Appendix E) from Dick Fisher, the Executive Director of CORAS, was also attached to the email sent to the population. Mr. Fisher echoed the importance of this study and encouraged the Appalachian Ohio High School Principals to participate.

The population was given one week to complete Round 1 Survey. A reminder email (Appendix F) was sent three days after the initial email was sent asking participants 
to reconsider completing Round 1 Survey. An incentive of a $\$ 100$ Visa Gift Card was used to persuade participants to participate. Round 1 Survey was sent to a population sample of 214 principals and $77(\mathrm{~N}=77)$ responded. At the conclusion of Round 1 Survey, an email (Appendix G) was sent thanking the participants and announcing the winner of $\$ 100$ Visa Gift Card.

At the end of one week, Round 1 Survey was closed and the data were gathered and analyzed. According to literature describing the Delphi Method, the use of descriptive statistics should be used for each item of the survey (Hanson et al., 2004). Central tendencies were used for the quantitative data, and the constant comparative method was used for the qualitative data. These statistics concluded which school districts were currently using virtual programs, what attributes were considered when choosing virtual programs, which types of students (credit reclamation, enrichment needs, AP course need, etc.) were chosen to enroll in virtual programs, and what best practices/policies govern the virtual programs once they are implemented.

The next step, according to the Delphi Method, was to use the findings from the Round 1 Survey to construct the Round 2 Survey. The goal of the Round 2 Survey was to examine further commonalities among the participants. This study sought to examine the use of virtual programs in Appalachian Ohio; therefore, only those school districts currently using virtual programs in their school districts were sent Round 2 Survey. Sixty-two principals were sent the invitation to complete Round 2 Survey and $33(\mathrm{~N}=33)$ complied.

Round 1 Survey had one open-ended question that asked the participants their thoughts (positive or negative) about virtual programs. Using the constant comparative 
method, two main themes arose from that question: Apprehensions of Virtual Programs and Alternative Uses of Virtual Programs. Because of these new results, additional questions surrounding these two themes were added to the Round 2 Survey.

When moving to each subsequent round, the definition of commonalities was used to determine which responses were kept and which were discarded. For example, after examination of Round 1 Survey questions, certain responses were rated "low" or "not important" or "disagree." If those responses equaled $41 \%$ or higher, they were deemed irrelevant and eliminated from Round 2 Survey. This process was used to further refine commonalities among participants and was repeated for each question of the Round 2 Survey.

In addition, responses that were more agreed upon by reporting "strongly agree", “important", etc. were also measured against the $41 \%$ commonalities definition to determine if a true commonality was emerging. This process identified common trends among and between the Appalachian Ohio High Schools and was repeated for each question of the Round 2 Survey.

An email (Appendix H) was sent to the 62 participants that matched the predetermined criteria of currently using virtual programs in their school districts, and 33 $(\mathrm{N}=33)$ complied. The email asked each to click on the provided link which would redirect to Round 2 Survey (Appendix I). The population was given one week to complete Round 2 Survey. A second request email (Appendix J) was sent three days after the initial email, and a third request (Appendix K) was sent four days after the initial email was sent. An incentive of a $\$ 100$ Visa Gift Card was used to persuade participants to participate. At the conclusion of Round 2 Survey, an email (Appendix L) was sent 
thanking the participants and announcing the winner of $\$ 100$ Visa Gift Card. After one week, Round 2 Survey was closed and the data were gathered. Central tendencies were used to analyze the quantitative data, and the constant comparative method was used to analyze the qualitative data.

After Round 2 Survey results were returned and analyzed, a focus group of seven principal to interview was chosen. The predetermined criteria required to be eligible for the interview included:

- high school currently uses a virtual program,

- principal has had that role for the past three years, and

- at least 10 students are enrolled in one or more online courses.

This criterion was used so that those principals who were currently using virtual programs and have held their position for three or more years would be chosen. Principals who have worked in the same role would have experience with their use of virtual programs and could speak with knowledge on this topic. Having 10 or more students enrolled in virtual programs was also used because this lead to a more knowledgeable interviewee.

Originally, only five principals were sought to participate in the focus group interview; however, seven principals matched the predetermined criteria so all seven were invited. An additional \$100 Visa Gift Card was used as an incentive to participate. Five principals $(\mathrm{N}=5)$ agreed to participate.

An email (Appendix M) was sent to the seven principals asking them to participate in a webinar using GoToMeeting.com regarding the use of virtual programs in their district. GoToMeeting.com is a technology that allows multiple users to share 
computer interfaces while speaking to one another through a conference call. Only one principal returned the email stating he had a scheduling conflict. No other principal responded. Because of this, individual emails were sent (Appendix N) asking each to agree to a one-on-one GoToMeeting.com interview. One principal responded stating that he was too busy. A telephone call was then placed to each of the remaining five principals and was asked if a phone interview could be scheduled. All five principals agreed. Schedules were coordinated and five interviews were scheduled over the next six days.

Interview questions were constructed based on the conclusions from the Round 2 Survey. In attempts to not inadvertently remove any main themes found from Round 2 Survey, interview questions were kept exactly as presented in Round 2 Survey.

An email (Appendix O) was sent to each of the five principals who agreed to be interviewed. It provided the principal with the interview questions (Appendix P) and the possible answers for the quantitative portion. Telephone calls were placed to each principal after the email was sent. The principals were asked to open the email in order to go through the questions together. As the subjects spoke, their answers were transcribed using Microsoft Word. Interview data files have been stored digitally on a laptop, desktop, and external drive. The data has been locked with only the researcher having access. After each interview, the principals were thanked for their time.

After all five interviews were conducted, analysis of the data was completed using the constant comparative method. The interview data was transcribed and coded based on common patterns of responses. These categories were compared further to refine the data and discover commonalities. 
The three research questions listed below guided the interview questions.

- RQ1 In the opinion of Appalachian Ohio High School Principals, what reasons are considered when using virtual programs as an alternative to traditional course offerings? What factors need to be in place to facilitate continued growth of virtual program use?

- RQ2 In the opinion of Appalachian Ohio High School Principals, what apprehensions of virtual programs impede their use? What factors need to be in place to overcome those apprehensions?

- RQ3 In the opinion of Appalachian Ohio High School Principals, what best practices and/or policies need to be in place to implement a successful virtual program?

The combination of both qualitative data and quantitative data will help add triangulation to this study. The quantitative methods were used to answer the "what" research questions and qualitative methods was used to answer the "why" research questions. Using the modified Delphi Method, along with the constant comparative method, commonalities were sought and further concluded the reliability of the data.

\section{Guarantee of Anonymity and Confidentiality}

The anonymity of participants in all parts of the study was assured and explained in a letter which accompanied the surveys. All data have been kept safe on both a personal laptop and an external data drive. The researcher has been the only person with access to the data and was solely responsible for disseminating the surveys, collecting the responses, and conducting the interviews. The confidentiality and anonymity of all participants was assured prior to each interview.

\section{Summary}

This chapter explained the exploratory, modified Delphi Method format that was used in this study. The quantitative portion sought to identify which school districts were using virtual programs and the types of students enrolled. The qualitative portion sought 
to identify why virtual programs were chosen and the specific best practices and policies used when deciding the types of students enrolled in virtual programs.

The population used was the Appalachian Ohio High Schools Principals. The instrument used to collect the data was the Sloan Consortium Survey Instrument used in two previous national studies on K-12 Online Learning and the Perceptions of U.S.

School District Administrators. An analysis of the findings gives insight into the world of virtual programs to all stakeholders. 


\section{Chapter 4}

\section{Results}

In this chapter, the data from this study is presented. The chapter begins with the results from Round 1 Survey, then moves to the results from Round 2 Survey, and finally the results from the Interview. Following the guidelines of the modified Delphi Method, each round was conducted separately so the results are presented as such.

\section{Principals and School Characteristics}

A total of $77(\mathrm{~N}=77)$ principals participated in Round 1 Survey, $33(\mathrm{~N}=33)$ principals in Round 2 Survey, and $5(\mathrm{~N}=5)$ principals in the follow up interview. Round 1 principals were chosen because they work in a school district in Ohio's Appalachian region. Round 2 principals were chosen because they work in Ohio's Appalachian region and they were also currently using virtual programs. The principals in the follow up interview were chosen because they work in Ohio's Appalachian region, were currently using virtual programs, had been a principal in their school building for at least three years, and had at least 10 students currently enrolled in at least one virtual course.

The school districts chosen for this study were an all inclusive group based upon being located in Ohio's 32 Appalachian Counties. Every high school principal who worked in a public school district in this region was asked to participate in Round 1 Survey.

\section{Round 1 Survey}

Round 1 Survey (Appendix B) was sent to a population of 214 principals in Appalachian Ohio's High Schools, of which 77 principals $(\mathrm{N}=77)$ responded, resulting in 
a 36\% return rate. Round 1 Survey began with demographic questions and was then followed by seven sections:

- Section 1 does the district use virtual programs;

- Section 2 barriers of enrolling students in virtual programs;

- Section 3 reasons school districts enroll students in virtual programs;

- Section 4 pedagogical feelings towards using virtual programs to service the district's students;

- Section 5 the types of students who are enrolled in virtual programs;

- Section 6 expected growth of the virtual programs in their districts; and

- Section 7 types of virtual programs and providers that are being used in the district.

When moving to each subsequent round, the definition of commonalities was used to determine which responses were kept and which were discarded. For example, after examination of Round 1 Survey questions, certain responses were rated "low" or "not important" or "disagree". If those responses equaled $41 \%$ or higher, they were deemed irrelevant and eliminated from Round 2 Survey. This process was used to further refine commonalities among participants.

In addition, responses that were more agreed upon by reporting "strongly agree", "important", etc. were also measured against the $41 \%$ commonalities definition to determine if a true commonality was emerging. This process identified common trends among and between principals in Appalachian Ohio High Schools.

\section{Demographics}

The following questions represent the demographic section of Round 1 Survey. 
Question 1 (Question 1 in Round 2 Survey and Question 2 in Interview) - Please answer the following demographic questions: name, school, address, county, email address, and phone number. In order to keep the participants' demographic information confidential, Figure Q1 depicts the counties representing participants. Of Ohio’s 32 Appalachian Counties, representatives from 28 counties participated.

Question 2 (Question 2 in Round 2 Survey and Question 2 in Interview) - What is your position in your school building? As shown in Table Q2, of the 77 participants, 71 $(92.2 \%)$ reported "Principals", 1 (1.3\%) reported "Teachers", and 5 (6.5\%) reported “Other." Of those who reported "Other", the following were listed: Superintendent, Guidance Counselor, Dean, Supervisor, and Counselor/VLA Coordinator.

Question 3 (Question 3 in Round 2 Survey and Question 3 in Interview) - If you chose "Principal/Direction for Question \#2, how long have you held that position? As shown in Table Q3, of the 77 participants, 47 (61\%) reported "More than three years", 5 (6.5\%) reported "Less than one year", 5 (6.5\%) reported "One year", 9 (11.7\%) reported "Two years", $6(7.8 \%)$ reported "Three years", and $5(6.5 \%)$ reported "Not a Principal/Director.”

\section{Districts Use of Virtual Programs}

Question 4 (Question 4 in Round 2 Survey and Question 4 in Interview) - Did students in your district take any fully online or blended courses between July 1, 2008 and June 30, 2009? As shown in Table Q4, of the 77 participants, 57 (77\%) reported the largest population were students who took "At least one fully online course." The smallest population, $5(6.8 \%)$ reported "Do not have students in fully online courses, but do plan to offer them within the next three years." 
Question 8 (Question 13 in Round 2 Survey and Question 13 in Interview) - In what school year did any student in your district first take a fully online or blended course? As shown in Table Q5, of the 77 participants, 28 (51\%) reported "Before 2005"; 8 (15\%) “2005-2006”; 6 (11\%) “2006-2007”; 3 (5\%) “2007-2008”; and 10 (18\%) “20082009." Twenty-two participants skipped this question.

\section{Barriers of Enrolling Students in Virtual Programs}

Question 5 (Question 5 in Round 2 Survey and Question 5 in Interview) - How much of a barrier are the following areas to your district in offering fully online or blended learning courses? As shown in Table Q6, of the 77 participants, the most important barriers (answered a "5" or a "4") were "Concerns about course quality" (63.1\%) and "Course development and purchasing costs" (54.6\%). The least important barriers (answered a "2" or a "1") were "Restrictive federal, state, or local laws and policies" (62.4\%), and "Limited technology infrastructure to promote distance education" $(44.2 \%)$

\section{Reasons School Districts Enroll Students in Virtual Programs}

Question 6 (Question 7 in Round 2 Survey and Question 7 in Interview) - How important do you believe the following reasons are for a school district to offer online or blended learning courses? As shown in Table Q7, of the 77 participants, the most important reason (answered a " 5 " or a " 4 ") reported "Meeting the needs of a specific group of students" (89.6\%), and "Permitting students who failed a course to take it again (89.4\%). The least important reasons (answered a "2" or a " 1 ") reported were "Addressing growing population and limited space" (50.7\%), "Online and blended 
offerings are pedagogically more beneficial" (49.4\%), and "Certified teachers are not available at the school" (45.5\%).

\section{Pedagogical Feelings Towards Using Virtual Programs to Service the District's}

\section{Students}

Question 7 (Question 9 in Round 2 Survey and Question 9 in Interview) - I am interested in your opinions. Please let me know your thoughts (positive or negative) on any aspect of online and blended courses and their potential for your district.

The results of this question were used to frame four additional questions in Round 2 Survey and the Interview. These questions were meant to further refine the participants' feelings (positive and negative) by asking them to agree/disagree with the finding of this open-ended response and then to rank the items according to importance.

Using Patton's (1990) Constant Comparative Method, the responses were analyzed and four main themes, with some sub themes, were discovered. Only the first two themes were used in Round 2 Survey and the Interview.

1. Virtual Programs as an "Alternative" - This theme surrounds the use of virtual courses as an alternate to traditional methods. Participants' answers that were categorized under the Alternative theme feel under three subthemes including:

a. Methodology - virtual programs used as a different methodology to educate students in a $21^{\text {st }}$ century workforce

b. Diverse Needs - virtual programs used to meet the diverse needs of students and district

c. Credit reclamation - virtual programs used for students who are credit deficient 
2. Virtual Program "Apprehensions" - This theme surrounds the apprehensions of virtual program use. Participants' answers that were categorized as

“Apprehensions" fell under five subthemes. These include:

a. Motivation - Students lack self-motivation

b. Quality - Quality of course content and/or program

c. Cost - cost of implementing virtual courses; cost of students withdrawing to enroll in other electronic schools

d. Elimination - Elimination of teachers because of virtual programs

e. Accountability - students/system accountable for success of programs

3. "NOT USING" - Responses by those not currently using virtual programs

4. "MISCELLANEOUS" - Responses that did not fit into the main themes

Each response was identified by the principal that answered the question. (i.e., “P47” was answered by Principal \#47). No editing was done to the responses and they are listed in no particular order.

The following comments fell under the "Alternative - Methodology" Category:

P22 - "I believe a lot higher percentage of the student population could be just as successful with these type of courses as with the traditional classroom."

P47 - "We have a stimulous grant tied directly to innovations in technology within our district. The clear concepts linked to this process are that we (public education) are absolutely NOT preparing our students to function in such a high technological work force. We are still teaching antiquated ideologies through antiquated methodologies. We still have policies on the books that do not permit cell phone, mp3, and even advanced calculator useage during the school day. How is this embracing technology and preparing our students for a future more advanced then where we currently are? Needless to say, the knee jerk oposition to online or computer based courses is driven by employee unions, justification for human interface, and being driven by social beings fighting for a social system. We can not pretend that a facebook, myspace, twitter, or blog does not develope strong relationships for our students that we have never quite grasped due to the aging populations still driving the classrooms. We do not live in the world that our students do. They text answers to tests, they photograph and video their own 
personal lives and events then post them for the world, they can communicate the whereabouts of everystaff member 3 minutes prior to the arrival of that person, and the list goes on farther than what our imaginations can grasp. Either we pretend to fight it and lose, or we need to embrace these devices and what they represent to the future of our students, community, society, and world."

The following comments fell under the "Alternative - Diverse Needs" Category:

(Within this theme, categories of Diverse Needs evolved. These include: Curriculum Requirements, Special Circumstances/Cannot function in school/Health Issues, Flexible

Opportunity, and AP Courses.)

Curriculum Requirements

P1 - "The use of online courses is a growing area. It is an opportunity to provide a quality education that is designed to meet student needs and school requirements. A blended approach is most appropriate for high school students but a strictly on line program is a positive solution for students with unique educational needs that can effectively and efficiently be met through online courses."

P5 - "students meet graduation requirements"

P25 - "Our district uses these types of online courses for credit recovery purposes at both the high school and middle school. The high school, due to budget cuts, had to reduce our foreign languages to only one offering. We allowed students who had been in the dropped language (French) for two years to complete an online third level course for Ohio's Honors Diploma purposes.”

P27 - "it provides another alternative for students to recover credits and it can be financially beneficial to the district,,,,quality of curriculum must always be upheld and ever changing to meet new standards"

P37 - "For the most part, Virtual Learning has been beneficial to our students in either reducing scheduling conflicts or allowing students to retake something they may not have had success."

P42 - "Online courses have proved to be very beneficial for our students. It keeps students on track and gives them direction for obtaining a high school diploma. The other option is to drop out because of family circumstances or health conditions." 
Special Circumstances/Cannot function in school/Health Issues

P3 - "Used only as alternative education option for students with special circumstances"

P4 - "They can serve a important link between direct instruction and on line classes for student wwho can not function in traditional school”

P11 - "We offer a form of virtual for students who have needs outside of schoolie- they need to work to help support the family or have children and can not afford child care. We have participated in offering AP classes online because we do not have trained staff to do it in house."

P39 - "Online courses especially help those students who cannot function in the regular classroom. This may be due to truancy issues, expulsion, etc. Also, online classes benefit those students who want to take a course that is not offered at the school level. It also used for summer intervention in lieu of summer school."

P40 - "The diverse needs of students can often be met by on line courses."

P42 - "Online courses have proved to be very beneficial for our students. It keeps students on track and gives them direction for obtaining a high school diploma. The other option is to drop out because of family circumstances or health conditions."

Flexible Opportunity

P13 - "As you may know Ohio has now provided credit flexibility students for all students. Online and blended courses will be a growing option for Ohio students."

P18 - "Online courses both internal and external to our school district have been a good option for our students”

P30 - "they can provide a lot of flexibility for students which I believe is a positive”

P34 - "As a small school, on-line courses offer opportunities for our students that otherwise they would not have."

P36 - "VLA courses are very vital to us for many reasons and have for the most part met with success" 


\section{AP Courses}

P11 - "We offer a form of virtual for students who have needs outside of schoolie- they need to work to help support the family or have children and can not afford child care. We have participated in offering AP classes online because we do not have trained staff to do it in house.”

P29 - "Presently we offer AP classes, Post secondary options to nearby universities, as well as classes offered from Univ. of Akron via distance learning where students attend a college class inside our building and do not visit the university except to enroll and for orientation."

The following comments fell under the "Alternative - Credit Reclamation" Category:

P16 - "We only allow it for credit if the course is remedial. The student must have faiked the course iin our building"

P19 - "We use virtual courses as credit recovery mostly. A few students do total virtual instead of attending school."

P20 - “They help students make up credit. Students need to be highly motivated.”

P21 - "Our online courses are offered through the Aventa program monitored by our school and used primarily for credit recovery."

P23 - "We use on-line courses for students to make-up credits and it has been very beneficial."

P32 - "Allows students who are discipline problems to gain their high school credits at home. It also allows students who have failed a class to take it online to receive their credit. Online classes I believe have assisted certain students to obtain their necessary credits in order that they may receive their high school diploma."

P43 - "Currently, we offer online courses as a credit recovery for students especially our seniors or those students who have transferred in and are credit deficient. I believe that online coursework provides a fabulous opportunity for students, however I am "old schooled" in ways that I believe students only have one opportunity to take in the whole high school experience which includes academics, activities, and the social experience."

The following comments fell under the "Apprehensions - Motivation" Category:

P6 - "Students not finishing the on-line course work with-in the time frame permitted ." 
P10 - "Students should have easy access to the Internet (not dial-up), in order for it to be effective. If a student is not an adequate (high school level) reader, they have difficulty. If the student is not comfortable using a computer (keyboarding, using the Internet) they have difficulty with on-line courses. The student needs self-discipline and motivation to complete an on-line course."

P12 - "It takes a very driven student to keep up with the online courses.

*Question 8 does not include 09 - 10 school year and that is when we started offering courses online."

P38 - "Motivating students to achieve through this techniques is difficult unless the time is set daily."

P41 - "I have witnessed very little success with any form of online courses. The majority of students which take the online courses seem to be below average achievers and not self-motivated. As you know, a student must have a lot of selfdetermination to achieve success. The small amount of success I have been involved with regarding online courses was with highly motivated students taking courses that were either not available to them in our school, or courses that would enable them to get to a higher level course sooner."

P45 - "I have been involved with lolon classes for many years at other schools. There are many advantages for offering online classes...as many well know, but the main disadvantae is a student must be self-motivated. On line classes become monotonus and laborious quickly for students. They have to have that intristict need to make it a positive experience”

The following comments fell under the "Apprehensions - Quality" Category:

P2 - "The lack of control about authentic assessment is a concern."

P44 - "Loss of money for district and quality of courses being offered"

The following comments fell under the "Apprehensions - Cost" Category:

P7 - "Unfortunately, in some instances it is causing enrollment concerns for some schools, students are seeking out computer academies as their school of choice"

P35 - "We are faced with on line schools "dumping" attendance problems back in the school now that there is some accountability. The idea of on-line courses is very beneficial in it inception, but has become clouded with students (not all, but a large contingency) who use it as an escape hatch toward not being accountable. I would love to offer AP and Honors courses for our kids. The opportunities here are very meager with our size and financial situation. We are trying to coordinate dual credit opportunities with the resources we have." 
P44 - "Loss of money for district and quality of courses being offered"

The following comments fell under the "Apprehensions - Elimination" Category:

P8 - "On line courses will never fully replace the classroom teacher. They do offer the option to supplement missed course work to help a student to graduate. We have also seen an increase in the number of students who chose the on line option because of behavioral issues with other students. Success rates have been mixed as far as completion. Generally, if a student struggles academically in the classroom, they are probably going to struggle on the virtual learning."

P17 - "The main concern of the staff is the loss of teaching positions within the school with on-line courses. Are we trying to eliminate staff by using this option? My feelings are that we are being directed by the state legislature towards virtual educational options anyway, so we might as well develop those options whether blended or fully on-line to benefit the high school and the district."

The following comments fell under the "Apprehensions - Accountability" Category:

P14 - "Must have an instructor with the online student."

P15 - "My concern with online courses is accountability. I am never sure who is doing the work"

P24 - "I believe there is inherent value in offering students the opportunity to access on-line courses. The critical issue is assuring that the course/program is legitimate and meets the specific needs of the student and the requirements of the district. It is also critical that the students who need assistance are provided that by licensenced educators."

P28 - "I believe online courses can be beneficial if the student does his or her own work and isn't getting help from other resources."

P35 - "We are faced with on line schools "dumping" attendance problems back in the school now that there is some accountability. The idea of on-line courses is very beneficial in it inception, but has become clouded with students (not all, but a large contingency) who use it as an escape hatch toward not being accountable. I would love to offer AP and Honors courses for our kids. The opportunities here are very meager with our size and financial situation. We are trying to coordinate dual credit opportunities with the resources we have."

The following comments fell under the "Not Using" Category:

P9 - "I am currently looking into blended or online courses. I have a growing interest." 
P26 - "We are currently looking at our Credit Flexibility policy and hope to have something in place by next school year. Also, we are hoping to assist our at-risk students with credit recovery classes"

P33 - "We are interested in online and/or blended courses for 2009-2010 and would love to received information from the survey and any comments that districts made about programs that are working for them."

The following comments fell under the "Miscellaneous" Category:

P31 - "I believe online courses have both positive and negative affects depending upon the individual student. At-risk students may need facetime with the instructor to be successful when other students may not"

P46 - "We have found them to be beneficial!"

Question 9 (Question 14 in Round 2 Survey and Question 14 in Interview) -

Select the level (1-5) at which you disagree/agree with the following statements with regard to students in your district. As shown in Table Q8, of the 77 participants, the statements that were most agreed (answered a "5" or a "4") reported, "Fully online and blended courses fulfill an important educational need" (74.1\%), and "Students need more discipline to succeed in an online course than in a traditional course" $(72.7 \%)$. The statements that were most disagreed (answered a "2" or a "1") reported, "State or local governing bodies or regulations are encouraging my district to enroll students in online and blended courses" (45.5\%) and "Fully online and blended courses have allowed my district to build important relationships with other organizations" (45.4\%). Twenty-two participants skipped this question.

\section{The Types of Students Enrolled in Virtual Programs}

Question 10 (Question 15 in Round 2 Survey and Question 15 in Interview) - The nature of online or blended courses taken by students in my district (check all that apply): 
As shown in Table Q9, of the 77 participants, the nature of online and blended courses most used were "Fully online - remedial courses" (75.5\%) and "Fully online required courses" (69.8\%). "Blended Courses - Elective" (64.3\%) and "Blended Courses - Required" (60.7\%). The nature of online and blended courses least used were "Fully online - Other" $(11.3 \%)$ and "Blended courses - Courses for college credit other than AP" $(14.3 \%)$. Twenty-two participants skipped this question.

\section{Growth of Virtual Programs}

Question 11 (Question 16 in Round 2 Survey and Question 16 in Interview) - What is your best estimate of the number of student enrollments (a student enrolled in more than one course should be counted only once) between July 1, 2008 and June 30, 2009?

As shown in Table Q10, of the 77 participants, the most enrollments reported were "Grades 9-12 Fully Online" (98\%) and “Grades 9-12 Blended courses" (98\%). The least enrollments reported were "Grades K-5 Fully Online" (58\%) and "Grades K-5 Blended Courses" (58\%). Twenty-two participants skipped this question.

Question 12 (Question 17 in Round 2 Survey and Question 17 in Interview) - Over the next two years, my district expects fully online course enrollments to:

As shown in Table Q11, of the 77 participants, 42 (76.4\%) reported "Stay about the same." Thirteen (23.6\%) chose to fill in a growth percentage, as shown in Table 4. Twenty-two participants skipped this question.

Table 4

Speculated Growth of Fully Online Courses - Answers Given

\begin{tabular}{ccc}
\hline $\begin{array}{c}\text { Growth } \\
\text { reported as \% }\end{array}$ & Frequency & Percentage \\
\hline 2 & 2 & $15.4 \%$ \\
3 & 1 & $7.7 \%$ \\
5 & 1 & $7.7 \%$
\end{tabular}




\begin{tabular}{ccc}
10 & 2 & $15.4 \%$ \\
$10-15$ & 1 & $7.7 \%$ \\
$15-20$ & 1 & $7.7 \%$ \\
20 & 2 & $15.4 \%$ \\
100 & 2 & $15.4 \%$ \\
200 & 1 & $7.7 \%$ \\
Total & 13 & $100.1 \%$ \\
\hline
\end{tabular}

Question 13 (Question 19 in Round 2 Survey and Question 18 in Interview) Over the next two years, my district expects blended enrollments to:

As shown in Table Q12, of the 77 participants, 43 (78.2\%) answered "Stay about the same." Twelve (21.8\%) chose to fill in a growth percentage, as shown in Table 5. Twenty-two participants skipped this question.

Table 5

Speculated Growth of Blended Courses - Answered Given

\begin{tabular}{ccc}
\hline $\begin{array}{c}\text { Growth } \\
\text { reported as } \%\end{array}$ & Frequency & Percentage \\
\hline 5 & 4 & $33.3 \%$ \\
10 & 1 & $8.3 \%$ \\
$10-15$ & 1 & $8.3 \%$ \\
20 & 3 & $25 \%$ \\
50 & 1 & $8.3 \%$ \\
n/a & 2 & $16.8 \%$ \\
Total & 12 & $100 \%$ \\
\hline
\end{tabular}

\section{Providers of Virtual Programs}

Question 14 (Question 21 in Round 2 Survey and Question 20 in Interview) - The provider(s) for fully online and blended courses for my district are (check all that apply):

As shown in Table Q13, of the 77 participants, the following was reported as the most used provider of fully online and blended courses: Fully online - Educational Service Agencies- 60\%, Independent Vendors - 42\%. Blended-Educational Service 
Agencies $-18 \%$, Independent Vendors $-13 \%$. Of the 55 participants, the following was reported as the least used provider of fully online and blended courses: Fully onlineOther schools in your district - 5\%, Blended -Districts or schools in other states $-0 \%$. Twenty-two participants skipped this question. 


\section{Round 2 Survey}

Round 2 Survey was sent to a population of 62 principals from 60 different school districts in Appalachian Ohio. The population was chosen based upon those who responded to Round 1 Survey. From the 77 participants of Round 1 Survey, 62 matched my predetermined criteria of currently using virtual programs. Thirty-three $(\mathrm{N}=33)$ of the 62 responded, resulting in a 53\% return rate. Round 2 Survey began with demographic questions and was then followed by seven sections:

- Section 1 does the district use virtual programs;

- Section 2 barriers of enrolling students in virtual programs;

- Section 3 reasons school districts enroll students in virtual programs;

- Section 4 pedagogical feelings towards using virtual programs to service the district's students;

- Section 5 the types of students who are enrolled in virtual programs;

- Section 6 expected growth of the virtual programs in their districts; and

- Section 7 types of virtual programs and providers that are being used in the district.

\section{Demographics}

The following questions represent the demographic section of Round 2 Survey.

Question 1 (Question 1 in Round 1 Survey and Question 1 in Interview) - Please answer the following demographic questions: name, school, address, county, email address, and phone number.

In order to keep the participants demographic information confidential, Figure R1 depicts the counties representing participants. Of Ohio's 32 Appalachian Counties, 
representatives from 19 counties participated. Table 6 compares the Round 2 Survey data to the Round 1 Survey data.

Table 6

\section{Participating Counties}

\begin{tabular}{lc}
\hline & Number of participating counties \\
\cline { 2 - 2 } Round 1 survey & 28 \\
Round 2 survey & 19 \\
\hline
\end{tabular}

Question 2 (Question 2 in Round 1 Survey and Question 2 in Interview) - What is your position in your school building? Results from previous survey (top two):

"Principals"- 92\% "Other"- 7\%.

As shown in Table R2, of the 33 participants, 29 (87.9\%) reported "Principals", and 4 (12.1\%) reported "Other." Of those who reported "Other", the following were listed: Superintendent, Guidance Counselor, Assistant Director/Career Tech Supervisor, and Counselor/VLA Coordinator.

When comparing the Round 2 Survey data to the Round 1 Survey data, as shown in Table 7, Round 1 Survey reported a rate of $92 \%$ of the participants were "Principals." The data percentages represent commonalities of responses among participants.

Table 7

Position of Participants

\begin{tabular}{lc}
\hline & $\%$ of principals \\
\cline { 2 - 2 } Round 1 survey & $92 \%$ \\
Round 2 survey & $88 \%$ \\
\end{tabular}

Question 3 (Question 3 in Round 1 Survey and Question 3 in Interview) - If you chose "Principal/Director for Question 2, how long have you held that position? Results from previous survey (top two) "Over 3 Years" - 61\% "2 years" - 12\% 
As shown in Table R3, of the 33 participants, 19 (57.6\%) reported "More than three years", $3(9.1 \%)$ reported "Less than one year", $0(0 \%)$ reported "One year", 4 (12.1\%) reported "Two years", 3 (9.1\%) reported "Three years", and 4 (12.1\%) reported "Not a Principal/Director".

When comparing the Round 2 Survey data to the Round 1 Survey data, as shown in Table 8, the highest response rate for "Length of Position" was the same across rounds. The data percentages represent commonalities of responses among participants.

Serving for "Three or more years" is one pre-determined criteria to be eligible for the follow-up interview. With the highest number of participants having served for "More than three years", a higher population of principals will be eligible for the interview.

Table 8

Length of Position

\begin{tabular}{lc}
\hline & Length of position - highest response \\
\cline { 2 - 2 } Round 1 survey & "More than three years" $-(61 \%)$ \\
Round 2 survey & "More than three years" $-(57.6 \%)$ \\
\hline
\end{tabular}

\section{District Use of Virtual Programs}

Question 4 (Question 4 in Round 1 Survey and Question 4 in Interview) - Did students in your district take any fully online or blended courses between July 1, 2008 and June 30, 2009? Results from previous survey: "At least one student took a fully online course" $-77 \%$.

As shown in Table R4, of the 33 participants, 30 (91\%) reported the largest population were students who took "At least one fully online course." The smallest 
population $(3 \%)$ were those districts that "Do not have students in fully online courses, and do not have plans to offer them within the next three years."

When comparing the Round 2 Survey data to the Round 1 Survey data, as shown in Table 9, the largest types of student enrollment were the same across rounds. The data percentages represent commonalities of responses among participants.

The smallest types of student enrollment changed between rounds. This could be due to the individual use of virtual programs by Appalachian Ohio High Schools Principals in their respective school districts.

Table 9

Virtual Program Enrollment

\begin{tabular}{|c|c|c|}
\hline & \multicolumn{2}{|c|}{ Virtual program enrollment type } \\
\hline & Largest & Smallest \\
\hline Round 1 survey & $\begin{array}{l}\text { "At least one fully online } \\
\text { course" }(77 \%)\end{array}$ & $\begin{array}{l}\text { "Did not have any students } \\
\text { in a fully online course, but } \\
\text { have plans to offer them } \\
\text { within three years" }(6.8 \%)\end{array}$ \\
\hline Round 2 survey & $\begin{array}{l}\text { "At least one fully online } \\
\text { course" }(91 \%)\end{array}$ & $\begin{array}{l}\text { "Do not have students in } \\
\text { fully online courses, and do } \\
\text { not have plans to offer them } \\
\text { within the next three years" } \\
(3 \%)\end{array}$ \\
\hline
\end{tabular}

Question 13 - (Question 8 in Round 1 Survey and Question 13 in Interview) In what school year did any student in your district first take a fully online or blended course? Results from previous survey: “Before 2005 " $51 \%$ “2008-2009” - 18\%.

As shown in Table R5, of the 33 participants, 19 (58\%) reported "Before 2005"; 2 (6\%) “2005-2006”; 3 (9\%) “2006-2007”; 3 (9\%) “2007-2008”; 0 (0\%) “2008-2009”; and 3 (9\%) "2009-2010." Three participants skipped this question. 
When comparing the Round 2 Survey data to the Round 1 Survey data, as shown in Table 10, the most common school year reported was the same across rounds. This represents the longevity of virtual program use among Appalachian Ohio High Schools. The data percentages represent commonalities of responses among participants.

The least common school year reported changed between rounds. This could be due to the individual use of virtual programs by Appalachian Ohio High Schools Principals in their respective school districts.

Table 10

School Year of First Enrollment

\section{Population}

\begin{tabular}{cc}
\hline Largest & Smallest \\
\hline "Before 2005" (51\%) & "2007-2008" (5\%) \\
"Before 2005" (58\%) & "2008-2009" (0\%)
\end{tabular}

\section{Barriers of Enrolling Students in Virtual Programs}

Question 5 (Question 5 in Round 1 Survey and Question 5 in Interview) - How much of a barrier are the following areas to your district in offering fully online or blended learning courses? Results from previous survey: Most important - "Concerns about course quality" - 63\% “Concerns about cost" - 55\%. Least important "Restrictive federal, state, or local laws and policies" - 62.4\% "Limited technology infrastructure to promote distance education" $-44.2 \%$.

As shown in Table R6, of the 33 participants, the most important barriers (answered "5" or a "4") reported were "Concerns about course quality" (71.9\%), and 
"Course development and purchasing costs" (48.5\%). The least important barrier (answered "2" or "1") reported was "The need for teacher training" $(18.8 \%)$.

When comparing the Round 2 Survey data to the Round 1 Survey data, as shown in Table 11, the most important barriers remained the same. The data percentages represent commonalities of responses among participants.

The least important barrier, however, changed after Round 1 Survey. This could be attributed because, in attempts to further refine commonalities, the two least important barriers, as reported in Round 1 Survey, were deleted in Round 2 Survey. "Restrictive federal, state, or local laws and policies (62.4\%) and "Limited technology infrastructure to promote distance education" (44.2\%) both met the $41 \%$ commonalities definition, and were deemed irrelevant. Therefore, they were deleted from Round 2 Survey.

Table 11

Virtual Program Barriers

\begin{tabular}{lll}
\hline & \multicolumn{2}{c}{ Virtual program barriers } \\
\cline { 2 - 3 } Round 1 & \multicolumn{1}{c}{ Highest } & \multicolumn{1}{c}{ Lowest } \\
\cline { 2 - 3 } survey & $(63.1 \%)$ & "Restrictive federal, state, or local laws \\
& "Course development and & $\begin{array}{l}\text { and policies" }(62.4 \%) \\
\text { "Limited technology infrastructure to } \\
\text { purchasing costs" }(54.6 \%)\end{array}$ \\
promote distance education" $(44.2 \%)$ \\
survey & $\begin{array}{l}(71.9 \%) \\
\text { "Concerns about course quality" }\end{array}$ & "The need for teacher training" $(18.8 \%)$ \\
& "Course development and & \\
purchasing costs" $(48.5 \%)$ & \\
\hline
\end{tabular}

Question 6 (not present in Round 1 Survey and Question 6 in Interview) - This question is in regards to Barriers that impede your district's implementation of virtual programs. Please rank the following four items as Barrier 1 or 2 or 3 or 4 in order of their importance. 1 is the highest and 4 is the lowest. This question was not included in Round 1 Survey. 
As shown in Table R7, of the 33 participants, the results are as follows:

- \#1 Barrier - Course development and/or purchasing costs

- \#2 Barrier - Concerns about course quality

- \#3 Barrier - Concerns about receiving funding based on student attendance

- \#4 Barrier - The need for teacher training

\section{Reasons School Districts Enroll Students in Virtual Programs}

Question 7 (Question 6 in Round 1 Survey and Question 7 in Interview) - How important do you believe the following reasons are for a school district to offer online or blended learning courses? Results from the previous survey (top two): Most Important: "Meeting the needs of a certain group of students" - $89.6 \%$ "Permitting students who failed a course to take it again" $-89.4 \%$.

As shown in Table R8, of the 33 participants, the most important reason (answered a "5" or a "4") reported "Permitting students who fail a course to take it again" (81.8\%), and "Meeting the needs of a specific group of students" $(81.3 \%)$. The least important reason (answered a "2" or a "1") reported "Students prefer online activities" (54.6\%), and "Online and blended offerings are financially beneficial" (30.3\%).

When comparing the Round 2 Survey data to the Round 1 Survey data, as shown in Table 12, the most important reasons are the same, just in reverse order. The data percentages represent commonalities of responses among participants.

The least popular reason changed after Round 1 Survey. This could be attributed because, in attempts to further refine commonalities, the three least popular reasons to use virtual programs, as reported in Round 1 Survey, were deleted in Round 2 Survey. "Addressing growing population and limited space" (50.7\%), "Online and blended 
offerings are pedagogically more beneficial" (49.4\%), and "Certified teachers are not available at the school" (45.5\%) all met the $41 \%$ commonalities definition, and were deemed irrelevant. Therefore, they were deleted from Round 2 Survey.

Table 12

Virtual Program Enrollment Reasons

\begin{tabular}{|c|c|c|}
\hline \multirow{4}{*}{ Round 1 survey } & \multicolumn{2}{|c|}{ Popular enrollment reasons } \\
\hline & Most & Least \\
\hline & $\begin{array}{l}\text { "Meeting the needs of a specific } \\
\text { group of students" }(89.6 \%) \\
\text { "Permitting students who failed }\end{array}$ & $\begin{array}{l}\text { "Addressing growing } \\
\text { population and limited space" } \\
(50.7 \%)\end{array}$ \\
\hline & $\begin{array}{l}\text { a course to take it again" } \\
(89.4 \%)\end{array}$ & $\begin{array}{l}\text { "Online and blended offerings } \\
\text { are pedagogically more } \\
\text { beneficial" }(49.4 \%)\end{array}$ \\
\hline & & $\begin{array}{l}\text { "Certified teachers are not } \\
\text { available at the school" }(45.5 \%)\end{array}$ \\
\hline Round 2 survey & $\begin{array}{l}\text { "Permitting students who fail a } \\
\text { course to take it again" }(81.8 \%)\end{array}$ & $\begin{array}{l}\text { "Students prefer online } \\
\text { activities" }(54.6 \%)\end{array}$ \\
\hline & $\begin{array}{l}\text { "Meeting the needs of a specific } \\
\text { group of students" }(81.3 \%)\end{array}$ & $\begin{array}{l}\text { "Online and blended courses are } \\
\text { financially beneficial }(30.3 \%)\end{array}$ \\
\hline
\end{tabular}

Question 8 (Not present in Round 1 Survey and Question 8 in Interview) - This question is in regards to Reasons Your District Offers Virtual Programs. Please rank the following six reasons as \#1 or \#2 or \#3 or \#4 or \#5 or \#6 in order of their importance. \#1 is the highest and \#6 is the lowest. This question was not included in Round 1 Survey.

As shown in Table R9, of the 33 participants, the results are as follows:

- \#1 Reason - Permitting a student who failed a course to take it again

- \#2 Reason - Meeting the needs of specific groups of students

- \#3 Reason - Reducing scheduling conflicts for students

- \#4 Reason - Offering Advanced Placement or college-level courses

- \#5 Reason - Students prefer online course activities

- \#6 Reason - Online and blended offerings are financially beneficial 


\section{Pedagogical Feelings Towards Using Virtual Programs to Service the District's}

\section{Students}

Question 9 (Question 7 Round 1 Survey and Question 9 in Interview) - In the previous survey, Question 7 read, "I am interested in your opinions. Please let me know your thoughts (positive or negative) on any aspect of online and blended courses and their potential for your district." After review of all participants' comments, two common themes arose. The first theme surrounded the use of virtual programs as an alternative. Please review the first common theme "Alternative" shown below and check the box that is most appropriate. This question was not in Round 1 Survey in this format. This question was the result of the open-ended question (Question 7) in Round 1 Survey.

As shown in Table R10, of the 33 participants, the theme that was most strongly agreed (answered "Strongly Agree”) was “Alternative - Credit Reclamation” (54.5\%), followed by "Alternative - Diverse Needs" (27.3\%), then "Alternative - Methodology $(18.2 \%)$

Question 10 (Not present in Round 1 Survey and Question 10 in Interview) Pleases rank the following three items as \#1 or \#2 or \#3 in order of their importance. \#1 is the highest and \#3 is the lowest. This question was not in Round 1 Survey in this format. This question was the result of the open-ended question (Question 7) in Round 1 Survey.

As shown in Table R11, of the 33 participants, the results are as follows:

- \#1 Alternative Use - Credit Reclamation

- \#2 Alternative Use - Diverse Needs

- \#3 Alternative Use - Methodology 
Question 11 (Not present in Round 1 Survey and Question 11 in Interview) - In the previous survey, Question 7 read, "I am interested in your opinions. Please let me know your thoughts (positive or negative) on any aspect of online and blended courses and their potential for your district." After review of all participants' comments, two common themes arose. The second theme surrounded the apprehensions of virtual program use. Please review the common theme "Apprehensions" shown below and check the box that is most appropriate. This question was not in Round 1 Survey in this format. This question was the result of the open-ended question (Question 7) in Round 1 Survey.

As shown in Table R12, of the 33 participants, the themes most agreed (answered Strongly Agree or Agree) reported “Apprehensions - Motivation” (100\%) and “Apprehensions - Quality” (94\%). The theme least agreed (answered "Strongly Disagree" or "Disagree") reported "Apprehensions - Elimination" (39.4\%).

Question 12 - (Not present in Round 1 Survey and Question 12 in Interview). Please rank the following five items as \#1 or \#2 or \#3 or \#4 or \#5 in order of their importance. \#1 is the highest and \#5 is the lowest. This question was not in Round 1 Survey in this format. This question was the result of the open-ended question (Question 7) in Round 1 Survey.

As shown in Table R13, of the 33 participants, the results are as follows:

- \#1 Apprehensions - Motivation

- \#2 Apprehensions - Quality

- \#3 Apprehensions - Cost

- \#4 Apprehensions - Accountability 
- \#5 Apprehensions - Elimination

Question 14 (Question 9 in Round 1 Survey and Question 14 in Interview) Select the level (1-5) at which you disagree/agree with the following statements with regard to students in your district. Results from previous survey (top two): "Fully online and blended courses fulfill an important educational role" - 74\% "Students need more discipline to succeed in online courses"-72\% Disagree: "State or local governing bodies or regulations are encouraging my district to enroll students in fully online or blended courses" - 45\%; "Fully online courses and blended courses have allowed my district to build relationships with other organizations" - $45 \%$ *Some answer choices have been eliminated from the previous survey.

As shown in Table R14, of the 33 participants, the statements most agreed (answered a "5" or a "4") reported "Students need more discipline to succeed in an online course than in a traditional course" (86.7\%), and "Fully online and blended courses fulfill an important educational need" (73.3\%). The statements that were most disagreed (answered a "2" or a "1") reported, "Fully online and blended course experiences are comparable in educational value" (56.6\%). Three participants skipped this question.

When comparing the Round 2 Survey data to the Round 1 Survey data, as shown in Table 13, the most agreed reasons are the same, only in reverse order. The data percentages represent commonalities of responses among participants.

In attempts to further refine commonalities, two potential responses were eliminated from Round 1 Survey. "State or local governing bodies or regulations are encouraging my district to enroll students in online and blended courses" (45.5\%), and "Fully online and blended courses have allowed my district to build important 
relationships with other organizations" (45.4\%). Both data percentages met the $41 \%$ commonalities definition and were deemed irrelevant. Therefore, they were deleted from Round 2 Survey. Because the most "disagreed" responses were eliminated as choices for Round 2 Survey, the responses for each round do not match.

It is noteworthy that principals did not feel "State or local governing bodies or regulations are encouraging my district to enroll students in online and blended courses" because the literature points to the lack of leadership in the virtual program arena in regards to policies and regulations.

Table 13

Pedagogical Feelings of Agreement/Disagreement

\begin{tabular}{|c|c|c|}
\hline \multirow[b]{3}{*}{ Round 1 survey } & \multicolumn{2}{|c|}{ Virtual program aspects } \\
\hline & Agreed & Disagreed \\
\hline & $\begin{array}{l}\text { "Fully online and blended courses fulfill } \\
\text { an important educational need" ( } 74.1 \%) \\
\text { "Students need more discipline to } \\
\text { succeed in an online course than in a } \\
\text { traditional course" }(72.7 \%) .\end{array}$ & $\begin{array}{l}\text { "State or local governing } \\
\text { bodies or regulations are } \\
\text { encouraging my district } \\
\text { to enroll students in } \\
\text { online and blended } \\
\text { courses" }(45.5 \%) \\
\text { "Fully online and } \\
\text { blended courses have } \\
\text { allowed my district to } \\
\text { build important } \\
\text { relationships with other } \\
\text { organizations" (45.4\%) }\end{array}$ \\
\hline Round 2 survey & $\begin{array}{l}\text { "Students need more discipline to } \\
\text { succeed in an online course than in a } \\
\text { traditional course" }(86.7 \%) \\
\text { "Fully online and blended courses fulfill } \\
\text { an important educational need" }(73.3 \%)\end{array}$ & $\begin{array}{l}\text { "Fully online and } \\
\text { blended course } \\
\text { experiences are } \\
\text { comparable in } \\
\text { educational value" } \\
(56.6 \%)\end{array}$ \\
\hline
\end{tabular}




\section{The Types of Students Enrolled in Virtual Programs}

Question 15 (Question 10 in Round 1 Survey and Question 15 in Interview) - The nature of online or blended courses taken by students in my district (check all that apply): Results from previous survey (top two): Fully online - "Remedial Courses" - 76\%, "Required Courses" - 70\%; "Blended courses - Elective Courses" - 64\%, "Required Courses" $-61 \%$.

As shown in Table R15, of the 33 participants, the nature of online and blended course most used were "Fully online - Remedial Courses" (73.3\%) and "Fully online Elective courses" (53.3\%), "Blended courses - Elective" (59.1\%) and "Blended Courses - Required" (54.5\%). The nature of online and blended courses least used were "Fully Online - Other" (10\%) and "Blended-AP" $(18.2 \%)$ and "Blended-Other" (18.2\%). Three participants skipped this question.

When comparing the Round 2 Survey data to the Round 1 Survey data, as shown in Table 14, the nature of online and blended courses most used was the same, with the exception of "Fully online - Required Courses" changed to "Fully Online- Elective Courses" in Round 2 Survey. The data percentages represent commonalities of responses among the population of both Round 1 Survey and Round 2 Survey. When comparing this question to Round 1 Survey, the nature of online and blended courses least used were also the same.

Table 14

Nature of Enrollment Type

\begin{tabular}{lll}
\hline & \multicolumn{2}{c}{ Popularity of virtual program type } \\
\cline { 2 - 3 } Round 1 survey & \multicolumn{1}{c}{ Most } & \multicolumn{1}{c}{ Least } \\
\cline { 2 - 3 } & "Fully online - Remedial & "Fully online - Other $(11.3 \%)$ \\
& courses" $(75.5 \%)$ & "Blended courses - Courses for
\end{tabular}




\begin{tabular}{|c|c|c|}
\hline & $\begin{array}{l}\text { "Fully online - Required } \\
\text { courses" }(69.8 \%) . \\
\text { "Blended Courses - Elective" } \\
(64.3 \%) \\
\text { "Blended Courses - Required" } \\
(60.7 \%)\end{array}$ & $\begin{array}{l}\text { college credit other than AP" } \\
(14.3 \%)\end{array}$ \\
\hline Round 2 survey & $\begin{array}{l}\text { "Fully online }- \text { Remedial } \\
\text { Courses" }(73.3 \%) \\
\text { "Fully online - Elective courses" } \\
(53.3 \%) \\
\text { "Blended courses - Elective" } \\
(59.1 \%) \\
\text { "Blended Courses - Required" } \\
(54.5 \%)\end{array}$ & $\begin{array}{l}\text { "Fully Online - Other" }(10 \%) \\
\text { "Blended-Courses for college } \\
\text { credit other than AP" }(18.2 \%) \\
\text { "Blended-Other" }(18.2 \%) .\end{array}$ \\
\hline
\end{tabular}

\section{The Growth of Virtual Programs}

Question 16 (Question 11 in Round 1 Survey and Question 16 in Interview) What is your best estimate of the number of student enrollments (a student enrolled in more than one course should be counted only once) between July 1, 2008 and June 30, 2009? “Grades 9-12 Fully Online” (98\%) and "Grades 9-12 Blended courses” (98\%). As shown in Table R16, of the 33 participants, The highest enrollments reported were "Grades 9-12 Fully Online" (100\%), followed by "Grades 9-12 Blended Courses" (97\%). The other four areas tied in terms of enrollments: "K-5 Fully Online" (60\%), “Grades 6-8 Fully Online” (60\%), "K-5 Blended" (60\%), and "Grades 6-8 Blended" (60\%). Three participants skipped this question.

When comparing the Round 2 Survey data to the Round 1 Survey data, as shown in Table 15, both the highest and lowest enrollments were the same. The data percentages represent commonalities of responses among participants. 
Table 15

Growth of Virtual Programs

\begin{tabular}{|c|c|c|}
\hline \multirow{4}{*}{$\begin{array}{l}\text { Round } 1 \\
\text { survey }\end{array}$} & \multicolumn{2}{|c|}{ Enrollment areas } \\
\hline & Highest & Lowest \\
\hline & “Grades 9-12 Fully Online” (98\%) & "Grades K-5 Fully Online" (58\%) \\
\hline & $\begin{array}{l}\text { "Grades 9-12 Blended courses" } \\
(98 \%)\end{array}$ & $\begin{array}{l}\text { "Grades K-5 Blended Courses" } \\
(58 \%)\end{array}$ \\
\hline Round 2 & "Grades 9-12 Fully Online" (100\%) & “K-5 Fully Online" (60\%) \\
\hline survey & "Grades 9-12 Blended Courses" & "Grades 6-8 Fully Online" (60\%) \\
\hline & $(97 \%)$ & "K-5 Blended Courses" (60\%) \\
\hline & & "Grades 6-8 Blended" (60\%) \\
\hline
\end{tabular}

Question 17 (Question 12 in Round 1 Survey and Question 17 in Interview)-Over the next two years, my district expects fully online course enrollments to: Results from previous survey: Stay about the same $-76 \%$. Three participants skipped this question.

As shown in Table R17, of the 33 participants, 19 (63.3\%) answered "Stay about the same." Twelve (40\%) chose to fill in a growth percentage, as shown in Table 16. Three participants skipped this question.

Table 16

Speculated Growth Percentage of Fully Online Courses -Answers Given

\begin{tabular}{ccc}
\hline $\begin{array}{c}\text { Growth } \\
\text { reported as \% }\end{array}$ & Frequency & Percentage \\
\hline 2 & 3 & $25 \%$ \\
5 & 3 & $25 \%$ \\
10 & 1 & $8.3 \%$ \\
15 & 2 & $16.8 \%$ \\
23 & 1 & $8.3 \%$ \\
30 & 1 & $8.3 \%$ \\
200 & 1 & $8.3 \%$ \\
Total & 12 & $100.0 \%$ \\
\hline
\end{tabular}

When comparing the Round 2 Survey data to the Round 1 Survey data, as shown in Table 17, the largest reported area in both surveys was "Stay about the same." This data represents commonalities of responses across each round. 


\section{Table 17}

Growth of Fully Online Courses

\begin{tabular}{ll} 
& Most common response \\
\cline { 2 - 2 } Round 1 survey & "Stay about the same" (76.4\%) \\
Round 2 survey & "Stay about the same" (63.3\%) \\
\hline
\end{tabular}

Question 18 (not present in Round 1 Survey or in Interview) - What factors need to be in place to allow growth of fully online courses within your district? Each response is marked by the principal that answered the question. (i.e., "P33" was answered by Principal \#33). No editing was done to the responses, and they are listed in no particular order.

Using Patton's (1990) Constant Comparative Method, these responses were summarized into themes and fed back to the participants in the interview round. These themes include:

1. Costs/Funding

2. Policy Issues

3. Technology

4. Teacher Training

5. Accountability/Motivation

6. Miscellaneous - responses that did not fit into the main themes

The following comments fell under the "Costs/Funding" theme:

$$
\begin{aligned}
& \text { P3 - "Money" } \\
& \text { P6 - "Costs" } \\
& \text { P7 - "Our clients can not afford computers and Internet service." } \\
& \text { P8 - “Money issues need to be satisfactory" }
\end{aligned}
$$


P10 - "School funding must be worked out in order to pay for the teacherstraining and availability. Teacher buy in to use the software that is available."

P13 - "No loss of funding and accountability of student performance and "attendance."”

P15 - "Money"

P17 - "More Money”

P25 - "Finances"

P27 - “Financing”

The following comments fell under the "Policy Issues" theme:

P2 - "increase online school for the district"

P11- "In house service"

P18 - "The opportunities are available a more flexible schedule could encourage greater participation."

P29 - "Student requirements set forth by the district"

P30 - "Potential Home-Schooled students making the transition to a fully online program offered through the local school district."

P33 - "new credit flexibility laws"

The following comments fell under the "Technology" theme:

P4 - "Transparent technology without delays and down time"

P7 - "Our clients can not afford computers and Internet service."

P14 - "more computers"

P15 - “Technology”

P20 - "Computer access by students at home"

P33 - "tech support"

The following comments fell under the "Teacher Training" theme: 
P6 - “Teacher jobs”

P9 - "teacher training”

P10 - "School funding must be worked out in order to pay for the teacherstraining and availability. Teacher buy in to use the software that is available."

P12 - "They currently exist, faculty acceptance."

P15 - “Training”

P32 - "Shortage of teachers in a particular area"

The following comments fell under the "Accountability/Motivation" theme:

P6 - "Socialization"

P15 - "Motivation of students"

P21 - "The motivation of the students to complete their work in time and the accountability that the data in the online course is valid to what they would be learning face to face."

P23 - "students' ability to be successful. Access to Internet outside of school"

P26 - "Encouragement"

P28 - “Student determination”

P33 - "student interest"

The following comments fell under the "Miscellaneous" theme:

P16 - None”

P19 - "I do not see a growth in online classes in our district"

P24 - "fully online already in place"

P33- "time"

Question 19 (Question 13 in Round 1 Survey and Question 18 in Interview) -

Over the next two years, my district expects blended enrollments to: Results from

previous survey: Stay about the same $-78 \%$. 
As shown in Table R18, of the 33 participants, 22 (73.3\%) reported "Stay about the same" and 1 (3\%) reported "Decrease." As shown in Table 18, seven (23.3\%) chose to fill in a growth percentage. Three participants skipped this question.

Table 18

Speculated Growth of Blended Courses - Answered Given

\begin{tabular}{ccc}
\hline $\begin{array}{c}\text { Growth } \\
\text { reported as \% }\end{array}$ & Frequency & Percentage \\
\hline 2 & 1 & $14 \%$ \\
10 & 4 & $58 \%$ \\
23 & 1 & $14 \%$ \\
25 & 1 & $14 \%$ \\
Total & 7 & $100.0 \%$ \\
\hline
\end{tabular}

When comparing the Round 2 Survey data to the Round 1 Survey data, as shown in Table 19, the largest reported area in both surveys was "Stay about the same" The data percentages represent commonalities of responses among participants.

Table 19

Growth of Blended Courses

\begin{tabular}{ll}
\hline & Most common response \\
\cline { 2 - 2 } Round 1 survey & "Stay about the same" $(78.2 \%)$ \\
Round 2 survey & "Stay about the same" $(73.3 \%)$ \\
\hline
\end{tabular}

Question 20 (Not present in Round 1 Survey or in Interview) - What factors need to be in place to allow growth of blended courses within your district? Each response is marked by the principal that answered the question. (i.e., "P33" was answered by Principal \#33). No editing was done to the responses, and they are listed in no particular order.

Using Patton's (1990) Constant Comparative Method, these responses were summarized into themes and fed back to the participants of the Interview round. These themes include: 
1. Costs/Funding

2. Policy Issues

3. Technology

4. Teacher Training

5. Accountability/Motivation

6. Miscellaneous - responses that did not fit into the main themes

The following comments fell under the "Costs/Funding" theme:

P8- money issues"

P10 - "School funding must be worked out in order to pay for the teacherstraining and availability. Teacher buy in to use the software that is available."

P12 -"no loss of funding and accountability for student performance"

P17 - "MORE MONEY”

P25 - "money issues”

P27 - "Financing”

The following comments fell under the "Policy Issues" theme:

P1 - "credit flexibility procedures and courses"

P2 - "add AP course offerings"

P7 - "We are blended because our teachers are enrolled in the program and allows our students to come in and visit them."

P11 - "In house service"

P18 - "The opportunies are available a more flexible schedule could encourage greater participation"

The following comments fell under the "Technology" theme:

P3 - "The students do not have the needed access to the technology"

P13 - "computer access by students at home” 


$$
\begin{aligned}
& \text { P14 - “more computers" } \\
& \text { P23 - “access to techonolgy" } \\
& \text { P24 - "Improvement in technology infrastructure within the whole building” }
\end{aligned}
$$

The following comments fell under the "Teacher Training" theme:

$$
\begin{aligned}
& \text { P4 - "teacher in-service" } \\
& \text { P9 - "teacher training" } \\
& \text { P10 - "School funding must be worked out in order to pay for the teachers- } \\
& \text { training and availability. Teacher buy in to use the software that is available." } \\
& \text { P12 - "faculty acceptance" } \\
& \text { P16 - "Training" } \\
& \text { P21 - "Same as Fully online courses except the staff would have to be on the } \\
& \text { same page." } \\
& \text { P32 - "Shortage of teachers in a particular area" } \\
& \text { P33 - "Teacher Training" }
\end{aligned}
$$

The following comments fell under the "Accountability/Motivation" theme:

P12 - "no loss of funding and accountability for student performance"

P15 - "Success of participants toward graduation"

P30 - "Finding an acceptible program.”

P33 - “interest”

The following comments fell under the "Miscellaneous" theme:

$$
\begin{aligned}
& \text { P6 - "not offered" } \\
& \text { P19 - "we dot not offer blended courses" } \\
& \text { P26 - " Nothing" } \\
& \text { P28 - "not looking at blended at this point" }
\end{aligned}
$$


P29 - "We will not be considering blended courses in the near future."

\section{Providers of Virtual Programs}

Question 21 (Question 14 in Round 1 Survey and Question 20 in Interview) - The provider(s) for fully online and blended courses for my district are (check all that apply): Results from the previous survey: Fully online - Educational Service Agencies $-60 \%$, Independent Vendors - 42\%. Blended - Educational Service Agencies - 18\%, Independent Vendors - 13\%.

As shown in Table R19, of the 30 participants, the following was reported as the most used provider of fully online and blended courses: Fully online - Educational Service Agencies- 63\%, Postsecondary institutions - 37\%, Blended - Educational Service Agencies $-37 \%$, Postsecondary Institutions $-23 \%$. Of the 30 participants, the following was reported as the least used provider of fully online and blended courses: Fully online Districts or schools in other states - 7\%, Blended-Cyber - 3\%, Other schools in your district $-3 \%$, Another school district $-3 \%$, Districts/schools in other states $-3 \%$, Three participants skipped this question.

When comparing the Round 2 Survey data to the Round 1 Survey data, as shown in Table 20, "Educational Service Agencies" was reported as the most used Provider of Fully Online Courses in both survey rounds. The data percentages represent commonalities of responses across both rounds. "Educational Service Agencies" was reported as the most used Provider of Blended Courses.

The least used Provider reported changed across rounds. This could be due to the individual use of virtual programs by Appalachian Ohio High School Principals in their respective school districts. 
Table 20

Providers of Virtual Programs

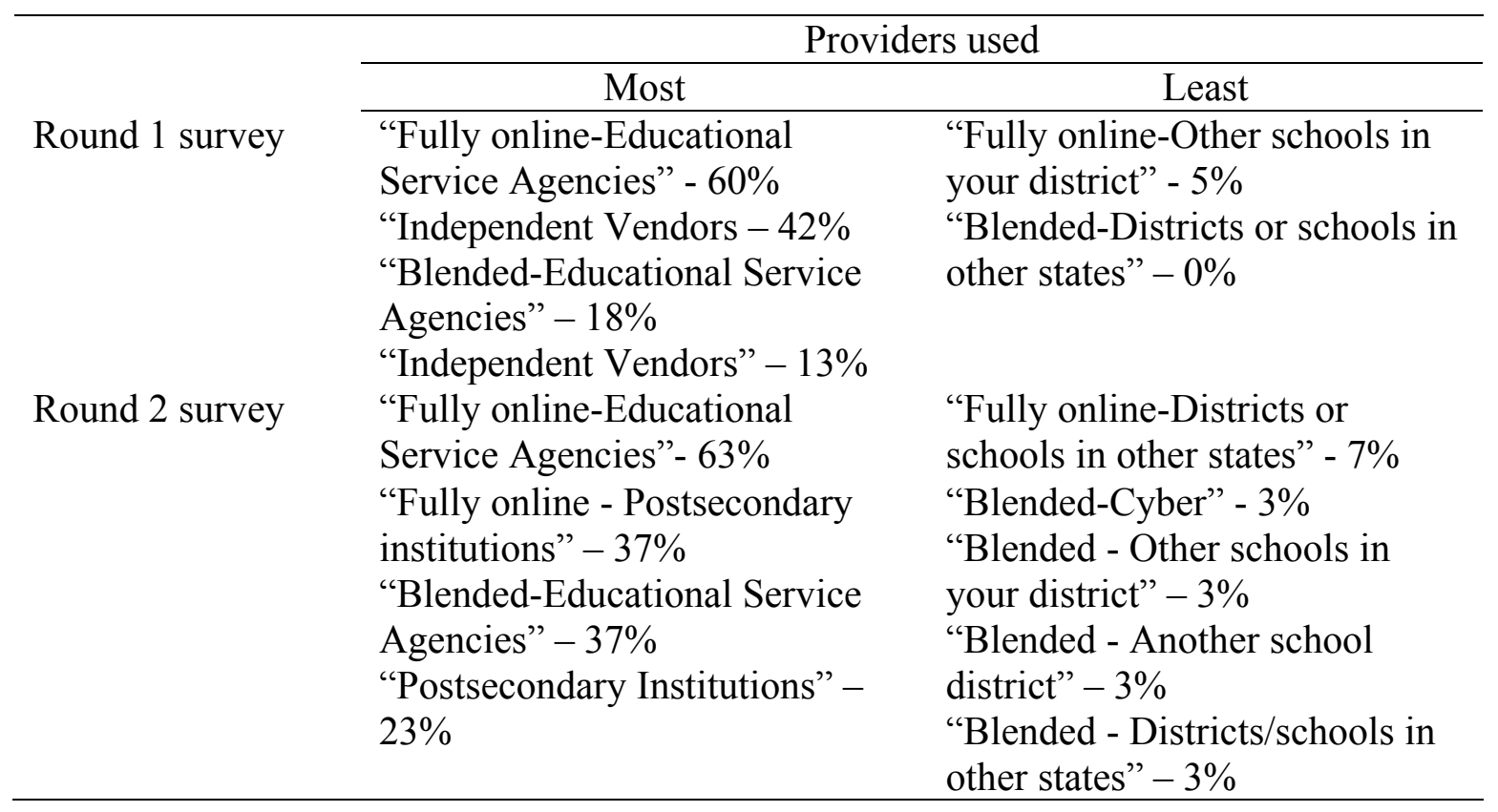




\section{Interview}

At the conclusion of Round 2 Survey, seven principals were chosen to participate in the follow up interview. These seven principals matched my predetermined criteria including:

- is a principal and has held that role for the past three years,

- is currently using virtual programs, and

- has enrolled ten or more students in at least one online course.

Originally, I planned to only interview five principals, but because the entire population matching my predetermined criteria was seven principals, I decided to expand the field and invite all seven. Ironically, only five $(\mathrm{N}=5)$ principals agreed to participate in the interview resulting in a $71 \%$ participation rate. The five principals were from five different Appalachian Ohio High Schools and five different counties.

Interview questions were constructed based on the conclusions from the Round 2 Survey. In attempts to not inadvertently remove any main themes found from Round 2 Survey, interview questions were kept exactly as presented in Round 2 Survey, with one exception. Round 2 Survey Question 18 "What factors need to be in place to allow growth of fully online courses within your district?” and Round 2 Survey Question 20 "What factors need to be in place to allow growth of blended online courses within your district?" were combined to form Interview Question 19 "What factors need to be in place to allow growth of fully online and blended courses within your district?"

The interview began with demographic questions and was then followed by seven sections: 
- Section 1 does the district use virtual programs;

- Section 2 barriers of enrolling students in virtual programs;

- Section 3 reasons school districts enroll students in virtual programs;

- Section 4 pedagogical feelings towards using virtual programs to service the district's students;

- Section 5 the types of students who are enrolled in virtual programs;

- Section 6 expected growth of the virtual programs in their districts; and

- Section 7 types of virtual programs and providers that are being used in the district.

\section{Demographics}

The following questions represent the demographic section of the interview.

Question 1 (Question 1 in Round 1 Survey and Question 1 in Round 2 Survey) - Please answer the following demographic questions: name, school, address, county, email address, and phone number.

In order to keep the participants' demographic information confidential, Figure S1 depicts the counties representing participants. Of Ohio's 32 Appalachian counties, representatives from 5 counties participated. Table 21 compares the interview data to the data from the previous survey rounds.

Table 21

Participating Counties

Round 1 survey

Round 2 survey

Interview
Number of participating counties 28

19 
Question 2 (Question 2 in Round 1 Survey and Question 2 in Round 2 Survey) What is your position in your school building? Results from previous survey:

"Principals" $-88 \%$ "Other" $-12 \%$

As shown in Table S2, of the 5 participants, $5(100 \%)$ reported "Principals/Director." When comparing the interview data to the data from the previous survey rounds, as shown in Table 22, Round 1 Survey reported a rate of $92 \%$ of the participants were principals. Round 2 Survey reported that $88 \%$ of the population was principals. The interview reported that $100 \%$ of the population was principals, which was one of my predetermined criteria to be eligible for the interview round. The data percentages represent commonalities of responses among participants.

Table 22

Position of Participants

\begin{tabular}{lc}
\hline & $\%$ of principals \\
\cline { 2 - 2 } Round 1 survey & $92 \%$ \\
Round 2 survey & $88 \%$ \\
Interview & $100 \%$ \\
\hline
\end{tabular}

Question 3 (Question 3 in Round 1 Survey and Question 3 in Round 2 Survey) If you chose "Principal/Director" for Question 2, how long have you held that position? Results from previous survey: "Over 3 years" $-58 \%$ "2 Years" $-12 \%$.

As shown in Table S3, of the 5 participants, 4 (80\%) reported "More than three years", and $1(20 \%)$ reported "Three Years." When comparing the interview data to the data from the previous survey rounds, as shown in Table 23, the most common response to length of position was "More than three years" across all rounds. The data percentages represent commonalities of responses among participants. 
Table 23

Length of Position

\begin{tabular}{lc}
\hline & Length of position \\
\cline { 2 - 2 } Round 1 survey & "More than three years" $-(61 \%)$ \\
Round 2 survey & "More than three years" $-(58 \%)$ \\
Interview & "More than three years" $-(80 \%)$ \\
\hline
\end{tabular}

\section{District Use of Virtual Programs}

The following questions represent the district use section of the Interview.

Question 4 (Question 4 in Round 1 Survey and Question 4 in Round 2 Survey) - Did students in your district take any fully online or blended courses between July 1, 2008 and June 30, 2009? Results from previous survey: "At least one fully online course" 91\% "At least one student took a blended course" $-30 \%$.

As shown in Table S4, of the 5 participants, the largest population was students who took "At least one fully online course" (100\%). The smallest populations were the following: those districts that "Do not have fully online students, but plans to offer them in the next three years" $(0 \%)$, "Do not have blended courses, but plan to offer them in the next three years" $(0 \%)$, and "Do not have students in fully online courses, and do not have plans to offer them within the next three years" $(0 \%)$.

When comparing the interview data to the data from the previous survey rounds, as shown in Table 24, the largest type of student enrollment was the same across rounds. The data percentages represent commonalities of responses among participants.

The smallest types of student enrollment changed between rounds. This could be due to the individual use of virtual programs by Appalachian Ohio High Schools Principals in their respective school districts. 
Table 24

Virtual Program Enrollment

\begin{tabular}{|c|c|c|}
\hline \multirow[b]{3}{*}{ Round 1 survey } & \multicolumn{2}{|c|}{ Virtual program enrollment type } \\
\hline & Largest & Smallest \\
\hline & $\begin{array}{l}\text { "At least one fully online } \\
\text { course" }(77 \%)\end{array}$ & $\begin{array}{l}\text { "Did not have any students } \\
\text { in a fully online course, but } \\
\text { have plans to offer them } \\
\text { within three years" }(6.8 \%)\end{array}$ \\
\hline Round 2 survey & $\begin{array}{l}\text { "At least one fully online } \\
\text { course" }(91 \%)\end{array}$ & $\begin{array}{l}\text { "Do not have students in } \\
\text { fully online courses, and do } \\
\text { not have plans to offer them } \\
\text { within the next three years" } \\
(3 \%)\end{array}$ \\
\hline Interview & $\begin{array}{l}\text { "At least one fully online } \\
\text { course" }(100 \%)\end{array}$ & $\begin{array}{l}\text { "Do not have fully online } \\
\text { students, but plans to offer } \\
\text { them in the next three } \\
\text { years" }(0 \%) \\
\text { "Do not have blended } \\
\text { courses, but plan to offer } \\
\text { them in the next three } \\
\text { years" }(0 \%) \\
\text { "Do not have students in } \\
\text { fully online courses, and do } \\
\text { not have plans to offer them } \\
\text { within the next three years" } \\
(0 \%)\end{array}$ \\
\hline
\end{tabular}

Question 13 (Question 8 in Round 1 Survey and Question 13 in Round 2 Survey) - In what school year did any student in your district first take a fully online or blended course? Results from previous survey: "Before 2005" - 58\% “2008-2009" - 0\%.

As shown in Table S5, of the 5 participants, $4(80 \%)$ answered they had students enrolled in fully online or blended courses "Before 2005"; 0 (0\%) during the "20052006" school year; 1 (20\%) during the "2006-2007" school year; $0(0 \%)$ during the “2007-2008” school year; 0 (0\%) during the "2008-2009" school year; and $0(0 \%)$ during the 2009-2010 school year. 
When comparing the interview data to the data from the previous survey rounds, as shown in Table 25, the most common school year reported was the same across rounds. This represents the longevity of virtual program use among Appalachian Ohio High Schools. The data percentages represent commonalities of responses among participants.

The least common school year reported changed between rounds. This could be due to the individual use of virtual programs by Appalachian Ohio High Schools Principals in their respective school districts.

Table 25

School Year of First Enrollment

\begin{tabular}{|c|c|c|}
\hline & \multicolumn{2}{|c|}{ Population } \\
\hline & Largest & Smallest \\
\hline Round 1 survey & "Before 2005" (51\%) & “2007-2008" (5\%) \\
\hline Round 2 survey & "Before 2005" (58\%) & “2008-2009”(0\%) \\
\hline Interview & "Before 2005" (80\%) & $\begin{array}{l}\text { “2005-2006" }(0 \%) \\
\text { "2007-2008"(0\%) } \\
\text { "2008-2009" (0\%) }\end{array}$ \\
\hline
\end{tabular}

\section{Barriers of Enrolling Students in Virtual Programs}

The following questions represent the barriers section of the interview. Question 5 (Question 5 in Round 1 Survey and Question 5 in Round 2 Survey) - How much of a barrier are the following areas to your district in offering fully online or blended learning courses? Results from previous survey: "Concerns about course quality" - 72\% “Concerns about costs" - 49\% Least Important: "The need for teacher training" - 18\%. 
As shown in Table S6, of the 5 participants, the most important barriers (answered a "5" or a " 4 ") reported were "Concerns about course quality" (100\%) and "Course development and purchasing costs" (80\%). The least important barrier was "Need for teacher training" (40\%).

When comparing the interview data to the data from the previous survey rounds, as shown in Table 26, the most important reported Barrier remained the same. The data percentages represent commonalities of responses among participants.

The lowest reported Barrier, however, changed after Round 1 Survey. This could be attributed because, in attempts to further refine commonalities, the two least important barriers, as reported in Round 1 Survey, were deleted in Round 2 Survey. "Restrictive federal, state, or local laws and policies (62.4\%) and "Limited technology infrastructure to promote distance education" (44.2\%) both met the $41 \%$ commonalities definition, and were deemed irrelevant. Therefore, they were deleted from Round 2 Survey. Once these choices were eliminated, both of the following rounds reported the same least important Barrier - "The need for teacher training."

Table 26

Virtual Program Barriers

\begin{tabular}{|c|c|c|}
\hline & \multicolumn{2}{|c|}{ Virtual program barriers } \\
\hline & Highest & Lowest \\
\hline $\begin{array}{l}\text { Round } 1 \\
\text { survey }\end{array}$ & $\begin{array}{l}\text { "Concerns about course quality" } \\
(63.1 \%)\end{array}$ & $\begin{array}{l}\text { "Restrictive federal, state, or local laws } \\
\text { and policies" }(62.4 \%)\end{array}$ \\
\hline $\begin{array}{l}\text { Round } 2 \\
\text { survey }\end{array}$ & $\begin{array}{l}\text { "Concerns about course quality" } \\
(71.9 \%) \\
\text { "Course development and } \\
\text { purchasing costs" }(48.5 \%)\end{array}$ & "The need for teacher training" (18.8\%) \\
\hline Interview & $\begin{array}{l}\text { "Concerns about course quality" } \\
(100 \%) \\
\text { "Course development and } \\
\text { purchasing costs" }(80 \%)\end{array}$ & "The need for teacher training" $(40 \%)$ \\
\hline
\end{tabular}


Question 6 (Not present in Round 1 Survey and Question 6 in Round 2 Survey) This question is in regards to Barriers that impede your district's implementation of virtual programs. Please rank the following four items as Barrier \#1 or \#2 or \#3 or \#4 in order of their importance. \#1 is the highest and \#4 is the lowest. Results from previous survey: \#1 Barrier - "Course development and purchasing costs" \#4 Barrier - "The need for teacher training." It is notable that "Concerns about receiving funding based on student attendance” had just as many \#1 Barrier choices and \#4 Barrier choices.

As shown in Table S7, of the 5 participants, the results are as follows:

- \#1 Barrier - Course development and/or purchasing costs

- \#2 Barrier Concerns about receiving funding based on student attendance

- \#3 Barrier - Concerns about quality

- \#4 Barrier - The need for teacher training

When comparing the interview data to the data from the previous survey rounds, as shown in Table 27, the \#1 Barrier and \#4 Barrier are the same.

Table 27

Virtual Program Barriers Ranked

\begin{tabular}{lll}
\hline & \multicolumn{2}{c}{ Barrier } \\
\cline { 2 - 3 } Round 1 survey & \multicolumn{1}{c}{$\# 1$} & \multicolumn{1}{c}{$\# 4$} \\
\cline { 2 - 3 } Round 2 survey & Question not present & Question not present \\
& "Course development and/or & purchasing costs" \\
"The need for teacher \\
Interview & $\begin{array}{l}\text { "Course development and/or } \\
\text { purchasing costs" }\end{array}$ & $\begin{array}{l}\text { "The need for teacher } \\
\text { training" }\end{array}$ \\
\hline
\end{tabular}

\section{Reasons School Districts Enroll Students in Virtual Programs}

The following questions represent the reasons used section of the interview.

Question 7 (Question 6 in Round 1 Survey and Question 7 in Round 2 Survey) - How 
important do you believe the following reasons are for a school district to offer online or blended learning courses? Results from the previous survey (top two): Most Important: "Meeting the needs of a certain group of students" - $81 \%$ "Permitting students who failed a course to take it again" $-82 \%$.

As shown in Table S8, of the 5 participants, the most important reasons (answered a "5" or a "4") reported "Meeting the needs of a specific group of students" (100\%), "Permitting students who failed a course to take it again" (80\%), and "Online and blended courses are financially beneficial" (80\%). The least important reason (answered a "2" or a "1") reported "Students prefer online course activities" (40\%).

When comparing the interview data to the data from the previous survey rounds, as shown in Table 28, the most popular reason to use virtual programs are the same. The data percentages represent commonalities of responses among participants.

The least popular reason to use virtual programs changed after Round 1 Survey. This could be attributed because, in attempts to further refine commonalities, the three least popular reasons to use virtual programs, as reported in Round 1 Survey, were deleted in Round 2 Survey. "Addressing growing population and limited space" (50.7\%), “Online and blended offerings are pedagogically more beneficial” (49.4\%), and "Certified teachers are not available at the school" (45.5\%) all met the $41 \%$ commonalities definition, and were deemed irrelevant. Therefore, they were deleted from Round 2 Survey. Once these choices were eliminated, both of the following rounds reported the same least popular reason - "Students prefer online course activities".

It is noteworthy that "Online and blended courses are financially beneficial" was reported as a least important reason to enroll students in virtual programs during the 
Round 2 Survey. However, during the interview it was reported as one of the most important reasons. This could be due to the interview population having more leadership experience, as one of the requirements for the interview was having a principal role for three or more years. These veteran principals may understand the intricacies of Ohio funding more than the less experienced Round 2 Survey population.

Table 28

Virtual Program Enrollment Reasons

\begin{tabular}{|c|c|c|}
\hline \multirow[b]{3}{*}{ Round 1 survey } & \multicolumn{2}{|c|}{ Popular enrollment reasons } \\
\hline & Most & Least \\
\hline & $\begin{array}{l}\text { "Meeting the needs of a specific } \\
\text { group of students" }(89.6 \%) \\
\text { "Permitting students who failed } \\
\text { a course to take it again" } \\
(89.4 \%)\end{array}$ & $\begin{array}{l}\text { "Addressing growing } \\
\text { population and limited space" } \\
(50.7 \%) \\
\text { "Online and blended offerings } \\
\text { are pedagogically more } \\
\text { beneficial" (49.4\%) } \\
\text { "Certified teachers are not } \\
\text { available at the school" }(45.5 \%)\end{array}$ \\
\hline Round 2 survey & $\begin{array}{l}\text { "Permitting students who fail a } \\
\text { course to take it again" }(81.8 \%) \text {, } \\
\text { and "Meeting the needs of a } \\
\text { specific group of students" } \\
(81.3 \%)\end{array}$ & $\begin{array}{l}\text { "Students prefer online } \\
\text { activities" }(54.6 \%) \\
\text { "Online and blended courses are } \\
\text { financially beneficial }(30.3 \%)\end{array}$ \\
\hline Interview & $\begin{array}{l}\text { "Meeting the needs of a specific } \\
\text { group of students" ( } 100 \%) \\
\text { "Permitting students who failed } \\
\text { a course to take it again" }(80 \%) \\
\text { "Online and blended courses are } \\
\text { financially beneficial }(80 \%)\end{array}$ & $\begin{array}{l}\text { "Students prefer online course } \\
\text { activities" }(40 \%)\end{array}$ \\
\hline
\end{tabular}

Question 8 (Not present in Round 1 Survey and Question 8 in Round 2 Survey) This question is in regards to Reasons Your District Offers Virtual Programs. Please rank the following six reasons as $\# 1$ or $\# 2$ or $\# 3$ or $\# 4$ or $\# 5$ or $\# 6$ in order of their importance. \#1 is the highest and \#6 is the lowest. This question was not included in 
Round 1 Survey. Results from previous survey: \#1 - "Permitting a student who failed a course to take it again" \#6 - "Online and blended offerings are financially beneficial".

As shown in Table S9, of the 5 participants, the results are as follows:

- \#1 Reason - "Meeting the needs of a specific group of students"

- \#2 Reason - "Permitting a student who failed a course to take it again"

- \#3 Reason - "Reducing scheduling conflicts for students"

- \#4 Reason - "Offering Advanced Placement or college-level courses"

- \#5 Reason - "Students prefer online course activities"

- \#6 Reason - "Online and blended offerings are financially beneficial”

When comparing the interview data to the data from the previous survey rounds, as shown in Table 29, the most popular reasons to use virtual programs are the same. The data percentages represent commonalities of responses among participants.

The least popular reason to use virtual programs is the same. The data percentages represent commonalities of responses among participants.

Table 29

Virtual Program Enrollment Reasons Ranked

\begin{tabular}{lll}
\hline & \multicolumn{2}{c}{ Popularity of enrollment reasons } \\
\cline { 2 - 3 } Round 1 survey & \multicolumn{1}{c}{ Most } & \multicolumn{1}{c}{ Least } \\
\cline { 2 - 3 } Round 2 survey & $\begin{array}{l}\text { Not present in Round 1 Survey } \\
\text { "Permitting a student who failed } \\
\text { a course to take it again" (\#1) }\end{array}$ & $\begin{array}{l}\text { Not Present in Round 1 Survey } \\
\text { "Students prefer online course } \\
\text { activities" (\#5) }\end{array}$ \\
& $\begin{array}{l}\text { "Meeting the needs of a specific } \\
\text { group of students" (\#2) }\end{array}$ & $\begin{array}{l}\text { "Online and blended offerings } \\
\text { are financially beneficial" (\#6) }\end{array}$ \\
& "Meeting the needs of a specific & "Students prefer online course \\
Interview & "Proup of students" (\#1) & activities" (\#5) \\
& "Permitting a student who failed & "Online and blended offerings \\
& a course to take it again" (\#2) & are financially beneficial" (\#6) \\
\hline
\end{tabular}




\section{Pedagogical Feelings Towards Using Virtual Programs to Service the District's Students}

The following questions represent the pedagogical feelings section of the Interview. Question 9 - (Question 7 in Round 1 Survey and Question 9 in Round 2 Survey) In the previous survey, Question 7 read, "I am interested in your opinions. Please let me know your thoughts (positive or negative) on any aspect of online and blended courses and their potential for your district." After review of all participants' comments, two common themes arose. The first theme surrounded the use of virtual programs as an alternative. Please review the first common theme "Alternative" shown below and check the box that is most appropriate. This question was not in Round 1 Survey in this format. This question was the result of the open-ended question (Question 7) in Round 1 Survey. Results from previous survey: Most strong agree “Alternative/Credit Reclamation" - 54.5\%.

As shown in Table S10, of the 5 participants, the theme most strongly agreed (answered "Strongly Agree) reported "Alternative - Diverse Needs" (60\%). "Alternative-Methodology" (60\%) and Alternative - Credit Reclamation" (60\%) tied for second and third most popular choices. It is noteworthy that no participant chose less than "agree" for their response.

When comparing the interview data to the data from the previous survey rounds, as shown in Table 30, no response matched exactly from round to round. This could be due to the individual use of virtual programs by Appalachian Ohio High School Principals in their respective school districts. 
While a true commonality does not exist, the responses are very close in importance because no participant listed any of the items as less than "agree."

Table 30

Pedagogical Feelings - Alternative Uses of Virtual Programs

\begin{tabular}{lll}
\hline & \multicolumn{2}{c}{ Alternative uses of virtual programs } \\
\cline { 2 - 3 } Round 1 survey & \multicolumn{1}{c}{ Most popular } & \multicolumn{1}{c}{ Least popular } \\
\cline { 2 - 3 } Round 2 survey & Not present in Round 1 Survey & Not Present in Round 1 Survey \\
& "Alternative - Credit & "Alternative - Diverse Needs" \\
& Reclamation" $(54.5 \%)$ & $(27.3 \%)$ \\
& & "Alternative - Methodology" \\
Interview & $(18.2 \%)$ \\
& "Alternative - Diverse Needs" & "Alternative-Methodology" \\
& $(60 \%)$ & $(60 \%)$ \\
& & Alternative - Credit \\
& Reclamation" (60\%) \\
\hline
\end{tabular}

Question 10 (Not present in Round 1 Survey and Question 10 in Round 2 Survey)

- Pleases rank the following three items as \#1 or \#2 or \#3 in order of their importance.

$\# 1$ is the highest and \#3 is the lowest. This question was not in Round 1 Survey in this format. This question was the result of the open-ended question (Question 7) in Round 1

Survey. Results from previous survey - \#1 - “Alternative - Credit Reclamation.”

As shown in Table S11, of the 5 participants, the results are as follows:

- \#1 Alternative Use - Diverse Needs

- \#2 Alternative Use - Credit Reclamation

- \#3 Alternative Use - Methodology

When comparing the interview data to the data from the previous survey rounds, as shown in Table 31, the most popular use of virtual programs does not match exactly, however the two answers are ranked \#1 and \#2 in both rounds. The order is just switched. This could be due to the individual use of virtual programs by Appalachian 
Ohio High School Principals in their respective school districts. The least popular use of virtual programs do match- "Alternative - Methodology."

Table 31

Pedagogical Feelings - Alternative Uses of Virtual Programs Ranked

\begin{tabular}{lll}
\hline & \multicolumn{2}{c}{ Virtual program use } \\
\cline { 2 - 3 } Round 1 survey & \multicolumn{1}{c}{ Most popular } & \multicolumn{1}{c}{ Least popular } \\
\cline { 2 - 3 } Round 2 survey & $\begin{array}{l}\text { Not present in Round 1 Survey } \\
\text { "Alternative - Credit }\end{array}$ & $\begin{array}{l}\text { Not Present in Round 1 Survey } \\
\text { "Alternative - Methodology" } \\
\text { Reclamation" (\#1) }\end{array}$ \\
& "Alternative - Diverse Needs" \\
& $\begin{array}{l}(\# 2) \\
\text { "Alternative - Diverse Needs" }\end{array}$ & "Alternative-Methodology" (\#3) \\
& (\#1) & \\
& "Alternative-Credit & \\
& Reclamation" (\#2) & \\
\hline
\end{tabular}

Question 11 (Not present in Round 1 Survey and Question 11 in Round 2 Survey) - In the previous survey, Question $7 \mathrm{read}$, "I am interested in your opinions. Please let me know your thoughts (positive or negative) on any aspect of online and blended courses and their potential for your district." After review of all participants' comments, two common themes arose. The second theme surrounded the apprehensions of virtual program use. Please review the common theme "Apprehensions" shown below and check the box that is most appropriate. This question was not in Round 1 Survey in this format. This question was the result of the open-ended question (Question \#7) in Round 1 Survey. Results from previous survey: Strongly agree - "Student Motivation" - 100\% “Quality" - 97\% Strongly Disagree - "Elimination of Teachers" - 39\%.

As shown in Table S12, of the 5 participants, the themes most agreed (answered “Strongly Agree” or "Agree”) were "Apprehensions - Motivation" (100\%), “Apprehensions - Accountability" (100\%), and "Apprehensions - Quality" (100\%). The 
theme least agreed (answered "Strongly Disagree" or "Disagree") was "Apprehensions Elimination" (20\%). It is noteworthy that no participant answered "Strongly Disagree" to any potential answer, and only $20 \%$ answered "Disagree" on one potential answer.

When comparing the interview data to the data from the previous survey rounds, as shown in Table 32, the theme most agreed, "Motivation" and "Quality," (answered 'Strongly agree" or "agree”) were the same. The data percentages represent commonalities of responses among participants. The least popular aspect of virtual programs was also the same.

Table 32

Pedagogical Feelings - Apprehensions

\begin{tabular}{lll}
\hline & \multicolumn{2}{c}{ Apprehensions } \\
\cline { 2 - 3 } Round 1 survey & \multicolumn{1}{c}{ Most popular } & \multicolumn{1}{c}{ Least popular } \\
Round 2 survey & "Apprehent in Round 1 Survey & Not Present in Round 1 Survey \\
& $(100 \%)$ & "Apprehensions - Elimination" \\
& "Apprehensions - Quality" & $(39.4 \%)$ \\
& $(94 \%)$ & \\
"Apprehensions - Motivation" & "Apprehensions - Elimination" \\
Interview & $(100 \%)$ & $(20 \%)$ \\
& "Apprehensions - & \\
& Accountability" (100\%) \\
& "Apprehensions - Quality" \\
& $(100 \%)$
\end{tabular}

Question 12 - (Not present in Round 1 Survey and Question 12 in Round 2 Survey). Please rank the following five items as \#1 or \#2 or \#3 or \#4 or \#5 in order of their importance. \#1 is the highest and \#5 is the lowest. Results from previous survey: \#1 - "Motivation" \#5 - “Elimination".

- As shown in Table S13, of the 5 participants, the results are as follows:

- \#1 Apprehensions - Quality 
- \#2 Apprehensions - Motivation

- \#3 Apprehensions - Cost

- \#4 Apprehensions - Accountability

- \#5 Apprehensions - Elimination

When comparing the interview data to the data from the previous survey rounds, as shown in Table 33, the most popular aspects and the least popular aspect of virtual programs were the same.

Table 33

Pedagogical Feelings - Apprehensions Ranked

\begin{tabular}{lll}
\hline & \multicolumn{2}{c}{ Apprehensions } \\
\cline { 2 - 3 } Round 1 survey & \multicolumn{1}{c}{ Most popular } & \multicolumn{1}{c}{ Least popular } \\
\cline { 2 - 3 } Round 2 survey & "Appresent in Round 1 Survey & Not Present in Round 1 Survey \\
& $\begin{array}{l}\text { (\#1) } \\
\text { "Apprehensions - Quality"(\#2) }\end{array}$ & $(\# 6)$ \\
Interview & "Apprehensions - Quality" (\#1) & "Apprehensions - Elimination" \\
& "Apprehensions - Motivation" & $(\# 6)$ \\
& $(\# 2)$ & \\
\hline
\end{tabular}

Question 14 (Question 9 in Round 1 Survey and Question 14 in Round 2 Survey) - Select the level (1-5) at which you disagree/agree with the following statements with regard to students in your district. Results from the previous survey (top two): Students need more discipline to succeed in online courses - 87\%; "Fully online and blended courses fulfill an important education role"-73\%; Strongly Disagree: "Fully online and blended course experiences are comparable in educational value" - 57\%; Some answer choices have been eliminated from the previous survey.

As shown in Table S14, of the 5 participants, the most agreed upon aspect of virtual programs (answered "5" or "4") reported "Fully online and blended courses fulfill 
an important educational need" (100\%) and "Students need more discipline to succeed in an online course than in traditional courses" $(100 \%)$. The aspect most strongly disagreed (answered "2" or "1") reported "Fully online and blended courses are comparable in educational value" (60\%).

When comparing the interview data to the data from the previous survey rounds, as shown in Table 34, the most agreed aspect are the same, just sometimes in reverse order. This represents a strong pedagogical opinion as these answers did not evolve into commonalities; they were there from the beginning. The data percentages represent commonalities of responses among participants.

In attempts to further refine commonalities, two potential responses were eliminated from Round 1 Survey. "State or local governing bodies or regulations are encouraging my district to enroll students in online and blended courses" (45.5\%), and "Fully online and blended courses have allowed my district to build important relationships with other organizations" $(45.4 \%)$. Both data percentages met the $41 \%$ commonalities definition and were deemed irrelevant. Therefore, they were deleted from Round 2 Survey. Once the most disagreed aspect of virtual programs from Round 1 Survey was removed, the answers were the same for each round. The data percentages represent commonalities of responses among participants.

Table 34

Pedagogical Feelings of Agreement/Disagreement

\begin{tabular}{lll}
\hline & \multicolumn{2}{c}{ Virtual program aspects } \\
\cline { 2 - 3 } Round 1 survey & \multicolumn{1}{c}{ Agreed } & \multicolumn{1}{c}{ Disagreed } \\
\cline { 2 - 3 } & $\begin{array}{l}\text { "Fully online and blended courses fulfill } \\
\text { an important educational need" }(74.1 \%)\end{array}$ & $\begin{array}{l}\text { "State or local governing } \\
\text { bodies or regulations are }\end{array}$ \\
& "Students need more discipline to & encouraging my district \\
succeed in an online course than in a & to enroll students in
\end{tabular}




\begin{tabular}{|c|c|c|}
\hline & traditional course" $(72.7 \%)$ & $\begin{array}{l}\text { online and blended } \\
\text { courses" }(45.5 \%) \\
\text { "Fully online and } \\
\text { blended courses have } \\
\text { allowed my district to } \\
\text { build important } \\
\text { relationships with other } \\
\text { organizations" }(45.4 \%)\end{array}$ \\
\hline Round 2 survey & $\begin{array}{l}\text { "Students need more discipline to } \\
\text { succeed in an online course than in a } \\
\text { traditional course" }(86.7 \%) \\
\text { "Fully online and blended courses fulfill } \\
\text { an important educational need" }(73.3 \%)\end{array}$ & $\begin{array}{l}\text { "Fully online and } \\
\text { blended course } \\
\text { experiences are } \\
\text { comparable in } \\
\text { educational value" } \\
(56.6 \%)\end{array}$ \\
\hline Interview & $\begin{array}{l}\text { "Fully online and blended courses fulfill } \\
\text { an important educational need" }(100 \%) \\
\text { "Students need more discipline to } \\
\text { succeed in an online course than in } \\
\text { traditional courses" }(100 \%)\end{array}$ & $\begin{array}{l}\text { Fully online and blended } \\
\text { courses are comparable } \\
\text { in educational value" } \\
(60 \%)\end{array}$ \\
\hline
\end{tabular}

\section{The Types of Students Enrolled in Virtual Programs}

The following questions represent the types of students section of the interview. Question 15 (Question 10 in Round 1 Survey and Question 15 in Round 2 Survey) - The nature of online or blended courses taken by students in my district (check all that apply): Results from previous survey (top two): "Fully Online - Remedial Courses" - 73\%, "Fully Online - Elective Courses" (53\%), "Blended- Elective Courses" - 59\%, "Blended - Required Courses" - 55\%.

As shown in Table S15, of the 5 participants, the nature of online and blended course most used were "Fully online -Required courses" (100\%); "Fully online Elective Courses" (100\%); and "Fully online- Remedial Courses" (100\%). "Blended Required" (75\%) and "Blended - Elective Courses" (50\%). The nature of online and blended courses least used were "Fully online - Other Courses" (20\%) and "Blended AP" $(0 \%)$ 
When comparing the interview data to the data from the previous survey rounds, as shown in Table 35, with the exception of "Blended-Required" being added in the Interview round, the most popular uses of virtual programs match. The data percentages represent commonalities of responses among participants. The least popular uses of virtual programs were the same.

Table 35

Nature of Enrollment Type

Popularity of virtual program type

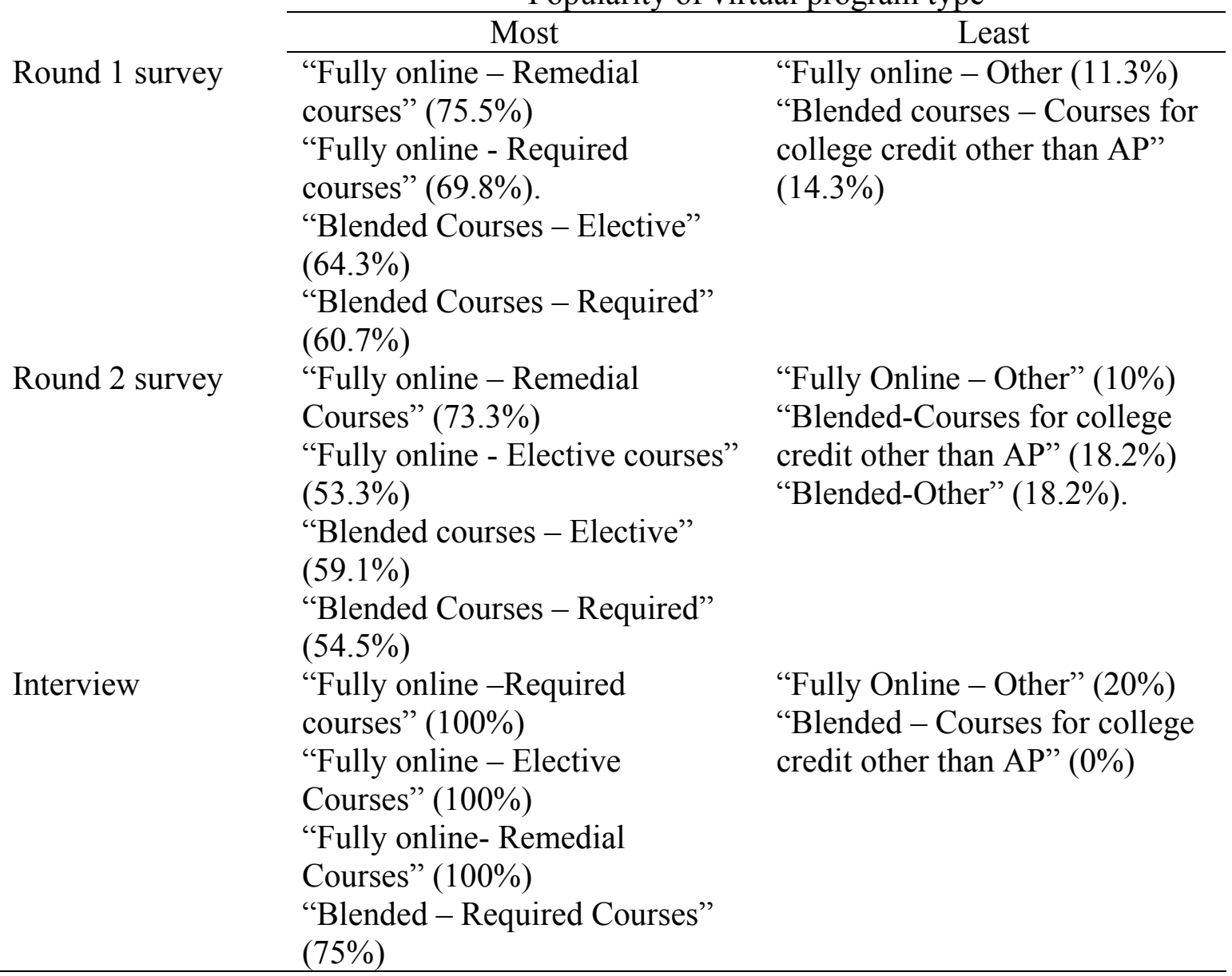

\section{The Growth of Virtual Programs}

The following questions represent the growth of virtual programs section of the Interview. Question 16 (Question 11 in Round 1 Survey and Question 16 in Round 2 
Survey) - What is your best estimate of the number of student enrollments (a student enrolled in more than one course should be counted only once) between July 1, 2008 and June 30, 2009? Results from previous survey: "Grades 9-12 Fully Online" - 100\% “Grades 9-12 Blended"- 97\%.

As shown in Table S16, of the 5 participants, the highest enrollments reported were "Grades 9-12 Fully Online" (100\%), followed by "Grades 9-12 Blended Courses" (60\%). The lowest enrollment reported were: "Grades 6-8 Fully Online” (20\%), “K-5 Fully Online” (0\%), “K-5 Blended” (0\%), and “Grades 6-8 Blended” (0\%).

When comparing the interview data to the data from the previous survey rounds, as shown in Table 36, the area of highest enrollments was the same. The data percentages represent commonalities of responses among participants.

The area of lowest enrollments was not the same. This could be due to the individual use of virtual programs by Appalachian Ohio Principals in their respective school districts.

Table 36

Growth of Virtual Programs

\begin{tabular}{lll}
\hline & \multicolumn{2}{c}{ Enrollment Areas } \\
\cline { 2 - 3 } Round 1 & \multicolumn{1}{c}{ Highest } & \multicolumn{1}{c}{ Lowest } \\
\cline { 2 - 3 } survey & "Grades 9-12 Fully Online" (98\%) & "Grades K-5 Fully Online" (58\%) \\
& $(98 \%)$ & "Grades K-5 Blended Courses" \\
Round 2 & "Grades 9-12 Fully Online" $(100 \%)$ & "K8\%) \\
survey & "Grades 9-12 Blended Courses" & "Grades 6-8 Fully Online" $(60 \%)$ \\
& $(97 \%)$ & "K-5 Blended Courses" $(60 \%)$ \\
& & "Grades 6-8 Blended" $(60 \%)$ \\
Interview & "Grades 9-12 Fully Online" (100\%) & "K-5 Fully Online" $(0 \%)$ \\
& "Grades 9-12 Blended Courses" & "K-5 Blended" $(0 \%)$ \\
& $(60 \%)$ & "Grades 6-8 Blended" $(0 \%)$ \\
\hline
\end{tabular}


Question 17 (Question 12 in Round 1 Survey and Question 17 in Round 2

Survey)-Over the next two years, my district expects fully online course enrollments to: Results from previous survey: "Stay about the same" $-63.3 \%$

As shown in Table S17, of the 5 participants, $2(40 \%)$ answered "Stay about the same". Three (60\%) chose to fill in a growth percentage, as shown in Table 37.

Table 37

Speculated Growth Percentage of Fully Online Courses - Answers Given

\begin{tabular}{ccc}
\hline $\begin{array}{c}\text { Growth } \\
\text { reported as } \%\end{array}$ & Frequency & Percentage \\
\hline 2 & 1 & $33.3 \%$ \\
10 & 1 & $33.3 \%$ \\
23 & 1 & $33.3 \%$ \\
Total & 3 & $100.0 \%$ \\
\hline
\end{tabular}

When comparing the interview data to the data from the previous survey rounds, as shown in Table 38, both surveys reported "Stay about the same" (76\% Round 1 Survey vs. $63.3 \%$ Round 2 Survey), however the interview participants chose to write in a percentage. Still, with a population of only five participants, it is noteworthy that $40 \%$ chose "Stay the same." This result is only $1 \%$ away from qualifying for commonalities of responses.

Table 38

Growth of Fully Online Courses

\begin{tabular}{ll}
\hline & Most common response \\
\cline { 2 - 2 } Round 1 survey & "Stay about the same" $(76.4 \%)$ \\
Round 2 survey & "Stay about the same" $(63.3 \%)$ \\
Interview & "Filled in Growth Percentage" (60\%) \\
\hline
\end{tabular}

Question 18 (Question 13 in Round 1 Survey and Question 19 in Round 2 Survey) - Over the next two years, my district expects blended enrollments to: Results from previous survey: "Stay about the same" $-73.3 \%$. 
As shown in Table S18, of the 5 participants, 2 (40\%) reported "Stay about the same." One (20\%) reported "Decrease." Two (40\%) chose to fill in a growth percentage, as shown in Table 39.

Table 39

Speculated Growth of Blended Courses - Answers Given

\begin{tabular}{ccc}
\hline $\begin{array}{c}\text { Growth } \\
\text { reported as \% }\end{array}$ & Frequency & Percentage \\
\hline 10 & 1 & $50 \%$ \\
23 & 1 & $50 \%$ \\
Total & 2 & $100.0 \%$ \\
\hline
\end{tabular}

When comparing the interview data to the data from the previous survey rounds, as shown in Table 40, Both surveys reported "Stay about the same", however the interview participants chose to write in a percentage. With a population of only five participants, it is noteworthy that $40 \%$ chose "Stay the same." This result was only $1 \%$ away from qualifying for commonalities of responses.

Table 40

Growth of Blended Courses

\begin{tabular}{ll}
\hline & Most common response \\
\cline { 2 - 2 } Round 1 survey & "Stay about the same" $(78.2 \%)$ \\
Round 2 survey & "Stay about the same" $(73.3 \%)$ \\
Interview & "Stay about the same" $(40 \%)$ and "Fill in \\
& Growth Percentage" $(40 \%)$ \\
\hline
\end{tabular}

Question 19 (Not present in Round 1 Survey or in Interview) - What factors need to be in place to allow growth of fully online courses within your district? Most common response from Round 2 Survey: Costs (24\%)

Each response is marked by the principal that answered the question. (i.e., "P33" was answered by Principal \#33). No editing was done to the responses, and they are listed in no particular order. Using Patton's (1990) Constant Comparative Method, the 
responses have been analyzed and five main themes were discovered. These themes include:

1. Costs/Funding

2. Policy Issues

3. Teacher Training

4. Accountability/Motivation

5. Quality

The following comments fell under the "Costs/Funding" theme:

P3 - "Understand how to fund it cause with state law and flex credit and what I can do if given opportunity - can transform school”

P3 - "funding is biggest thing"

P3 - "money is an issue"

P4 - "Costs - we need help; district does have some money"

P5 - "Costs must be there"

The following comments fell under the "Policy Issues" theme:

P1 - "need assurance it is the student completing the work"

P1 - "People need to monitor student progress"

P2 - "Staff needs to be comfortable, training, professional development and have to understand kids are entertained in so many other ways and we don't find a way to tap into their interests we lose them; teachers need to understand that"

P2 - "More student need; growth of blended courses - a little more understanding of how that benefits education and the student"

P3 - "With state law and flex credit, what I can do if given an opportunity; Can transform school; school will be like a college campus - students only need to come to access technology. I don't know if the perception of school will ever allow that to happen; people's perception of school - I don't know if anyone is ready for that; perception of school will impede you from growing;" 
P3 - “ I'm crazy; I'm a fanatic. I think about school all day; worry about school; I have been a principal six years both elementary and high school; taught inner city; had kids nobody wanted; believe that if you lead from front, don't have to catch what is in the end"

P3 - "Kids need different experiences; they just don't pass college class; they need to be exposed to something different; different ideas projected"

P4 - "Need to have students better prepared as to advantages of taking online/;blended courses"

The following comments fell under the "Teacher Training" theme:

P2 - "Staff needs to be comfortable, training, professional development and have to understand kids are entertained in so many other ways and we don't find a way to tap into their interests we lose them; teachers need to understand that"

P4 - "Teacher training, even ones that have worked with online courses; how to do it and how to put together a top notch course so quality is worthy; Teachers also need to know enough to respect it; Even if the teachers are not the ones doing it...if a student gets a " $B$ " in a course, teacher needs to have enough confidence in it that the student now knows; have respect for it"

The following comments fell under the "Accountability/Motivation" theme:

P1 - "Student's don't have motivation to complete courses"

P1 - "need assurance it is the student completing the work"

P1 - "People need to monitor student progress”

P2 - "More student need; has to be need for situation"

$P 2$ - "Have to understand kids are entertained in so many other ways and we don't find a way to tap into their interests we lose them; teachers need to understand that"

P3 - "Our drop out rate is atrocious; academics are tough; Kids in this county want to go home jobs don't need high school diploma in this area; some want to make same amount of money; this is reality; kids need different experiences, they need to get exposed to something different; differently ideas projected"

P4 - "Need to have students better prepared as to advantages of taking online/blended courses; need to help improve their motivation"

The following comments fell under the "Quality" theme: 
P4 - "Need to know how to put together a top notch course so quality is worthy"

P5 - “Quality assurance”

P5 - "Once we find a tool that is user friendly, that is the most important issue"

As shown in Table 41, when comparing the following two Round 2 Survey

Questions: Question 18 - "What factors need to be in place to allow growth of fully online courses in your district?" and Question 20 - "What factors need to be in place to allow growth of blended courses in your district?” with Interview Question: Question 19 - "What factors need to be in place to allow growth of fully online and blended courses in your district?"

Table 41

Qualitative Responses - Factors that Allow Virtual Program Growth

\begin{tabular}{|c|c|c|c|c|c|c|c|}
\hline \multicolumn{8}{|c|}{$\%$ of responses } \\
\hline & Costs & Policy & $\begin{array}{l}\text { Teacher } \\
\text { Training }\end{array}$ & $\begin{array}{l}\text { Accountability/ } \\
\text { Motivation }\end{array}$ & Quality & Technology & Misc. \\
\hline $\begin{array}{l}\text { Round } 1 \\
\text { survey }\end{array}$ & \multicolumn{7}{|c|}{ Question not present in this round } \\
\hline Round 2 & Q18-10/33 & Q18-6/33 & Q18-6/33 & Q18-7/33 & Not & Q18-6/33 & Q18-4/33 \\
\hline Kound 2 & Q20-6/33 & Q20-5/33 & Q20-8/33 & Q20-4/33 & identified & Q20-5/33 & Q20-5/33 \\
\hline survey & $24 \%$ & $17 \%$ & $21 \%$ & $17 \%$ & as a theme & $17 \%$ & $\begin{array}{l}14 \% \\
\text { Not }\end{array}$ \\
\hline Interview & $\begin{array}{c}\text { Q19-5/5 } \\
100 \%\end{array}$ & $\begin{array}{c}\text { Q19-8/5 } \\
160 \%\end{array}$ & $\begin{array}{c}\text { Q19-2/5 } \\
40 \%\end{array}$ & $\begin{array}{c}\text { Q19-7/5 } \\
140 \%\end{array}$ & $\begin{array}{c}\text { Q19-3/5 } \\
60 \%\end{array}$ & $\begin{array}{c}\text { Not identified as } \\
\text { a theme }\end{array}$ & $\begin{array}{c}\text { identified } \\
\text { as a } \\
\text { theme }\end{array}$ \\
\hline
\end{tabular}

Note. Each cell lists the number of responses reported divided by the sample. (i.e.: 10/33 represents ten responses regarding that theme/33 person sample.) The percentage reported represents the number of responses reported by the sample on the identified themes. "Q" represents "Question".

\section{Providers of Virtual Programs}

Question 20 (Question 14 in Round 1 Survey and Question 21 in Round 2 Survey)

- The provider(s) for fully online and blended courses for my district are (check all that apply): Results from previous surveys: Fully online "Educational Service Agencies" - 
63\%, "Postsecondary institutions" - 37\%, Blended-"Educational Service Agencies" $37 \%$, and "Postsecondary Institutions" $-23 \%$.

As shown in Table S19, of the 5 participants, the most widely used Providers were: Fully online - "Educational Service Agencies” - 100\%, Blended-“Educational Service Agencies" - 40\%, "Postsecondary Institutions" - 40\%. Of the 5 participants, the following were reported as the least used provider of fully online and blended courses: Fully online-"Cyber" - 0\%, "Districts/schools in other states" - 0\%, "Independent Vendors" - $0 \%$, “Other" - 0\%, Blended-“Cyber" - 0\%, "Independent Vendors" - $0 \%$, "Other schools in your district" - 0\%, "Another school district" $-0 \%$.

When comparing the interview data to the data from the previous survey rounds, as shown in Table 42, the most popular Provider of fully online courses match. The data percentages represent commonalities of responses among participants. The most popular Provider of blended courses also match across participants. When comparing the responses of each round, the least popular provider of virtual programs changed. This could be due to the individual use of virtual programs by Appalachian Ohio High School Principals in their respective school districts.

Table 42

Providers of Virtual Programs

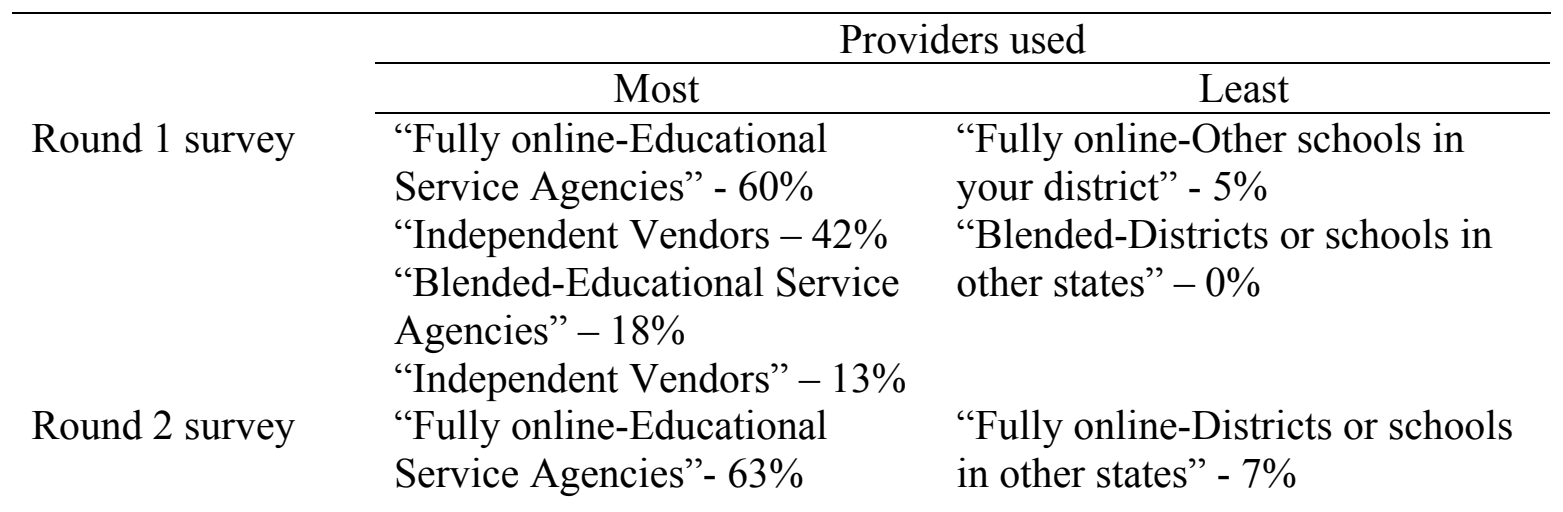




\begin{tabular}{|c|c|c|}
\hline & $\begin{array}{l}\text { "Fully online - Postsecondary } \\
\text { institutions" - } 37 \% \\
\text { "Blended-Educational Service } \\
\text { Agencies" - } 37 \% \\
\text { "Postsecondary Institutions" - } \\
23 \%\end{array}$ & $\begin{array}{l}\text { "Blended-Cyber" - 3\% } \\
\text { "Blended - Other schools in your } \\
\text { district" - 3\% } \\
\text { "Blended - Another school } \\
\text { district" - 3\% } \\
\text { "Blended - Districts/schools in } \\
\text { other states"-3\% }\end{array}$ \\
\hline Interview & $\begin{array}{l}\text { "Fully online - Educational } \\
\text { Service Agencies within your } \\
\text { State" }(100 \%) \\
\text { "Blended - Educational } \\
\text { Service Agencies within your } \\
\text { state" }(40 \%) \\
\text { "Postsecondary Institutions" - } \\
(40 \%)\end{array}$ & $\begin{array}{l}\text { "Fully Online - Cyber (online) } \\
\text { charter school in your district" } \\
(0 \%) \\
\text { "Fully Online - Other schools in } \\
\text { your district" }(0 \%) \\
\text { "Fully Online - Independent } \\
\text { Vendors" }(0 \%) \\
\text { "Fully Online - Other" }(0 \%) \\
\text { "Blended - Cyber (online) charter } \\
\text { school in your district" }(0 \%) \\
\text { "Blended - Other schools in your } \\
\text { district" (0\%) } \\
\text { "Blended - Independent Vendors" } \\
(0 \%) \\
\text { "Blended - Other" }(0 \%)\end{array}$ \\
\hline
\end{tabular}


Table 43 represents commonalities found in each survey/interview question.

Table 43

Summary of Commonalities to each Interview Question

\begin{tabular}{|c|c|c|}
\hline \multirow[t]{2}{*}{ Question } & \multicolumn{2}{|c|}{ Response } \\
\hline & Most agreed & Least agreed \\
\hline 1-Demographics & $\mathrm{n} / \mathrm{a}$ & $\mathrm{n} / \mathrm{a}$ \\
\hline 2-Position & Yes & $\mathrm{n} / \mathrm{a}$ \\
\hline 3-Length of position & Yes & $\mathrm{n} / \mathrm{a}$ \\
\hline 4-Student enrollment & Yes - "At least one fully online course" & No \\
\hline 5-Barriers & Yes - "Concerns of course quality" & No \\
\hline 6-Barriers ranked & Yes -"Costs" & Yes - Need for teacher training \\
\hline \multirow[t]{2}{*}{ 7-Reasons of use } & $\begin{array}{l}\text { Yes - "Permitting a student to take a class } \\
\text { again" }\end{array}$ & $\begin{array}{l}\text { No, but very close. } \\
\text { "Students prefer online course activities" }\end{array}$ \\
\hline & $\begin{array}{l}\text { Yes -“"Meeting the needs of a specific group of } \\
\text { student" }\end{array}$ & $\begin{array}{l}\text { was } 1 \% \text { away from meeting the } \\
\text { commonalities definition }\end{array}$ \\
\hline \multirow[t]{2}{*}{ 8-Reasons ranked } & $\begin{array}{l}\text { Yes - "Permitting a student to take a class } \\
\text { again" }\end{array}$ & $\begin{array}{l}\text { Yes - "Students prefer online activities" } \\
\text { Yes - "Online and blended course }\end{array}$ \\
\hline & $\begin{array}{l}\text { Yes -" Meeting the needs of a specific group of } \\
\text { student" }\end{array}$ & offerings are financially more beneficial" \\
\hline 9-Alternative theme & No & No \\
\hline 10-Alternative ranked & No & No \\
\hline \multirow[t]{2}{*}{ 11-Apprehensions theme } & Yes - "Motivation" & No \\
\hline & Yes - "Quality" & \\
\hline 12-Apprehensions ranked & Yes - "Motivation" & No \\
\hline 13-School year & Yes - "Before 2005" & No \\
\hline \multirow[t]{2}{*}{ 14-Aspects } & $\begin{array}{l}\text { Yes - "Students need more discipline to } \\
\text { succeed in an online course than a traditional } \\
\text { course" }\end{array}$ & $\begin{array}{l}\text { Yes - "Fully online and blended courses } \\
\text { are comparable in educational value" }\end{array}$ \\
\hline & $\begin{array}{l}\text { Yes - "Fully online and blended courses fulfill } \\
\text { an important educational need" }\end{array}$ & \\
\hline \multirow[t]{2}{*}{ 15-Types of students } & Yes - "Fully online - Elective" & No \\
\hline & Yes - "Fully online - Remedial" & \\
\hline \multirow[t]{2}{*}{16 - Student enrollment } & Yes - "Grades 9-12 Fully Online" & No \\
\hline & Yes - "Grades 9-12 Blended" & \\
\hline $\begin{array}{l}17 \text { - Fully online } \\
\text { enrollment }\end{array}$ & $\begin{array}{l}\text { No - but only } 1 \% \text { away from meeting } \\
\text { commonalities definition for "Stay about the } \\
\text { same" }\end{array}$ & $\mathrm{n} / \mathrm{a}$ \\
\hline 18-Blended enrollment & $\begin{array}{l}\text { No - but only } 1 \% \text { away from meeting } \\
\text { commonalities definition for "Stay about the } \\
\text { same" }\end{array}$ & $\mathrm{n} / \mathrm{a}$ \\
\hline $\begin{array}{l}\text { 19-Growth factors: fully } \\
\text { online/blended courses }\end{array}$ & No & No \\
\hline 20 - Providers & $\begin{array}{l}\text { Yes - "Educational Service Agencies - Fully } \\
\text { online courses" }\end{array}$ & No \\
\hline
\end{tabular}

Note. "Yes" represents $41 \%$ agreement among participant responses. "No" represents $40 \%$ or less agreement among participant responses. " $\mathrm{n} / \mathrm{a}$ " represents non applicable comparison value of agreed or disagreed responses 


\section{Chapter 5}

The purpose of this study was to examine Appalachian Ohio High Schools and their use of virtual programs to supplement traditional course offerings. This exploratory study investigated which school districts are using virtual programs, what attributes are important when choosing to use virtual programs, why certain students are chosen to enroll in virtual programs, and what best practices govern the use of virtual programs once they are implemented. The conclusions of this study will provide all stakeholders additional research to base policy decisions in regards to virtual programs.

Two of the most notable findings of this study were the importance of funding in regards to the use and the expansion of virtual programs among Appalachian Ohio High Schools and a concern for the quality of virtual programs. Further, the need for self discipline as well as improved student motivation was significant in the responses from the principals.

In this chapter, key findings of the data, separated by the research questions, will be presented. Implications of the findings on policy, as well as policy recommendations for all stakeholders, will be made.

\section{Research Questions}

Table 44 presents the research questions separated by the survey/interview questions use to answer the questions. Parentheses are used to signify questions that had commonalities. 
Table 44

Research Questions Separated by Survey/Interview Questions

\begin{tabular}{|c|c|c|c|}
\hline & \multicolumn{3}{|c|}{ Question numbers } \\
\hline & $\begin{array}{l}\text { Round } 1 \\
\text { survey }\end{array}$ & $\begin{array}{l}\text { Round } 2 \\
\text { survey }\end{array}$ & Interview \\
\hline \multirow{7}{*}{ Demographics } & 1 & 1 & 1 \\
\hline & 2 & 2 & 2 \\
\hline & 3 & (3) & (3) \\
\hline & 4 & (4) & (4) \\
\hline & 8 & (13) & (13) \\
\hline & 11 & (16) & (16) \\
\hline & 14 & (21) & (20) \\
\hline RQ1 - In the opinion of Appalachian Ohio High & 6 & 7 & (7) \\
\hline School Principals, what reasons are considered & 10 & 8 & (8) \\
\hline when using virtual programs as an alternative to & 11 & 9 & 9 \\
\hline \multirow{4}{*}{$\begin{array}{l}\text { traditional course offerings? What factors need to } \\
\text { be in place to facilitate continued growth of virtual } \\
\text { program use? }\end{array}$} & 13 & 10 & 10 \\
\hline & & (15) & (15) \\
\hline & & 18 & 19 \\
\hline & & 20 & \\
\hline \multirow{5}{*}{$\begin{array}{l}\text { RQ2 - In the opinion of Appalachian Ohio High } \\
\text { School Principals, what apprehensions of virtual } \\
\text { programs impede their use? What factors need to } \\
\text { be in place to overcome those apprehensions? }\end{array}$} & 5 & (5) & (5) \\
\hline & & (6) & (6) \\
\hline & & 11 new & (11) \\
\hline & & question) & (12) \\
\hline & & $\begin{array}{l}12 \text { (new } \\
\text { question) }\end{array}$ & \\
\hline \multirow{5}{*}{$\begin{array}{l}\text { RQ3 - In the opinion of Appalachian Ohio High } \\
\text { School Principals, what best practices and/or } \\
\text { policies need to be in place to implement a } \\
\text { successful virtual program? }\end{array}$} & 7 & (14) & (14) \\
\hline & 9 & (15) & (15) \\
\hline & 10 & (17) & 17 \\
\hline & 12 & (19) & 18 \\
\hline & 13 & & \\
\hline
\end{tabular}

Note. ( ) represent those questions that have commonalities of responses.

\section{Demographics}

This exploratory study, through the eyes of Appalachian Ohio High Schools

Principals, investigated

1. which school districts were using virtual programs,

2. what attributes were important when choosing to use virtual programs,

3. why certain students were chosen to enroll in virtual programs, and 
4. what best practices govern the use of virtual programs once they were implemented.

The role of the principal is key to determining which educational methodologies are used to educate students. Seventy-seven principals $(\mathrm{N}=77)$ participated in Round 1 Survey, thirty-three principals $(\mathrm{N}=33)$ participated in Round 2 Survey, and five principals $(\mathrm{N}=5)$ participated in the interview. These principals represented 28 of Ohio's 32 Appalachian counties. Their experience varied, however, most (61\% in Round 1 Survey; $51 \%$ in Round 2 Survey; and $80 \%$ in the Interview) reported they held their principal position for "more than three years."

Commonalities were present on the largest types of student enrollment. Seventyseven percent (Round 1 Survey) grew to 100\% (Interview) of students took "at least one fully online course." In addition, most school districts enrolled their online students “before 2005." The largest area of student enrollment was Grades 9-12, fully online courses. This data is consistent with what is found in literature. Picciano and Seaman (2009) reported that over one million students took an online course during the 20072008 school year.

\section{Research Question 1}

Research Question 1 asked, "In the opinion of Appalachian Ohio High School Principals, what reasons are considered when using virtual programs as an alternative to traditional course offerings? What factors need to be in place to facilitate continued growth of virtual program use?"

One of the most notable findings was the commonalities of reasons why school districts use virtual programs as an alternative to traditional course offerings. The participants repeatedly reported that virtual programs were used to service the "specific 
needs of a certain group of students" and "permitting students who failed a course to take it again." These items were given by the principals across all three rounds as the major reasons to use virtual programs. In addition, these same two reasons were found to be the major reasons to use virtual programs as reported in both previous national studies that used this survey instrument. This represents a strong pedagogical belief as it replicated itself over all rounds.

It is also notable that the least popular reason as reported by the principals to use virtual programs was "students prefer online activities." This reason was also the same reported in both previous national studies that used this survey instrument. However, Project Tomorrow (2009) states that students chose online courses because they like to learn at their own pace and to take classes not offered at their school. It seems this conflicting data may illustrate a disconnect between principals' opinion and the opinion of the students themselves.

The principals reported five factors that affect the growth of virtual program use:

- costs/funding,

- policy issues,

- teacher training,

- accountability \& motivation, and

- quality.

Costs, policy issues, and accountability/motivation were also listed as factors that affect growth of virtual programs in the previous national studies that used this survey instrument. Watson, Gemin, Ryan, and Wicks (2009) state the single largest factor limiting the size of individual programs which are not growing is funding. He also stated 
the number of students taking online courses in a state is directly proportional to a combination of policy (whether students have the right to chose an online course) and funding (whether online programs are well-funded or funding follows students who choose online courses or schools).

Policy issues were noted with the highest frequency during the interview. Ohio has passed a law that requires school districts to offer flex credit. Flex credit is the ability to earn credits through means other than traditional delivery methods. Principals named this type of policy issues as both an opportunity and a barrier. One principal noted he could transform the school if he had the funds to offer virtual programs as he would like, but noted that policy regulations on funding, such as per pupil funding following the student, cripples his budget when those same students enroll in other community schools in the state.

\section{Research Question 2}

Research Question 2 asked, "In the opinion of Appalachian Ohio High School Principals, what apprehensions of virtual programs impede their use? What factors need to be in place to overcome those apprehensions?"

When analyzing the data regarding apprehensions of virtual program use, common themes clearly arose. Costs and funding, concerns of quality, and motivation of students were reported on various survey questions. In addition, these same themes were listed as barriers during the Interview. It is notable that, "Quality", was reported on this study and both previous national studies using this survey instrument as the primary barrier that impedes district use of virtual programs.

According to the SREB Educational Technology Cooperative's Standards for Online Learning (2009), there are two ways to determine the quality of virtual programs. 
First, the course and program inputs, such as content and student support, must maintain the upmost standards of excellence. Many states use their existing state curriculum standards. iNACOL (2007) was the first organization to create standards for virtual programs, however, monitoring their adoption is a challenge.

The second determinant of the quality of virtual programs is program outcomes, or student performance. However, without proper data reporting, it is difficult to track how student performance is affected when taking an online course.

Motivation was another key issue reported by the participants. During the interview, each of the five principals listed the need for more discipline as a vital aspect of student success. They felt students should be intrinsically motivated and work to complete their courses without constant supervision. Research has shown that students prefer online courses because they are able to work at their own pace (Tallent-Runnels et al.,2005 and Project Tomorrow, 2009). School administrators should create policies that allow students more flexibility with online course pacing, thus taping into the completion motivators of the student.

One principal noted the fact that students are entertained and school administrators need to tap into their intrinsic motivations, such as gaming technology, to provide curriculum that is engaging and will keep their attention. As mentioned earlier, student support is key to the success of virtual programs. Interaction is the heart of online learning and was named the primary difference between online and face-to-face instruction (Weiner, 2003). In virtual schools, participants seek both deeper and stronger relationships, and they also value frequent and timely responses to their questions (Weiner, 2003). Just as it is important that the principals recognized the need of 
continued motivation from the student, they must also recognize the need to create policy to help facilitate their motivation. Consider the debate over the use of cell phones on school property. Many school district administrators govern policies from fear and find ways to say "No" to technology. My call for action is to find a way to say "Yes", and utilize the many instructional uses a cell phone, and other mobile technologies, can facilitate.

Cost was a common theme echoed repeatedly by the participants. One principal stated that money was an issue. Another principal stated that funding is their biggest hurdle and that if he could find a way to fund virtual programs, he could transform the school.

In addition to the intrinsic funding challenges facing rural schools (i.e. low tax base, limited federal funding, teacher shortages), Ohio rural schools also face another funding barrier. Ohio is a state that allows community schools. Each year, public school districts lose funding because students opt to leave their school districts to enroll in other charter schools, some of them electronic. During the 2008-2009 school year, $\$ 648,000,000$ was transferred from public school districts to community schools. School district administrators need virtual programs, not only to offer a program to those with diverse needs, but also to remain competitive by keeping their funds intact. Many students and families want choices and become disenfranchised with districts which are not flexible. Virtual programs can help districts offer that choice to families and in turn, protect their financial base.

In contrast, the least important barrier given was "the need for teacher training." This too, was listed as the least important barrier in both previous national studies that 
used this survey instrument. Lowes (2005) reported that online teaching improves practices in both virtual and face-to-face settings, and $75 \%$ of teachers surveyed said that teaching online had a positive impact on their face-to-face teaching (Blomeyer, 2005). Furthermore, Weiner (2003) found that interaction is the primary difference between online and face-to-face instruction and one of the most important aspects of the online settings. In virtual schools, participants seek both deeper and stronger relationships, and they also value frequent and timely responses to questions.

Given the importance of the teacher role in virtual programs, it is alarming to find that most principals reported "the need for teacher training" as the least important barrier to implementing virtual programs. This conclusion could be looked at through two lenses. The first could be that the district feels their teachers are already qualified and know the importance of their role. The second, however, is that school administrators underestimate the importance of proper teacher training for online courses. Some administrators believe if a teacher is a good classroom teacher, then he/she will be a good online teacher.

This issue points to the importance of this study and others like it. School administrators need to understand what factors contribute to student success (i.e. interaction and timely responses from their teachers) and make sure those factors are in place. When data is available through research, stakeholders gain insightful knowledge of how best to implement virtual programs in their respective school districts. This knowledge helps drive good policy creation and the formation of best practices, which in turn, increases student achievement. 
Finally, it is important to note that all survey/interview questions that answered Research Question 2 had commonalities of responses from the participants. This points to strong pedagogical beliefs regarding apprehensions of virtual program use and methods to overcome those apprehensions.

\section{Research Question 3}

Research Question 3 asked, "In the opinion of Appalachian Ohio High School Principals, what best practices and/or policies need to be in place to implement a successful virtual program?"

When analyzing the data regarding best practices/policies of virtual program use, common themes clearly arose. "Fully online and blended courses fulfill an important educational need" and "Students need more discipline to succeed in an online course than in traditional courses" were reported as the most agreed aspects of virtual programs. It is notable that, both of these aspects were also listed as the most agreed aspect of virtual programs in both previous national studies using this survey instrument.

It is important that principals believe virtual programs are important for a specific student population because their beliefs transfer into which students are enrolled in online courses. Many students enrolled in virtual programs are in need of credit reclamation and without virtual programs, they would not graduate. When district policies allow for choice to fulfill needs, it is a win/win situation for all.

Although the national average of growth ranges from $15 \%$ to $50 \%$ (Evergreen Consulting, 2009), the data from this study reported most principals believed their virtual program use will stay the same. Reasons for this could stem from funding. Funding has already been established as being highly correlated to virtual program growth, and with 
the budget constraints most school districts are experiencing, it is not surprising that many principals feel they do not have the means to expand programs.

Educational Service Agencies were reported as the most used provider of virtual programs of both fully online and blended courses. In contrast, the previous national studies that used this survey instrument reported "state virtual schools within your state" as the most used provider of virtual programs. This data could be explained because the participants of this study were from Ohio. Ohio is one of the few states that do not have a state run virtual school, therefore Ohio school districts are forced to look elsewhere for virtual programs. Ohio has 58 Educational Service Centers whose primary mission is to provide services to school districts. The Jefferson County Educational Service Center, in Steubenville, Ohio offers a Virtual Learning Academy (VLA) to 170 of Ohio's 614 school districts. VLA partners with school districts to provide 100 fully online courses to students in Grades K-12 that are 100\% aligned to Ohio's Academic Content Standards (Jefferson County Educational Service Center, 2009).

Fully online courses for grades 9-12 were reported as the highest enrollment category. Require courses, elective courses, and remedial courses were all ranked highest as to the largest population of student enrollment. Because enrollment in virtual programs is typically a school district decision, this shows the versatility of virtual programs in order to service a larger variety of student needs.

In contrast, "Fully online and blended course experiences are comparable in educational value" was rated with commonalities as the most disagreed aspect of virtual programs. This finding is especially important when looking at data in regards to policy. If principals, who are instrumental in determining the educational methodologies of their 
buildings, believe online courses are not as worthy as traditional courses, their implementation may be limited or not at all, even if the principals feel they do serve some student populations well.

The findings of this question directly conflict with the research reported last spring by the U.S. Department of Education, which found that "online education is as good or better than traditional delivery models" (U.S. Department of Education, 2009). This is important because it again points to the direct need for policy reform and awareness among educators.

\section{Implications for Policy}

One of the reasons why this study and others like it are so important is because it points to the lack of policy that exists regarding virtual programs. Because virtual programs vary in comprehensiveness, reach, type, location, delivery methods, operational control, and type of instruction, it is difficult to create policies that will fit all programs.

Because of the variables of virtual programs, policymakers need to establish some base line principles to help guide decisions. According to iNACOL and the Trujillo Commission (2007), which was established to assist policymakers in Colorado respond to the state's audit of online schools, quality online learning policy should:

- begin with a premise that public education should include a variety of high quality learning options, including online learning;

- include both full-time and supplemental online opportunities;

- provide equal access to all students;

- provide fair and sensible funding that allows online learning to expand with demand while maintaining state-of-the-art quality;

- provide reasonable oversight and reporting requirements to ensure quality; 
- facilitate a range of online learning opportunities;

- require high quality curricula, aligned with state and applicable district standards;

- address existing policies that do not fit or that hinder online learning process and accessibility, including removing enrollment caps and artificial limits restricting student access to online courses.

This list is not exhaustive and can be added to by individual state policy makers. Setting common principles is a critical first step to understanding policy. Once a common understanding of key principles is established, it can be applied to various issues.

As mentioned in Chapter 2, Watson (2005) listed five policy issues regarding virtual programs: Quality: program, teacher, course, student support; Funding; Access and Quality; Accountability and Oversight; and Research and Evaluation Data. Good policy and best practice models will determine whether a virtual program succeeds or fails, not only within individual school districts, but state adopted programs as well.

\section{Quality}

Second only to funding, concern of quality was reported over and over by the principals. Because of NCLB, accountability is paramount to educators because without student achievement growth, school districts may have certain rights revoked. Administrators want to ensure that virtual programs are aligned to standards to best prepare their students. Policymakers should promote a common core of national standards or adopt a digital curriculum in order to ensure all virtual programs have measurable, quality components.

Principal responses from the interview stated the importance of finding virtual programs that are user friendly. They also stated the need for teacher professional 
development in order to create top notch courses. Teacher professional development has already been mandated by some states. Wisconsin's online learning bill requires that as of July 1, 2010, public or charter online teachers must have completed at least 30 hours of professional development specific to online teaching. South Dakota requires that distance learning instructional staff must annually demonstrate proficiency in instruction. Hawaii's law calls for developing and establishing a mentoring and training program for online teachers (Online learning policy and practice survey, 2010).

Policymakers would be wise to recognize the need to bring highly qualified teachers to rural areas. Hard to staff areas such as chemistry, physics, advanced math, and foreign languages could be offered to districts that do not currently have these options. In addition, there needs to be more emphasis placed on teacher preparation programs. Given the growth of virtual programs, and the staggering statistic that by 2019, 50\% of all courses will be delivered online (U.S. Department of Education, 2009; Christensen, 2008), students preparing to be teachers need to familiarize themselves with this educational methodology. Policymakers should explore teacher preparation curricula at the university level and ensure virtual program training, from teacher preparedness to student support mechanisms, are taught.

Student support is key to the success of virtual programs and their ability to aid student learning. The principals' paramount concern over student motivation was clearly heard. It is not enough that the technology for virtual programs is in place, or that the students actually enroll in these types of courses. Student achievement is still the destination of the educational journey. Students have to feel supported in order to succeed (Cavanaugh et al., 2004). If students are simply enrolled in virtual programs, 
without proper supervision and support, they lack the motivation to complete the courses.

Policies need to be in place in the individual school districts that mandate a supervisor who monitors student progress, serves as a student mentor, and promotes student achievement. It is not enough to just have a teacher assigned to the student. There also needs to be a district administrator who oversees the virtual program as a whole. This person could serve as the liaison between the district and the teacher and the student. Ideally, each school building would have its own point of contact so that students have easier access to support when they need it.

\section{Funding}

The overarching theme echoed throughout this entire study was funding. Watson et al. (2009) also found that funding is the single most important policy issue in online learning. In fact, the single largest factor limiting size of individual virtual programs that are not growing is funding. States that have funding tied directly to public education dollars have more sustained growth than states that have their virtual program funding tied to non-sustainable methods, such as grants (Evergreen Consulting Group, 2009).

Some virtual programs enroll students from across the entire state, so some argue that a single virtual program base funding level should be established within the range of the brick and mortar model. Critics of this belief state that it does not cost as much to educate an online student as it does to educate a traditional student. Although virtual schools do not have transportation costs or brick and mortar costs, they do have significant technological costs, such as equipment and telephone infrastructure, as well as content delivery costs. Augenblick, Palaich, and Associates, a school finance consulting 
group, found that the operating costs of online programs are about the same as the operating costs of a brick and mortar school (2006).

In Ohio, funding is based on two reporting periods, one in October and one in February. School districts are funded based upon student enrollment during this critical "reporting week." The challenge is born when a student enrolls into a district the week after "reporting week" because that school district does not receive funding for that student, yet is required to educate him/her for the remainder of the school year.

One innovative alternative for policymakers is to fund students based on outcomes, not seat time and census counts. States could fund school districts based upon successful completion of certain benchmarks and student outcomes. The Florida Virtual School is an example of outcome-based funding, as they do not receive funding until a student successfully completes a course. In this example, funding is aligned directly with student achievement, not something that has no bearing on student success, enrollment during a certain week of the year.

If states adopt funding policy based on student outcomes, they must also account for student attendance. Truancy becomes an issue if seat time is removed as a requirement. Specific completion dates and check in times may be necessary so that active participation is achieved. In Wisconsin, if a student fails to respond to a school assignment within five days, the school must notify the parent. If a student fails to participate three times in a semester, a transfer to another school could necessitate. (Wisconsin Legislative Reference Bureau, 2008).

Virtual programs can serve as a cost effective method to provide students opportunities of course selections that may have not otherwise been available. 
Policymakers need to find ways to ensure equal funding for all students across all geographic areas. It is only then will a true adoption of this new methodology be allowed to offer its potential.

\section{Access and Quality}

In Appalachian Ohio, equal access to quality curriculum is imperative. Through virtual programs, students have opportunities to experience coursework that was unattainable in previous generations. Virtual programs allow students enriched curriculum experiences that open their minds to content outside of the brick and mortar buildings. So often school districts are limited to textbooks on a shelf. In stark contrast, a computer with Internet access can allow students to expand their breadth of knowledge exponentially.

Policymakers need to understand the potential that virtual programs can bring small school districts, with limited course offerings. In addition, individual school administrators need to formulate school policy that allows open access to all students, not just a chosen few. According to the Evergreen Consulting Group (2009), policymakers should consider two key aspects when considering the equality of virtual program adoption.

1. Are students informed about online courses and schools?

2. Do students have the right to choose an online course or school, regardless of where they live? Alternatively, does the student's home district have the right to tell a student that the online school or course is not available to him or her?

States with the most virtual program growth are those that allow students to cross district lines, which provide opportunities to access school options that best meet individual needs (Evergreen Consulting Group, 2009). 
Policymakers could achieve higher accessibility by rewarding states that ensure a full spectrum of online learning opportunities is available to every student. One method that could be used is to consider removing enrollment caps and restrictions on virtual programs. Tying this requirement to federal funding would emphasize the importance of virtual program utilization.

Another policy implication for the US Department of Education, as well as the state's Departments of Education, is to ensure the portability of virtual program credits across state lines. If students have a guarantee their efforts will count towards graduation at various educational institutions, a greater number may take advantage of virtual program opportunities.

Finally, all policymakers should institute an initiative to ensure Internet access to all. Although some may argue that access is available, it is not always equitable. Bandwidth is still an issue in many Appalachian communities and although they can access the Internet, dial up speeds prohibit efficient use. Policymakers can expand eRate with a $21^{\text {st }}$ century focus on broadband for virtual programs.

\section{Accountability and Oversight}

Because many virtual program protocols exist, accountability and oversight is a very difficult policy issue to tackle. Many schools use accreditation institutions to prove accountability and oversight, however, because many virtual programs are not classified as actual schools, even accreditation issues vary. AdvancED, which has now acquired The Commission on International Trans-Regional Accreditation (CITA) and is the parent company of North Central Association on Accreditation and School Improvement and the Southern Association of Colleges and Schools Council on Accreditation and School 
Improvement, has provided standards to accredit virtual programs worldwide.

(AdvancED, 2010). These include:

1. Vision and purpose

2. Governance and leadership

3. Teaching and learning

4. Documentation and using results

5. Resources and support systems

6. Stakeholder communication and relationships

7. Commitment to continuous improvement

In addition, quality standards for both virtual programs and teacher professional development have been established by iNACOL. These standards are met to give users a road map to best practices and to give policymakers a frame of reference for which to build policy.

Policymakers have a tough job when trying to build common accountability measures. Trying to frame guidelines for unique virtual programs is difficult to do. NCLB has inherently built in some specific policies that all schools must follow. Highly qualified teachers and yearly student achievement progress are required of all schools. In addition to NCLB, policymakers should allow the path of least resistance so that all school districts receive equal funding, and all students should be given the opportunity to enroll in online courses.

\section{Research and Evaluation Data}

As the survey/interview questions were described above, all of the policy issues were examined, with one exception, research and evaluation data. It is interesting that 
none of the principals mentioned the need for research or data collection. A principal wears many hats and they are so busy "doing", they lack the initiative to collect data. Without documented data and results, it is difficult to measure the success and quality of any virtual program.

The implications of data gathering are important. Not only does it allow for true measurement of student success, but it offers a glimpse into student progress that is not always available when tracking traditional course deliveries. Virtual programs inherently allow tracking of student progress, seat time, pre-tests, post-tests, comments to and from teachers, scores, and online participation that traditional courses cannot. Real time data tracking is invaluable to evaluators because without it, educators would have to rely on the previous year's test scores to pinpoint individual student deficiencies.

Policymakers would be wise to look at individual course data because virtual programs allow a comparative glimpse among teachers. In the brick and mortar environment, when the same course is taught by different teachers, it is difficult to measure how differences in teaching styles impact student achievement. However, in virtual programs, the course is the same, so true comparisons begin to emerge and areas of weakness become apparent. Stakeholders, such as district administrators would find it beneficial to allow professional development time through team teaching and peer coaching to help improve areas of weakness in the teaching staff. In addition, curriculum providers also could use this data to address remediation areas.

Real time data allows rapid evaluation of programs. It is important that policymakers know what data to collect and then how to interpret it to form best practices for virtual program implementation and use. 


\section{Message to Stakeholders}

This study has many implications to the stakeholders in the online community including school boards, school administrators, teachers, teacher unions, parents, community members, higher education, and, of course, students.

School boards and administrators are finding themselves at the fork in the road deciding which path to walk - the traditional or the online. I believe there is not a "one size fits all" model and that school officials should look at a variety of methodologies based upon student need. The master and deficiency areas of each student should be diagnosed and the best methodology should be prescribed.

Virtual programs are an educational choice, but should be used with transparency. All students and families should be aware of their availability, as well as understand how these programs remove geographic barriers and allow for content, that would otherwise not be available, to be reached.

Teacher's unions have much to gain from becoming more educated about the worth of virtual programs. Some, as shown from the principal's responses, believe virtual programs may eliminate the need of a classroom teacher. This belief could be both true and false. As previously mentioned, Ohio is a community school state. When disenfranchised families opt to send their students to a community school, thousands of dollars are removed from the local school district. When funds deplete, cuts are forced. Teachers, under this circumstance, become in jeopardy of losing their jobs. However, when school officials and teachers understand the power of virtual courses, and how they can actually be used as a marketing tool, teacher's jobs can be preserved because enrollment is intact. 
Teachers and unions need to become more informed on Ohio's funding system and understand that the door to educational choice continues to widen. First, through open enrollment to adjacent districts, and now to any district, more authority over their children's education is being realized by families. Teachers and unions have a choice as the paradigm is changing. They can buy into the idea of virtual programs and use them as a method to keep and recruit more students, or they can sit back and do nothing, thus watching the demise of their local school district and community. Teachers and unions need to become proactive and find ways to work with school officials to increase student interest and motivation. They cannot watch the open enrollment train roll by, taking students and funds out of the local school districts. When teachers and unions begin to truly understand this phenomenon, cohesiveness will begin to form and all school personnel can begin to work together to keep students educated locally.

Most parents' paramount concern is that their students receive a quality education. In Ohio, open enrollment has allowed parents to compare different school districts and decide which facility is right for their child. Virtual courses give a competitive edge to many school districts and community schools because they expand the breadth and depth of content that a student can be exposed to. Parents will serve their children well by becoming more educated on their educational rights and ensuring that the best methods are used to educate their children and their specific needs.

Parents should caution themselves, however, when judging their local school district too quickly or harshly because the effects of that will eventually be felt by their families and other community members. For example, when a family becomes disenfranchised with the local school district and opts to exercise their right to open 
enrollment into another school district, thousands of dollars are transferred out of that local school district. When this occurs too often, the local school district is forced to make cuts including teacher positions. When teacher positions are cut, these individuals are forced to look for employment out of that school district of residence. As community members move away in search of a new job, the local community suffers economically because the population is decreasing. As the population decreases, and the school districts become smaller, the attraction to that area is not as great to those who may be considering moving into the area. In addition, when a community begins to shrink, property values begin to decrease, thus bringing additional economic woes to the community and to the school. This scenario is what is actually happening in many Ohio communities today. It is not something that may happen, it is happening. Parents and other community members must realize the importance of ensuring their local school district succeeds in order to preserve the community for all. This may include supporting school levies, school activities, and community events for K-12 students; and donating time and resources to the school.

Higher education institutes also have a lot at stake with the direction of virtual programs in K-12 environments. Although higher education enrollment still outnumbers K-12 enrollment, it is a growing field. The data of this study showed that principals are not concerned with teacher training for virtual courses. As mentioned earlier, this is alarming because of the importance of the teacher role. Teacher professional development in the online environment is necessary to make ensure teachers possess the tools that will best educate online students. Too often, school officials believe if a teacher is good in the traditional classroom, they will be good in the online classroom. If 
this belief is apparent in most school districts, the regulations regarding teacher professional development may be too lax.

Higher education institutes have an obligation to society to closely examine their teacher preparation programs and ensure they are graduating teachers who know how to teach in this environment. Research shows that by $2019,50 \%$ of all courses will be online (US Department of Education, 2009 and Christensen, 2008). If this prediction even comes close to fruition, teachers need to be well prepared. This means that higher educational institutions need to create curricula that will expose potential teachers to the online learning environment, such as learning management systems, content management systems, social networking tools, online communications standards, and the requirements for creating a quality, online course. If teachers do not know how to use these tools, then students will be forced to make up their own rules. This system puts students in jeopardy of online predators because they are not prepared to avoid certain situations. The responsibility of student protection not only falls on the backs of the parents, but also relies heavily on the training they receive from their teachers. If teachers are not prepared to give this guidance, our youth become in jeopardy not only to online predators, but also to global competiveness.

Students are being exposed to so much digital information. The Internet has changed the lives of all Americans and has allowed geographic barriers to be eroded. Students can talk to other students in countries across the globe with a few clicks of a mouse. Information dissemination is almost immediate and students have the potential to be exposed to more content than any previous generation. Students today are in a world that is exciting, but frustrating all at the same time. According to Project Tomorrow 
(2009), students want to take online courses because they like to work at their own pace and they like the ability to take a class they could not take traditionally. The fact that students are seeking out additional coursework should prove to all stakeholders that we need to facilitate that desire by allowing access to students to take as many courses as they want. All too often, however, districts have a plethora of rules as to who is allowed to take virtual courses and who is not. This study showed that school administrators believe students lack motivation when taking online courses. A counterpoint may be that students are not permitted to take the courses they are interested in and are governed by policies of fear. When school administrators realize the value of exposing their students to a variety of instructional methods, I believe they will see their student's motivation increase because a feeling of autonomy will arise. Ohio has legislation, beginning with the 2010-2011 school year, that mandates school districts to provide credit flexibility options to all students. This system rewards students, with credit earning ability, for all educational experiences. It also allows students and families to dictate how they earn their credits. With out of the box thinking such as this credit flex policy, students will be allowed to tap into their own strengths and can show proficiency of content using a method other than a standardized test. It is through this type of flexibility, that all students can flourish according to their own areas of mastery.

\section{Summary}

The true question seems to surround the issue of virtual programs and their effect on the education system and student achievement. Students need to be prepared for a $21^{\text {st }}$ century workforce, which means exposure to concepts beyond the traditional math, science, social studies, and English is necessary if American students want to compete in a global market. Consider, two-thirds of jobs being created now require college or 
postsecondary technical education (Strong American Schools, n.d.), and $90 \%$ of the fastest growing jobs require a college degree (U.S. Department of Education, 2009). According to iNACOL (2009), online college prep, Advanced Placement, credit recovery, and dropout prevention programs ensure more American students are ready for college, however, $40 \%$ of the nation's high schools, particularly those who serve lowincome, minority and rural youth, do not offer Advanced Placement courses. Virtual programs can be the catalyst to diminish the digital divide that still exists in Appalachian Ohio regions. It is only through equal access that no child will truly be left behind. 


\section{References}

AdvancED. (2010). Accreditation standards. Retrieved from http://www.advanc-ed.org/

Alexander, J. \& Kroposki, M. (1999). Outcomes for community health nursing practice. Journal of Nursing Administration. 29, 49-56.

Allen, I. E. \& Seaman, J. (2006). Making the grade. Online education in the United States, 2006. The Sloan Consortium. Retrieved from www.sloan-c.com

Appalachian Regional Commission. (2009). History. Retrieved from www.arc.org

Augenblick, Palaich and Associates, Inc. (2006). Costs of funding of virtual schools. Retrieved from www.inacol.org/research/docs/costs\&funding.pdf

Beech, B. F. (1997). Studying the future: A Delphi survey of how multi-disciplinary clinical staff view the likely development of two community mental health centers over the course of the next two years. Journal of Advanced Nursing, 25, 331-338. doi:10.1046/j.1365-2648.1997.1997025331

Burns, F. M. (1998). Essential components of schizophrenia care: A Delphi approach. Acta Psychiatry Scand 98, 400-405.

Cavanaugh, C., Gillan, K. J., Kromrey, J., Hess, M., \& Blomeyer, R. (2004). The effects of distance education on K-12 student outcomes. A meta-analysis. Naperville, IL: Learning Point Associates.

Christensen, C., Horn, M. B. \& Johnson, C. (2008). Disrupting class. New York, New York: McGraw Hill.

Clark, T. (2001). Virtual schools. Retrieved from www.wested.org/online/pubs/virtualschools.pdf

Coalition of Rural and Appalachian Schools. (2009). Vital statistics for Appalachian Ohio school districts. Retrieved from http://www.coras.org/character.html

Crisp, J., Pelletier, D. Duffield, C., Adams, A. \& Nagy, S. (1997). The Delphi method? Nursing Research, 46, 116-118.

D’Orio, W. (2004). Open season. District Administrator. Retrieved from www.districtadministrator.com/viewarticle.aspx?articleid $=489 \& \mathrm{p}=1$

Duffield, C. (1993). The Delphi technique: a comparison of results obtained using two expert panels. International Journal of Nursing Studies, 30(3), 227-237. 
Evergreen Consulting Group. (2009). Keeping pace with K-12 online learning. Retrieved from www.kpk12.com

Goodman, C.M. (1987). The Delphi technique: a critique. Journal of Advanced Nursing. 12, 729-734. doi:10.1080/13611260500069947

Green, B., Jones, M., Hughes D. \& Williams, A. (1999). Applying the Delphi technique in a study of GP's information requirements. Health and Social Care in the Community, 7(3), 198-205.

Harlen, W., \& Doubler, S. (2004). Can teachers learn through enquiry online? Studying professional development in science delivered online and on-campus. International Journal of Science Education, 26(10), 1247-1267.

Hasson, F., Keeney, S. \& McKenna, H. (2000). Research guidelines for the Delphi survey technique. Journal of Advanced Nursing, 32(4), 1008-1015. doi:10.1046/j.1365-2648.2000.01567

Hiltz, S. R., \& Goldman, R. (2005). Learning together online: Research on asynchronous learning networks. Mahwah, New Jersey: Lawrence Erlbaum.

iNACOL. (2007). iNACOL national standards of quality for online courses. Available online www.inacol.org

iNACOL. (2009). iNACOL fast facts about online learning. Retrieved from www.inacol.org

iNACOL \& The Trujillo Commission. (2007). Every student's right to online learning opportunity. Retrieved from http://inacol.org/resources/docs/Trujillo CommissionOnlineEducationFinalReport-2-15-2007.pdf

Jaffe, R., Moir, E., Swanson E., \& Wheeler, G. (2006). eMentoring for student success: Online mentoring and professional development for new science teachers. In C. Dede (Eds.), Online professional development for teachers: Emerging models and methods (pp. 89-116). Cambridge, Mass.: Harvard Education Press.

Jerkins, D. \& Smith, T. (1994). Applying Delphi methodology in family therapy research. Contemporary Family Therapy, 16, 411-430.

Jefferson County Educational Service Center. (2009). Retrieved from www.virtuallearningacademy.net

Levy, Y. (2007). Comparing dropouts and persistence in e-learning courses. Computers \& Education, 48, 185-204. 
Loughlin, K. \& Moore, L. (1979). Using Delphi to achieve congruent objectives and activities in a pediatrics department. Journal of Medical Education, 54, 101-106.

Lowes, S. (2005). Online teaching and classroom change: the impact of virtual high school on its teachers and their schools. Naperville, IL: Learning Point Associates.

McKenna, H. P. (1994). The Delphi technique: a worthwhile approach for nursing? Journal of Advanced Nursing, 19, 1221-25. doi:10.1111/j.13652648.1994.tb01207

Moe, T. \& Chubb, J. (2009). Liberating learning: Technology, politics and the future of American education. Josey-Bass Publishing.

Ohio Department of Education. (2009). Ohio school district report card data. Retrieved from www.ode.state.oh.us

Online Learning Policy and Practice Survey: A survey of the states from Center for Digital Education. (2010). Retrieved from www.convergemag.com/paper/onlinelearning-2009.html

Park, J. (2007). Factors related to learner dropout in online learning. In F. M. Nafukho, T. H. Chermack, \& C. M. Graham (Eds.), Proceedings of the 2007 Academy of Human Resource Development Annual Conference (pp. 25.1-25.8). Indianapolis, IN: Academy of Human Resource Development.

Patton, M. Q. (1990). Qualitative evaluation and research methods. Newbury Park, CA: Sage.

Picciano, A. G., Seaman, J. (2007). K-12 online learning. A survey of U.S. school district administrators. Retrieved from http://www.sloanc.org/publications/survey/pdf/K-12_Online_Learning.pdf

Picciano, A. G., Seaman, J. (2009). K-12 online learning. A 2008 follow-up of the survey of U.S. school district administrators. Retrieved from http://www.sloanc.org/publications/survey/pdf/k-12_online_learning_2008.pdf

PSK12.com (2009). Ohio school rankings. Retrieved from http://www.psk12.com/rating/USindexphp/STATE_OH.html

Proctor, S. \& Hunt, M. (1994). Using the Delphi survey technique to develop a professional definition of nursing for analyzing nursing workload. Journal of Advanced Nursing, 19, 1003-1014. doi:10.1111/j1365-2648.1994.tb01180

Project Tomorrow. (2009). Learning in the $21^{\text {st }}$ century: 2009 trends update. Retrieved from www.tomorrow.org/speakup/learning21report_2009_update.html 
Riel, M., \& Polin, L. (2004). Online communities: Common ground and critical differences in designing technical environments. Designing for virtual communities in the service of learning. Cambridge, Mass.: Cambridge University Press.

Schmidt, R. C. (1997). Managing Delphi surveys using nonparametric statistical techniques. Decision Sciences, 28, 763-774.

Schwen, T. M., \& Hara, N. (2004). Community of practice: A metaphor for online design. In S. A. Barah, R. Kling, \& J. H. Gray (Eds.), Designing for virtual communities in the service of learning (pp. 154-78). Cambridge, U.K.: Cambridge University Press.

Smith, R., Clark, T., \& Blomeyer, R. (2005). A synthesis of new research on K-12 online learning. Retrieved from http://www.ncrel.org/tech/synthesis

SREB Educational Technology Cooperative. (2009). Guidelines for professional development of online teachers. Retrieved from http://publications.sreb.org/2009/09T01_Guide_profdev_online_teach.pdf

Strong American Schools. (n.d.) Retrieved from http://www.strongamericanschools.org/sas-says-facts

Sumsion, T. (1998). The Delphi technique: an adaptive research tool. British Journal of Occupational Therapy, 61(4), 153-156.

The Sloan Consortium. (2009). Retrieved from www.sloan-c.com

Tallent-Runnels, M., Thomas, J., Lan, W., Cooper, S., Ahern, T., Shaw, S., \& Liu, X. (2006). Teaching courses online: A review of the research. Review of Educational Research, 76, 93-135.

U.S. Department of Education. (2009). Evaluation of evidence-based practices in online learning: A meta-analysis and review of online learning studies. Retrieved from www.ed.gov/about/offices/list/opepd/ppss/reports.html

Van Dusen, C. (2009). Learning without limits. Retrieved from http://www.eschoolnews.com/news/top-news/?i=58076

Vrasidas, C., \& Glass, G. V. (2004). Teacher professional development: Issues and trends. In C. Vrasidas \& G. V. Glass (Eds.) Online professional development for teachers (pp. 1-12). Greenwich, Conn.: Information Age.

Watson, J. F., Winograd, K., \& Kalmon, S. (2004). Education evolution: The need to keep pace with development of K-12 online learning. Learning Point, 17, 1-15. 
Watson, J. (2005). Keeping pace with online learning. A review of state level policy and practice. Naperville, IL: Learning Point Associates/North Central Regional Educational Library.

Watson, J., Gemin, B., \& Ryan, J. (2008). Keeping pace with K-12 online learning. A review of state-level policy and practice. Retrieved from www.kpk12.com

Watson, J. Gemin, B., Ryan, J. \& Wicks, M. (2009). Keeping pace with K-12 online learning: A review of state-level policy and practice. Retrieved from www.kpk12.com/downloads/keepingpace09-fullreport.pdf

Weiner, C. (2003). Key ingredients to online learning: Adolescent students study in cyberspace. International Journal of eLearning, 2(3), 44-50. Norfolk, VA:AACE.

Williams, P. L. \& Webb, C. (1994). The Delphi technique: an adaptive research tool. British Journal of Occupational Therapy, 61(4), 153-156.

Wisconsin Legislative Reference Bureau. (2008). Legislative brief: virtual charter schools. Retrieved from www.legis.state.wi.us/irb/pubs/LB/081b6.pdf

Young, W. H. \& Hogben, D. (1978). An experimental study of the Delphi technique. Education Research Perspective, 5, 57-62. 
Appendix A

Permission-Figure Use

Re: permission to use a figure

John Watson[johnw@evergreenassoc.com]

To: wendy.hanasky

Cc:

Hi Wendy,

Yes, feel free to use that figure, but unfortunately I don't have an electronic copy. Actually to be honest I don't even remember that article!

John

From: wendy.hanasky <wendy.hanasky@omeresa.net>

To: johnw@evergreenassoc.com

Cc: wendy.hanasky <wendy.hanasky@omeresa.net>

Sent: Friday, July 31, 2009 8:23:48 AM

Subject: permission to use a figure

Hi John,

My name is Wendy Hanasky and I am a doctoral student at WVU. I have been reading a lot of your articles and I came across a figure that I would like to use in my prospectus. It is Figure 1 in the article Education Evolution: The need to keep pace with development of the K-12 Online Learning. Learning Point Associates. No. 17 Dec. 2004.

Would you allow me to use this figure? If so, do you have it in electronic form? If not, I could probably recreate it.

Thank you for your consideration.

Wendy Hanasky

Wendy Hanasky

Director of Technology Services

Jefferson County Educational Service Center

2023 Sunset Blvd.

Steubenville, $\mathrm{OH} 43952$

740-283-3347 - phone

740-282-1677 - fax 
Appendix B

Sloan Consortium Survey Instrument/Round 1 Survey

\section{Virtual Programs in Appalachian Ohio High Schools}

Questions 1-7 should be answered by all participants, regardless if your school district is using virtual programs or not.

1. Please complete the following demographic information.

Your name:

Name of school

district:

Address:

Address 2:

City/Town:

State:

zup/Postal Code:

County

Emall Address:

Phone Number:

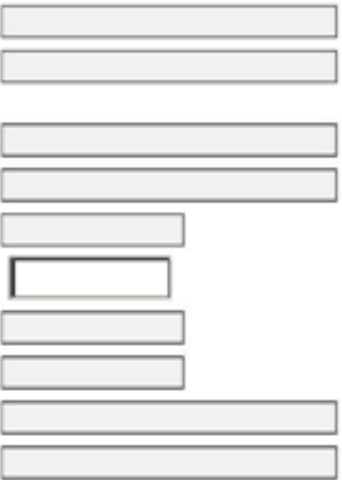

* 2 . What is your position in your school building?

Principal/Director

Assistant Principal

Teacher

Other (please specify)

* 3. If you chose "Principal/Director" for Question \#2, how long have you held that position?
Less than one year
Tone Year
$\square$ Two Years
$\square$ Three Years
$\square$ More than three years
$\square$ I am not a Principal/Director 
* 4. Did students in your district take any fully online or blended courses between July 1, 2008 and June 30, 2009?

Fully online courses. A course where most or all of the content is delivered online, typically has no face to face meetings Blended courses. A course that blends online and face to face delivery. Substantial proportion of the content is delivered online, sometimes uses online discussions, and typically has few face to face meetings.

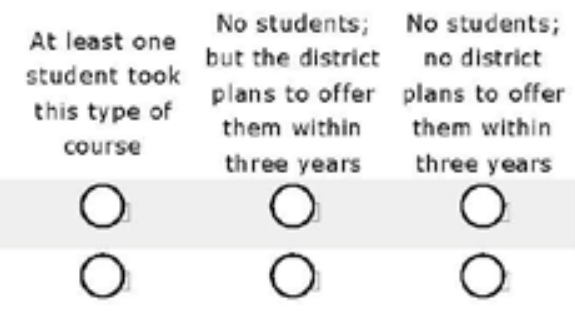

* 5 . How much of a barrier are the following areas to your district in offering fully online or blended learning courses?

Course development and/or purchasing costs.

Limited technological infrastructure to support distance education.

$\begin{array}{cccc}1 \text { Not at all } & \begin{array}{c}3 \\ \text { Somewhat } \\ \text { important }\end{array} & 4 & \begin{array}{c}5 \text { Very } \\ \text { important }\end{array}\end{array}$

Concerns about course quality.

Restrictive federal, state, or local laws or policies.

The need for teacher training.

Concerns about receiving funding based on student

attendance for online and/or blended education courses.
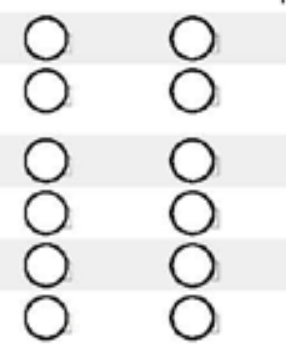

$\bigcirc$

$\bigcirc$

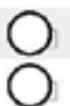

* 6 .

6. How important do you believe the following reasons are for a school district to offer online or blended learning courses?

Online and blended offerings are pedagogically more
beneficial.
Addressing growing populations and limited space.
Online and blended offerings are financially beneficial.
Students prefer online course activities.
Certified teachers are not available at the school.
Offering Advanced Placement or college-level courses.
Reducing scheduling conflicts for students.
Permitting students who failed a course to take it again.
(positive or negative) on any aspect on online and blended courses and
their potential for your district.




\section{Virtual Programs in Appalachian Ohio High Schools}

Questions 8-14 are for districts that offer online or blended courses. If you do not offer online or blended courses, please scroll to the bottom of the page and click the "Done" button. Thank you for participating.

* 8. In what school year did any student in your district first take a fully online or blended course?

\begin{tabular}{lc} 
School Year & School Year \\
\hline
\end{tabular}

* 9. Select the level (1-5) at which you disagree/agree with the following statements with regard to students in your district.

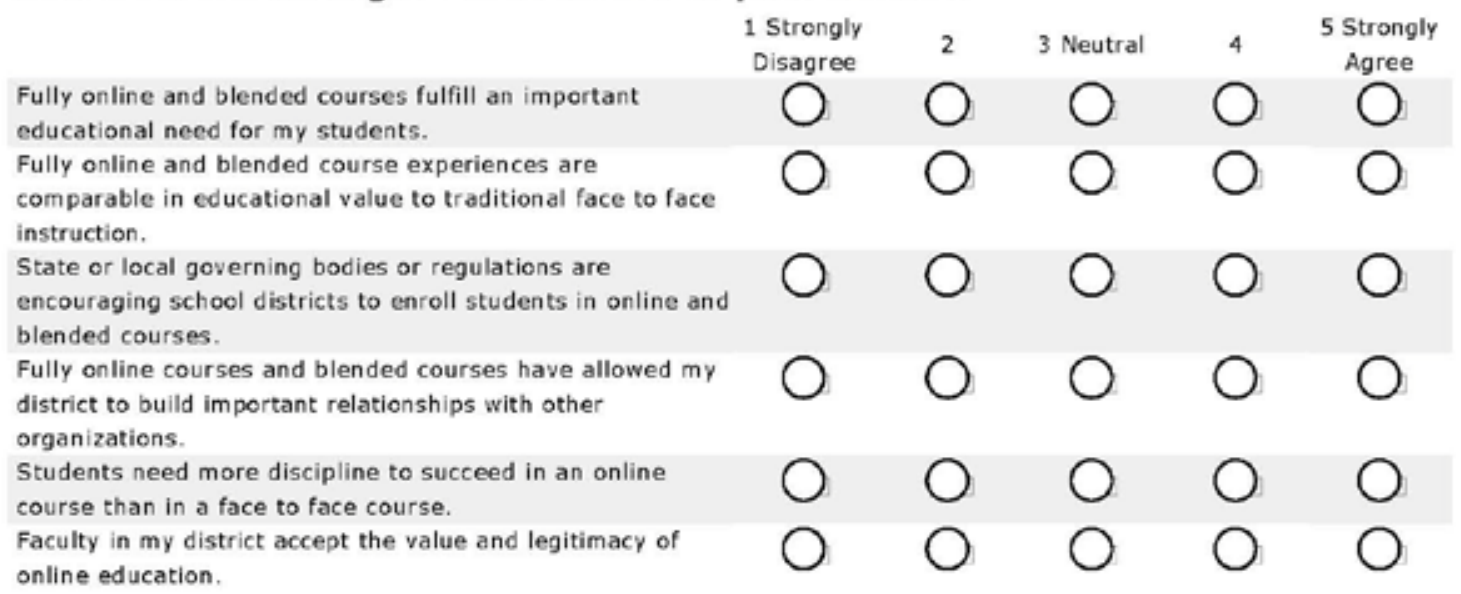

* 10. The nature of online or blended courses taken by students in my district (check all that apply):

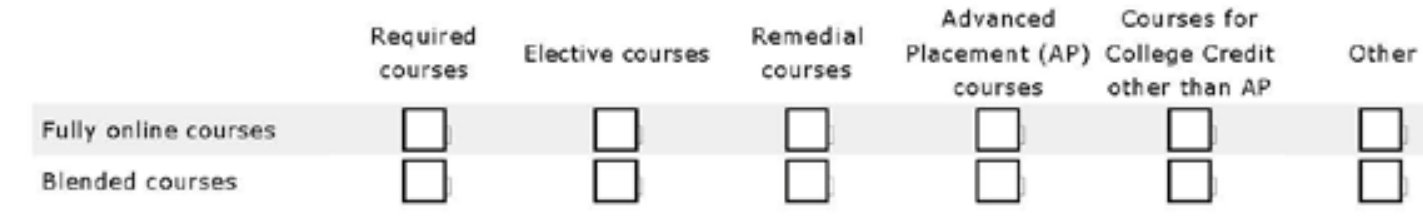

* 11. What is your best estimate of the number of student enrollments (a student enrolled in more than one course should be counted only once) between July 1, 2008 and June 30, 2009?

Number of students taking at least one fully online course
Grades K-5
Grades $6-8$
Grades $9-12$

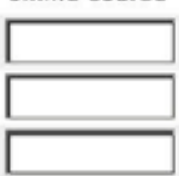

Number of students taking at least one blended course

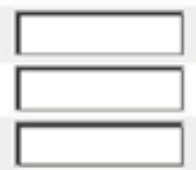


* 12. Over the next two years, my district expects fully online course enrollments to:

$\square$ Decrease.

$\square$ Stay about the same

$\square$ Grow by about __ percent (please specify).

-

* 13. Over the next two years, my district expects blended enrollments to:

Decrease.

$\square$ Stay about the same

$\square$ Grow by about __ percent (please specify)

* 14. The provider(s) for fully online and blended courses for my district are (check all that apply):

Your district (i.e., delivered centrally from the district)

Cyber (online) charter school in your district

Other schools in your district

Another local school district, or schools in another district, in your state

Education service agencies within your state, not including the state education agency or local school districts

State virtual school in your state

Districts or schools in other states (other than state virtual schools)

Postsecondary institution

Indepedent vendor

Other (please specify)

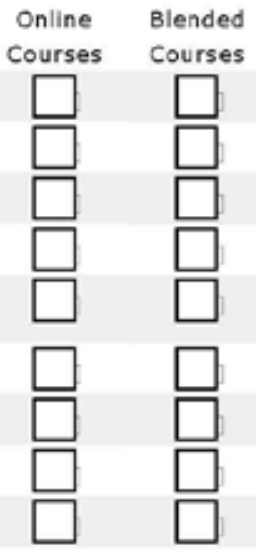

Thank you for participating in this survey. Please click the "Done" button below. 


\author{
Appendix C \\ Round 1 Survey - Initial Email to Population
}

Dear Appalachian Ohio High School Principals,

My name is Wendy Hanasky and I am a student at West Virginia University working towards my doctoral degree in Technology Education. I am working under the guidance of Dr. Terence C. Ahern, Associate Professor in the Department of Technology, Learning, and Culture and the college of Human Resources and Education.

I am completing my dissertation entitled Virtual Programs in Appalachian Ohio High Schools in which the primary objective of my research is to discover how Appalachian Ohio High Schools are using virtual programs within their district to supplement traditional course offerings. I believe the results of this study will aid current and future administrators when determining key policy issues and best practices within delivery models.

I am searching for participants to complete this short, 14 question survey estimated to take four-five minutes to complete. Would you please consider clicking on the link below and completing the survey? http://www.surveymonkey.com/s/N6MJSX7

If you complete this survey by 5:00 pm Friday and be entered to win a \$100 Visa Gift Card.

Please read the attached letter that outlines this study further.

I thank you in advance for your participation.

Wendy Hanasky 


\section{Appendix D}

Round 1 Survey - Initial Email Letter Attachment

TO: $\quad$ Principal

FROM: Wendy Hanasky

DATE: $\quad$ December 1, 2009

RE: $\quad$ Participation in research project
Use the link below to access the survey. Come on, it only takes 4-5 minutes!!!! http://www.surveymonkey.com/s/N6MJSX7

***Complete the survey by 5:00 pm Friday and be entered to win a $\$ 100$ Visa Gift Card!

My name is Wendy Hanasky and I am a student at West Virginia University working towards my doctoral degree in Technology Education. I am working under the guidance of Dr. Terence C. Ahern, Associate Professor in the Department of Technology, Learning, and Culture and the college of Human Resources and Education.

I am completing my dissertation entitled Virtual Programs in Appalachian Ohio High Schools in which the primary objective of my research is to discover how Appalachian Ohio High Schools are using virtual programs within their district to supplement traditional course offerings. I believe the results of this study will aid current and future administrators when determining key policy issues and best practices within delivery models.

I am using the Delphi Model research technique, which is a systematic, interactive method for data gathering that uses a winnowing approach based on an initial survey. This initial survey has been sent to all high school principals within the designated Appalachian region of Ohio. I am searching for participants to complete this short, 14 question survey estimated to take four-five minutes to complete. Would you please consider clicking on the link below and completing the survey? http://www.surveymonkey.com/s/N6MJSX7

For this study, two-rounds of surveys and a follow-up focus group interview will be used. The first round responses will be analyzed in order to select the sample for the second round, therefore you may be asked to participate in the second round survey. The second round will provide an anonymous summary of the responses from the previous round as well as the reasons the subjects provided their judgments. The second round participants will be encouraged to revise their earlier answers in light of the replies from the other participants. Additionally, irrelevant questions will be dropped from the second round survey. The second round of participants will form the selection pool from which a representative sample will be chosen for a focus group follow-up interview. The questions for the focus group follow-up interview will be taken from the same set of questions in the original questionnaire. These interviews will last approximately 45 minutes.

The following points are listed for your understanding of the process. 
- You must be 18 years of age or older to participate.

- Your participation is entirely voluntary. You can choose to withdraw your participation at any time.

- Your responses will be kept as confidential as legally possible. Your name will be erased once your responses are recorded. At no time will your name be revealed during reporting.

- The focus group interview will be recorded electronically using a technology named Go To Meeting. After the data is coded and analyzed, the audio files will be destroyed.

- West Virginia University's Institutional Review Board acknowledgment of this project is on file.

Thank you in advance for your cooperation and participation. Please feel free to contact me if you have any questions or if you are interested in receiving a copy of my final research project.

Wendy Hanasky

Wendy.hanasky@omeresa.net

740-391-0325

Use the link below to access the survey.

Come on, it only takes 4-5 minutes!!!!

http://www.surveymonkey.com/s/N6MJSX7

Complete the survey by 5:00 pm Friday and be entered to win a $\$ 100$ Visa Gift Card! 


\title{
Appendix E
}

\author{
Round 1 Survey - Initial Email Attachment, CORAS Support Letter
}

\section{COALITION OF RURAL AND APPALACHIAN SCHOOLS}

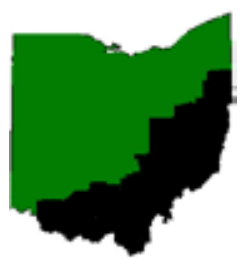

313E McCracken Hall

Ohio University

Athens, Ohio 45701

(740) $593-4414$

rfishe5@columbus.rr.com

TO: $\quad$ High School Principals in Ohio's Appalachian Region

FROM: Dick Fisher, Executive Director, Coalition of Rural and Appalachian

Schools

DATE: $\quad$ November 24, 2009

RE: $\quad$ Participation in a survey

The Coalition of Rural and Appalachian Schools is requesting your participation to complete a survey entitled "Virtual Programs and their impact on Appalachian Ohio High Schools" being conducted by Wendy Hanasky, Director of Technology Services at the Jefferson County Educational Service Center. This 5-minute survey invites participants to share their opinions about virtual programs and how they can be used within school districts. The primary objective of this research is to discover how Appalachian Ohio High Schools are using virtual programs to supplement traditional course offerings. The results of the study will aid current and future administrators when determining key policy issues and best practices within their delivery models.

The Coalition of Rural and Appalachian Schools does not endorse a specific online learning approach or provider. However, we do support the collection of data that can be used as a planning tool that may ultimately assist schools in selecting among the various online learning alternatives.

Your efforts to improve the lives of children, and your support for public education in Appalachian Ohio school districts, are truly appreciated. Thank you for assisting with this survey. 


\section{Appendix F \\ Round 1 Survey - Second Request Email}

Dear Appalachian Ohio High School Principals,

Please consider responding to my short, 14-question survey that will only take 4-5 minutes to complete. If you complete the survey before 5:00 pm Friday, you will be registered to win a $\$ 100$ Visa Gift Card.

Thank you in advance for your cooperation.

Wendy Hanasky 


\section{Appendix G}

\section{Round 1 Survey - Thank You Email}

Dear Appalachian Ohio High School Principals,

Thank you for your participation in my research study, entitled "Virtual Programs in Appalachian Ohio High Schools". I am happy to announce Kristin Baird from Felicity School District as the winner of the $\$ 100$ Visa Gift Card.

Thanks again to each of you.

Wendy Hanasky 


\title{
Appendix H
}

\author{
Round 2 Survey - Initial Email to Population
}

Dear Principal/Director:

I am writing again asking for your participation in the Second Round Survey of my Virtual Programs and Appalachian Ohio High Schools research project. As explained earlier, I am using the Delphi Method of data gathering which is a winnowing approach based on the results of an initial survey.

As you may recall, the first round survey was sent the beginning of December. I have since analyzed the results and have attached them to this email as an Excel document. I am asking that you review the results of the previous survey and then click on the following link http://www.surveymonkey.com/s/BYMPGRD to participate in the Second Round Survey. I am encouraging each of you to revise your answers in light of the other participants' responses.

In summary,

1. Please open the Excel attachment and review the results of each Round 1 Survey Question. The tabs at the bottom of the workbook are entitled "Q1 for Question 1; Q2 for Question 2; etc.

(You may want to keep this document open as you complete the Round 2 Survey so that you have the results at your fingertips.)

2. Click on the following link http://www.surveymonkey.com/s/BYMPGRD to access the Round 2 Survey. For each question in the Round 2 Survey, I have provided the Number 1 and Number 2 most common responses from the Round 1 Survey.

Again, I encourage you to review and revise any answer that you see necessary in light of the previous survey results.

As promised, your participation will register you for another $\$ 100$ Visa Gift Card if you submit your survey by Tuesday, January 19, 2010 at 5:00 p.m. The number of participants receiving this invitation to participate in the Second Round Survey is narrowed from the initial pool of participants, so your chances of winning are greater this time!!!

Please feel free to contact me if you have any questions/concerns/problems with the survey.

I know that each of you are busy, especially this time of year, and I thank you in advance for your participation. Wendy Hanasky 
Appendix I

Round 2 Survey - Survey

\section{Virtual Programs in Appalachian Ohio High Schools Survey \#2}

\section{Virtual Programs in Appalachian Ohio High Schools}

Please read each question carefully before answering.

1. Please complete the following demographic information.

Your name:

Name of school

district:

Address:

Address 2:

City/Town:

State:

ZIP/Postal Code:

County

Email Address:

Phone Number:

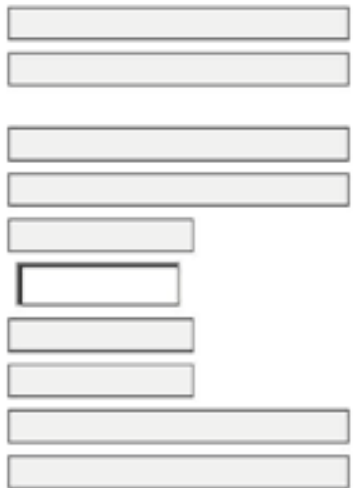

* 2. What is your position in your school building?

Results from previous survey (top two):

Principals - 92\%

Other - 7\%

$\triangle$ Principal/Director

Assistant Principal

$\square$ Teacher

$\square$ other (please specify) 


\section{Virtual Programs in Appalachian Ohio High Schools Survey \#2}

* 3 . If you chose "Principal/Director" for Question \#2, how long have you held that position?

Results from previous survey (top two):

Over 3 years $-61 \%$

2 Years - 12\%

$\square$ Less than one year

$\square$ One Year

Two Years

Three Years

More than three years

I am not a Principal/Director

* 4. Did students in your district take any fully online or blended courses between July 1, 2008 and June 30, 2009?

Results from previous survey (top two): At least one student took a fully online course - $77 \%$ At least one student took a blended course - $49 \%$

Fully online courses. A course where most or all of the content is delivered online, typically has no face to face meetings.

Blended courses. A course that blends online and face to face delivery.

Substantial proportion of the content is delivered online, sometimes

uses online discussions, and typically has few face to face meetings.

At least one student took this type of course

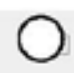
$\bigcirc$
No students; No students: but the district no district plans to offer plans to offer them within them within three years

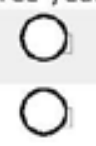
ree years 


\section{Virtual Programs in Appalachian Ohio High Schools Survey \#2}

* $\mathbf{5}$. How much of a barrier are the following areas to your district in offering fully online or blended learning courses?

Results from previous survey (top two):

Most Important:

Concerns about course quality $-37 \%$

Concerns about cost - $\mathbf{3 4 \%}$

Least Important:

Federal/State/Local Laws \& Policies - 34\%

Limited Technology Infrastructure - 33\%

\footnotetext{
Course development and/or purchasing costs.

Limited technological infrastructure to support distance education.

Concerns about course quality.

Restrictive federal, state, or local laws or policies.

The need for teacher training.

Concerns about receiving funding based on student

attendance for online and/or blended education courses.
}

1 Not at all important
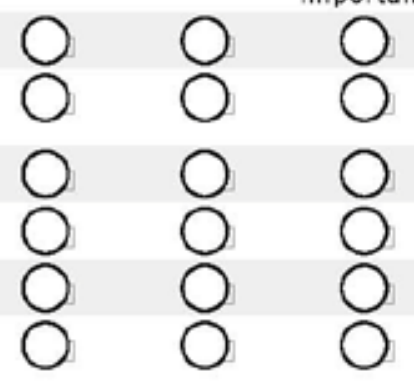


\section{Virtual Programs in Appalachian Ohio High Schools Survey \#2}

* 6. How important do you believe the following reasons are for a school district to offer online or blended learning courses?

Results from previous survey (top two):

Most Important:

Meeting the needs of a certain group of students - $53 \%$

Permitting students who failed a course to take it again-53\%

\section{Least Important:}

Addressing growing populations and limited space - $\mathbf{2 5} \%$

Certified teachers not available at the school - $\mathbf{2 5} \%$

Online and blended offerings are pedagogically more
beneficial.
Addressing growing populations and limited space.
Online and blended offerings are financially beneficial.
Oftudents prefer online course activities.
Meeting the needs of specific groups of students.
Peducing scheduling conflicts for students.

* 7. You will find the previous survey responses attached to the email that was sent to you. (They are included in the Excel spreadsheet as "Q7" located at the bottom of the worksheet.) Please carefully read through those responses and add any additional opinions you have regarding virtual programs (positive or negative). Did reading the other participant's responses change your view?

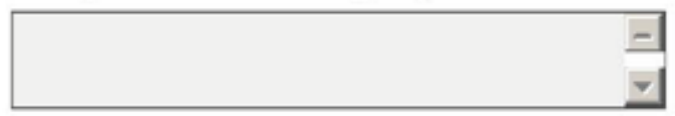




\section{Virtual Programs in Appalachian Ohio High Schools Survey \#2 \\ 2. Virtual Programs in Appalachian Ohio High Schools}

Please read each question carefully before answering.

* 8. In what school year did any student in your district first take a fully online or blended course?

Results from previous survey:

Before 2005 - 51\%

2008-2009 - 18\%

School Year

School Year 


\section{Virtual Programs in Appalachian Ohio High Schools Survey \#2}

* 9. Select the level (1-5) at which you disagree/agree with the following statements with regard to students in your district.

Results from previous survey (top two):

Strongly Agree:

Students need more discipline to succeed in online courses-42\%

Agree:

Fully online and blended courses fulfill an important educational role $-52 \%$

\section{Strongly Disagree:}

Fully online and blended course experiences are comparable in educational value - $29 \%$

Disagree:

Fully online courses and blended courses have allowed my district to build relationships with other organizations - $33 \%$

Fully online and blended courses fulfill an important educational need for my students.

1 Strongly

Fully online and blended course experiences are

comparable in educational value to traditional face to face instruction.

State or local governing bodies or regulations are encouraging school districts to enroll students in online and blended courses.

Fully online courses and blended courses have allowed my district to build important relationships with other organizations.

Students need more discipline to succeed in an online course than in a face to face course.

Faculty in my district accept the value and legitimacy of online education.

Disagree
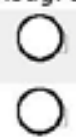

2

0

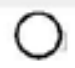

3 Neutral

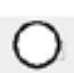

0
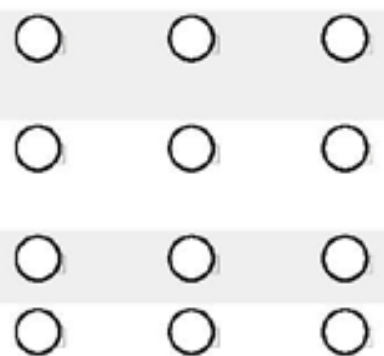

0
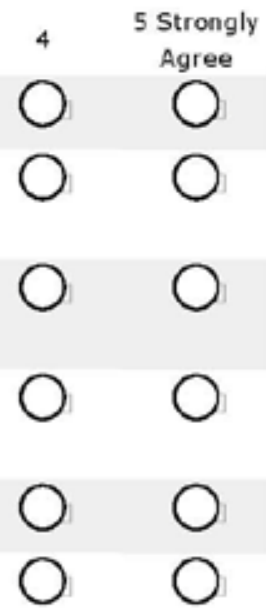


\section{Virtual Programs in Appalachian Ohio High Schools Survey \#2}

* 10. The nature of online or blended courses taken by students in my district (check all that apply):

Results from previous survey (top two):

Fully online courses - Remedial courses - $76 \%$

Fully online courses - Required courses - $70 \%$

Blended courses - Elective courses - $64 \%$

Blended courses - Required courses - $61 \%$

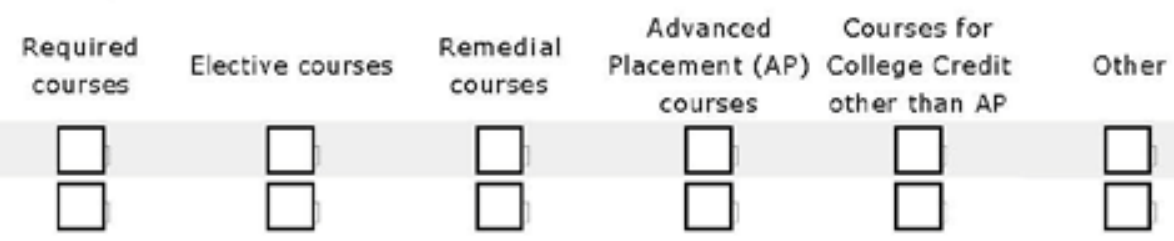

Fully online courses

Blended courses

* 11. What is your best estimate of the number of student enroliments (a student enrolled in more than one course should be counted only once) between July 1, 2008 and June 30, 2009?

Results from previous survey:

K-5 Fully online courses - 0 - 91\%

6-8 Fully online courses - 0 - 57\%

9-12 Fully online courses - 1-10 - 35\%

K-5 Blended Courses - 0 - 94\%

6-8 Blended Courses - 0 - 79\%

9-12 Blended Courses - 0 - 61\%

Number of students taking at least one fully online course

Grades K-5

Grades 6-8

Grades 9-12

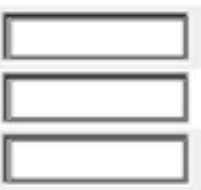

Number of students taking at least one blended course

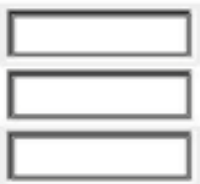




\section{Virtual Programs in Appalachian Ohio High Schools Survey \#2}

* 12. Over the next two years, my district expects fully online course enroliments to:

Results from previous survey:

Stay about the same $-76 \%$ Grow by __ \% - 24\% (Please reference the email attachment to see the specific percents that were listed on the previous survey).

$\square$ Decrease.

Stay about the same. percent (please specify).

* 13. What factors need to be in place to allow growth of fully online courses within your district?

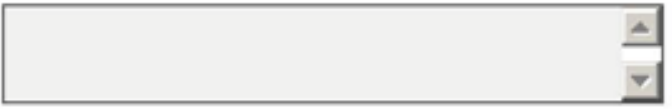

* 14. Over the next two years, my district expects blended enrollments to:

Results from previous survey:

Stay about the same $-78 \%$ Grow by _ $\%-22 \%$ (Please reference the email attachment to see the specific percents that were listed on the previous survey).

$\square$ Decrease.

Stay about the same.

Grow by about percent (please specify).

* 15. What factors need to be in place to allow growth of blended courses within your district?

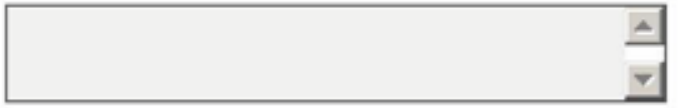




\section{Virtual Programs in Appalachian Ohio High Schools Survey \#2}

* 16. The provider(s) for fully online and blended courses for my district are (check all that apply):

\section{Results from previous survey: \\ Fully online - Educational Service Agencies - 60\% \\ Fully online - Independent Vendors - $42 \%$ \\ Blended - Educational Service Agencies - 18\% \\ Blended - Independent Vendors - 13\%}

Your district (i.e., delivered centrally from the district)

Cyber (online) charter school in your district

Other schools in your district

Another local school district, or schools in another district, in your state

Education service agencies within your state, not including the state education agency or local school districts

State virtual school in your state

Districts or schcols in other states (other than state virtual schools)

Postsecondary institution

Indepedent vendor

Other (please specify)

Thank you for participating in this survey. Please click the "Done" button below.

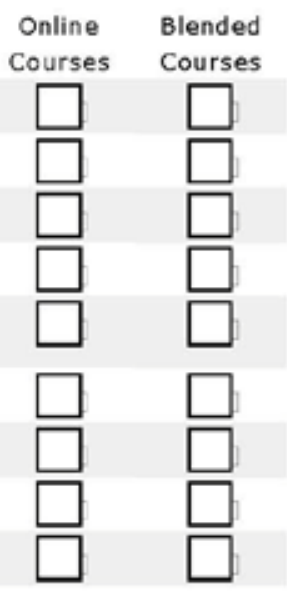




\section{Appendix J}

$$
\text { Round } 2 \text { Survey - Second Request Email }
$$

Dear Principal/Director:

This email is a second request to complete a survey entitled, "Virtual Programs in Appalachian Ohio High Schools". This is a follow up survey to the one you completed the beginning of December. I am asking that you use the link below to participate. http://www.surveymonkey.com/s/BYMPGRD

IF YOU COMPLETE THE SURVEY BY TUESDAY, JANUARY 19 AT 5:00 P.M. YOU WILL BE REGISTERED FOR A \$100 VISA GIFT CARD!!!!!!!!!

Please consider spending approximately 8 minutes to participate in this survey.

Thank you, Wendy Hanasky

PS The original email sent last Thursday is below for your reference. Please read it before you complete the survey.

PSS If you have already completed the survey, thank you!!!! 


\author{
Appendix K \\ Round 2 Survey - Third Request Email
}

$1 / 19 / 10$

SURVEY 2

THIRD REQUEST

Dear Principal/Director:

At this point, if you think I am desperate for your participation....you are right!!!!!

Complete the survey by 5:00 pm today and you will be registered for a $\$ 100$ gift card!!!!

Please consider completing the survey entitled, "Virtual Programs in Appalachian Ohio High Schools". This is a follow up survey to the one you completed the beginning of December. I am asking that you use the link below to participate.

http://www.surveymonkey.com/s/BYMPGRD

IF YOU COMPLETE THE SURVEY BY TUESDAY, JANUARY 19 AT 5:00 P.M. YOU WILL BE REGISTERED FOR A \$100 VISA GIFT CARD!!!!!!!!!

Please consider spending approximately 8 minutes to participate in this survey.

Thank you,

Wendy Hanasky

PS The original email sent last Thursday is below for your reference. Please read it before you complete the survey. 
Appendix L

\section{Round 2 Survey - Thank You Email}

All,

Please accept my dearest appreciation for your participation in my research study.

I am happy to announce that John Crowder from Newton Falls, Ohio was the winner of the $\$ 100$ Visa Gift Card.

Again, thank you to each of you!

Wendy Hanasky

Wendy Hanasky

Director of Technology Services

Jefferson County Educational Service Center

2023 Sunset Blvd.

Steubenville, $\mathrm{OH} 43952$

740-283-3347 - phone

740-282-1677 - fax 


\author{
Appendix M \\ Interview - Initial Email to Population
}

Dear Principals,

I owe a debt of gratitude to each of you for your participation in both rounds of my survey entitled, "Virtual Programs and Appalachian Ohio High Schools". Your participation has allowed me to gather insightful data on your opinions and use of virtual programs in your district.

I am in the final stage of data gathering, the interview, and need your help one last time. Out of the original population of 215 participants, I have narrowed the field to 7 . You are one of the seven who met my pre-determined interviewee criteria.

1. School district is currently using virtual programs

2. Interviewee is a Principal and has had that role for three or more years.

3. Have at least 10 students enrolled in a virtual program.

I would like to invite you to an interview in which we will discuss:

1. The implementation of virtual programs in your school district

2. The policies that govern your virtual program.

3 . The best practice models in place regarding your virtual programs.

4. The barriers that impede your use/implantation of virtual programs.

5. The student population that enrolls in virtual programs in your school district.

6. The reasons your district uses virtual programs.

7. Your overall feelings regarding virtual programs.

I estimate the interview will last approximately 30-45 minutes.

I understand that each of you are extremely busy, so I would like to use

Gotomeeting.com to facilitate this interview. If you haven't used this technology before, you simply login to a website and you will be able to see my presentation as we conduct the interview. You will also phone a conference call number that will allow the eight of us (the seven interviewees + myself) to talk to each other.

Again, because you are all so busy, I would like to add an incentive. Each of you will be registered to win one of two $\$ 100$ Visa Gift Cards. Your odds are better than 50\% with only having a population of seven people!!! (If less than five people participate, only one $\$ 100$ Visa gift card will be given.)

Please consider participating once more. I would like to schedule this interview next Thursday, February 4, 2010 at 10:00 am. Can you please respond to this email and let me know if you are available so that I can send you the link for gotomeeting.com?

Again, thank you for your participation and I hope to hear from you. 


\section{Appendix N \\ Interview - Individual Email}

I hadn't heard from you so I am assuming your schedule is busy on Thursday.

I was wondering if you would consider having a one-on-one interview with me using gotomeeting.com. You wouldn't have to leave your desk and I estimate it will only take 15-20 minutes.

I can work with your schedule. Just let me know what time/date would work for you. Please! Please!

Thank you, Wendy Hanasky 


\section{Appendix O \\ Interview - Email with Interview Questions Email Attachment}

Hi John,

Attached are the questions we will use for our interview today.

Thanks again for agreeing to participate.

I'll call you at 10:00 a.m.

Wendy 


\section{Appendix P \\ Interview - Interview Questions}

What barriers impede your use of virtual programs in your school district and what factors would facilitate growth of these programs?

Do the lack of resources impede the use of virtual programs in Appalachian Ohio High Schools?

Break down each barriers

Does the lack of

Does socioeconomic status impede using NCLB

Turn it into a null hypothesis

Does the lack of teacher training impede the use of

RQ1 In Appalachian Ohio, which high schools are using virtual programs to supplement traditional course offerings?

RQ2 In Appalachian Ohio, what types of virtual programs are being used to supplement traditional course offerings?

RQ3 In Appalachian Ohio, what best practices are used to determine whether to enroll a student in a virtual course, be it one course or a full schedule of courses?

Interview Questions

1. How much of a barrier are the following areas to your district in offering fully online or blended learning courses?

a. Course development and/or purchasing costs

b. Concerns about course quality

c. Need for teacher training

d. Concerns about receiving funding based on student attendance for online/blended courses

2. This question is in regards to BARRIERS that impede your district's implementation of virtual programs. Please rank the following four items as Barrier \#1 or \#2 or \#3 or \#4 in order of their importance. \#1 is the highest and \#4 is the lowest.

a. Course development and/or purchasing costs

b. Concerns about course quality

c. Need for teacher training

d. Concerns about receiving funding based on student attendance for online/blended courses 
3. How important do you believe the following reasons are for a school district to offer online or blended learning courses?

a. Online and blended offerings are financially beneficial

b. Students prefer online course activities

c. Offering Advanced Placement or college-level courses.

d. Meeting the needs of specific groups of students

e. Reducing scheduling conflicts for students

f. Permitting students who failed a course to take it again

4. This question is in regards to REASONS YOUR DISTRICT OFFERS VIRTUAL PROGRAMS. Please rank the following six reasons as \#1 or \#2 or \#3 or \#4 or \#5 or \#6 in order of their importance. \#1 is the highest and \#6 is the lowest.

a. Online and blended offerings are financially beneficial

b. Students prefer online course activities

c. Offering Advanced Placement or college-level courses.

d. Meeting the needs of specific groups of students

e. Reducing scheduling conflicts for students

f. Permitting students who failed a course to take it again

5. In the previous survey, question \#7 read, "I am interested in your opinions. Please let me know your thoughts (positive or negative) on any aspect of online and blended courses and their potential for your district." After review of all participant's comments, two common themes arose. The first theme surrounded the use of virtual programs as an alternative.

a. ALTERNATIVE (Methodology) - Virtual programs can be used as an alternate methodology to educate students in a 21 st century workforce

b. ALTERNATIVE (Diverse Needs) - Virtual programs can be used to meet the diverse needs of students and the school district.

c. ALTERNATIVE (Credit Reclamation) - Virtual programs can be used for students who are credit deficient.

6. Please rank the following three items as \#1 or \#2 or \#3 in order of their importance. \#1 is the highest and \#3 is the lowest.

a. ALTERNATIVE (Methodology) - Virtual programs can be used as an alternate methodology to educate students in a 21 st century workforce

b. ALTERNATIVE (Diverse Needs) - Virtual programs can be used to meet the diverse needs of students and the school district.

c. ALTERNATIVE (Credit Reclamation) - Virtual programs can be used for students who are credit deficient.

7. In the previous survey, question \#7 read, "I am interested in your opinions. Please let me know your thoughts (positive or negative) on any aspect of online and blended courses and their potential for your district." After review of all participant's comments, two common themes arose. The second theme surrounded the apprehensions of virtual programs use. 
a. APPREHENSIONS (Motivation) - Students must have self-motivation in order to succeed

b. APPREHENSIONS (Quality) - Quality of course content and/or program must be ensured

c. APPREHENSIONS (Cost) - Cost of implementing virtual courses/cost of students withdrawing to enroll in other electronic schools prohibit our district from offering virtual programs

d. APPREHENSIONS (Elimination) - Elimination of teachers because of virtual programs is a cause for concern in our district.

e. APPREHENSIONS (Accountability) - Virtual program students/system must be accountable for the success of its programs

8. Please rank the following five items as $\# 1$ or $\# 2$ or $\# 3$ or $\# 4$ or $\# 5$ in order of their importance. $\# 1$ is the highest and $\# 5$ is the lowest.

a. APPREHENSIONS (Motivation) - Students must have self-motivation in order to succeed

b. APPREHENSIONS (Quality) - Quality of course content and/or program must be ensured

c. APPREHENSIONS (Cost) - Cost of implementing virtual courses/cost of students withdrawing to enroll in other electronic schools prohibit our district from offering virtual programs

d. APPREHENSIONS (Elimination) - Elimination of teachers because of virtual programs is a cause for concern in our district.

e. APPREHENSIONS (Accountability) - Virtual program students/system must be accountable for the success of its programs

9. In what school year did any student in your district first take a fully online or blended course? Results from previous survey:
a. Before 2005
b. $2005-2006$
c. $2006-2007$
d. $2007-2008$
e. 2008-2009

10. Select the level (1-5) at which you disagree/agree with the following statements with regard to students in your district

a. Fully online and blended courses fulfill an important educational need for my students

b. Fully online and blended course experiences are comparable in educational value to traditional face to face instruction.

c. Students need more discipline to succeed in an online course than in a face to face course.

d. Faculty in my district accepts the value and legitimacy of online education. 
11. The nature of online or blended courses taken by students in my district (check all that apply):
a. Required courses
b. Elective courses
c. Remedial courses
d. Ap courses
e. College credit courses, other than ap
f. Other

12. What factors need to be in place to allow growth of fully online courses within your district?

13. What factors need to be in place to allow growth of blended courses within your district? 


\section{Appendix Q}

\section{Round 1 Survey Questions}

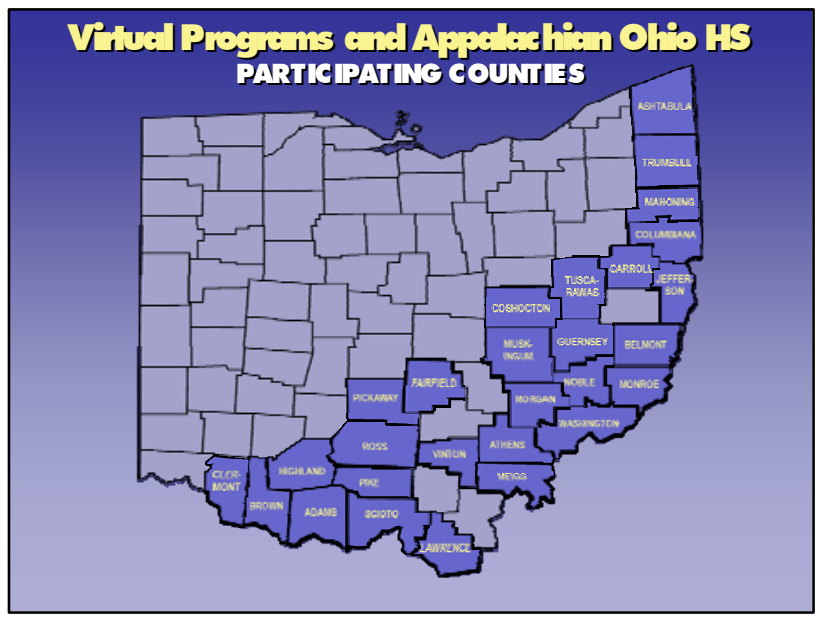

Figure Q1. Participating Counties

Table Q2

Position of Participants

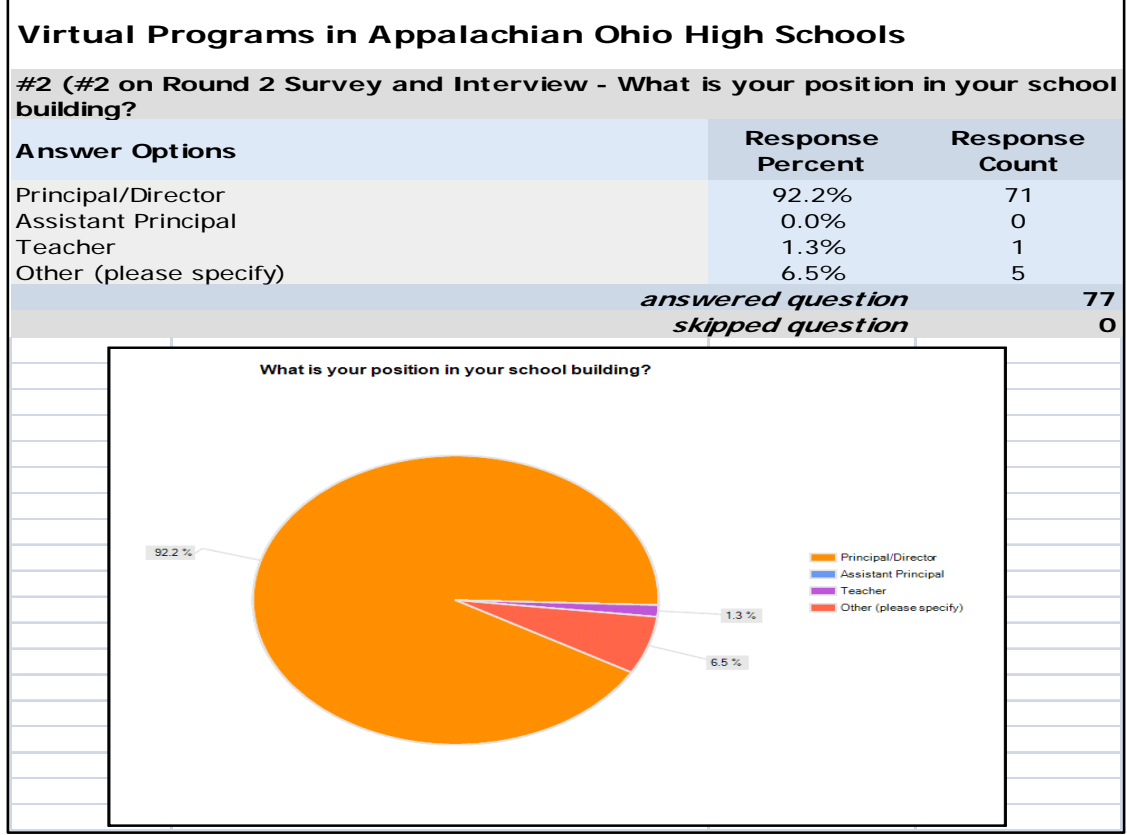


Table Q3

Length of Position

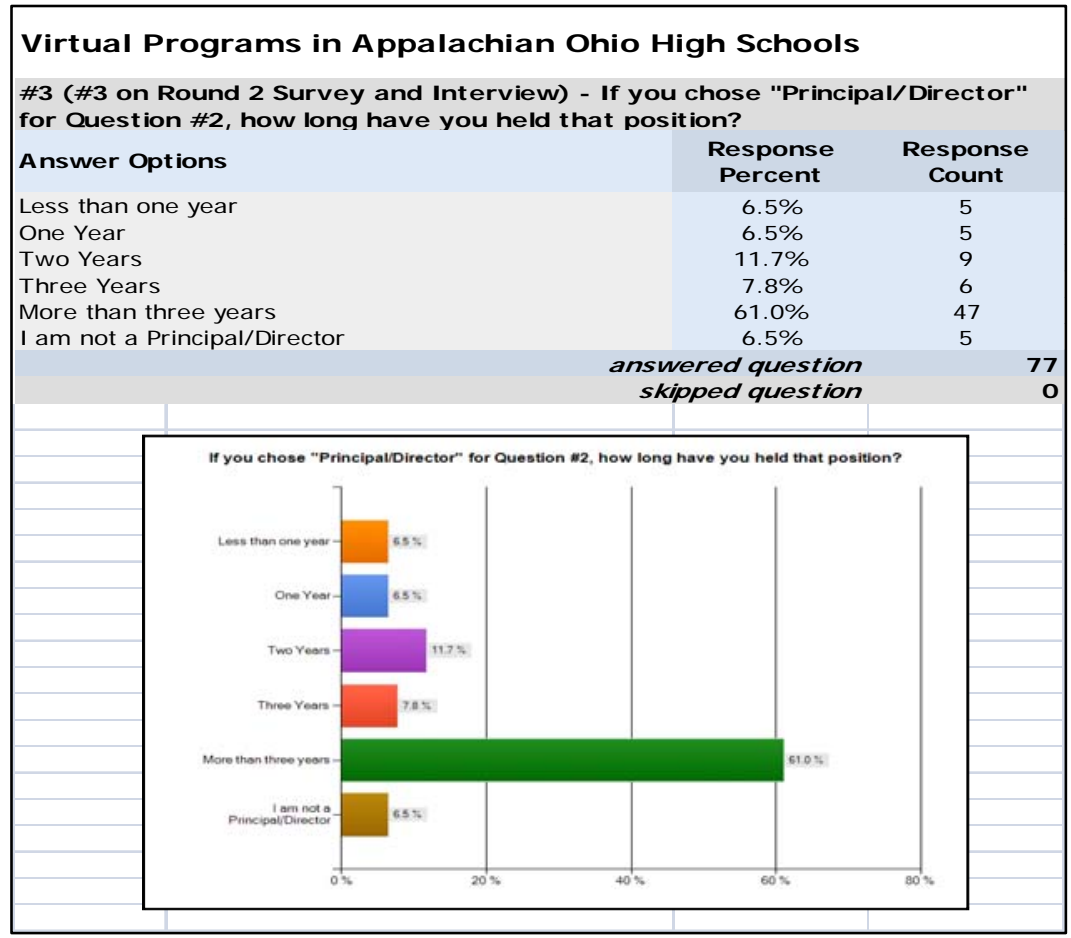

Table Q4

Virtual Program Enrollment

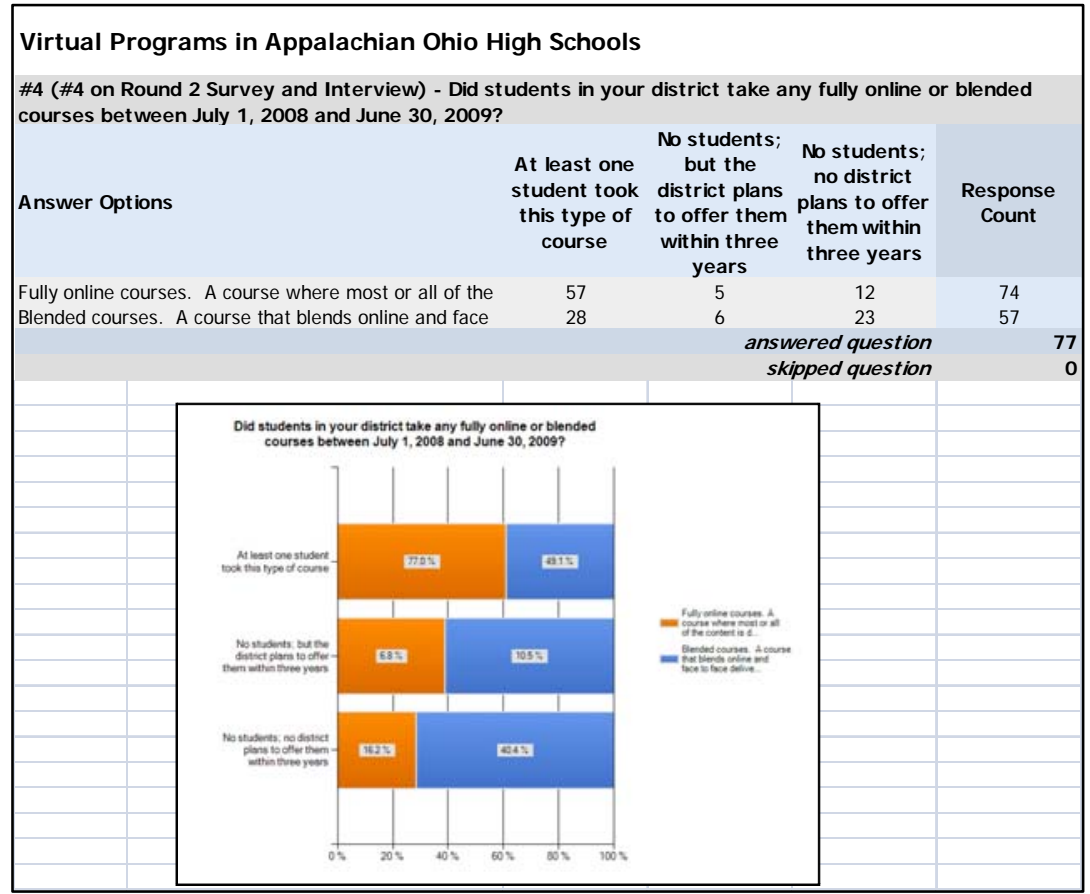


Table Q5

School Year of First Enrollment

\begin{tabular}{|c|c|c|c|c|c|c|}
\hline \multicolumn{7}{|c|}{ Virtual Programs in Appalachian Ohio High Schools } \\
\hline \multicolumn{7}{|c|}{ \#8 (\#13 on Round 2 Survey and Interview) In what school year did any student in your district first take a fully online or blended course? } \\
\hline \multicolumn{7}{|l|}{ School Year } \\
\hline Answer Options & Before 2005 & 2005-2006 & 2006-2007 & 2007-2008 & 2008-2009 & $\begin{array}{l}\text { Response } \\
\text { Count }\end{array}$ \\
\hline \multirow[t]{3}{*}{ School Year } & 28 & 8 & 6 & 3 & 10 & 55 \\
\hline & & & & & & $\begin{array}{c}\text { Question } \\
\text { Totals }\end{array}$ \\
\hline & & & & \multicolumn{2}{|c|}{$\begin{array}{l}\text { answered question } \\
\text { skipped question }\end{array}$} & $\begin{array}{l}55 \\
22\end{array}$ \\
\hline
\end{tabular}

\section{Table Q6}

Virtual Program Barriers

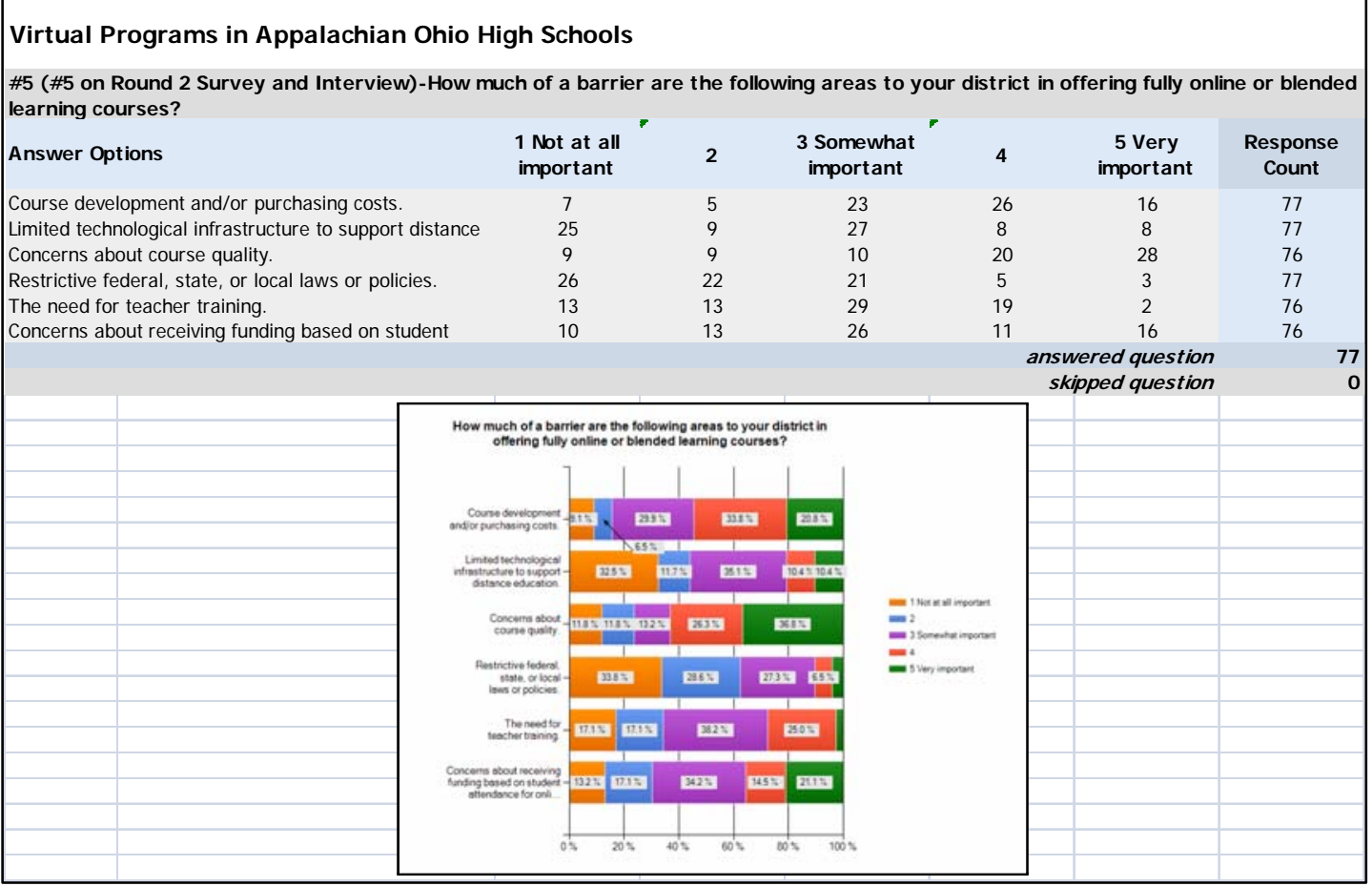


Table Q7

\section{Virtual Program Enrollment Reasons}

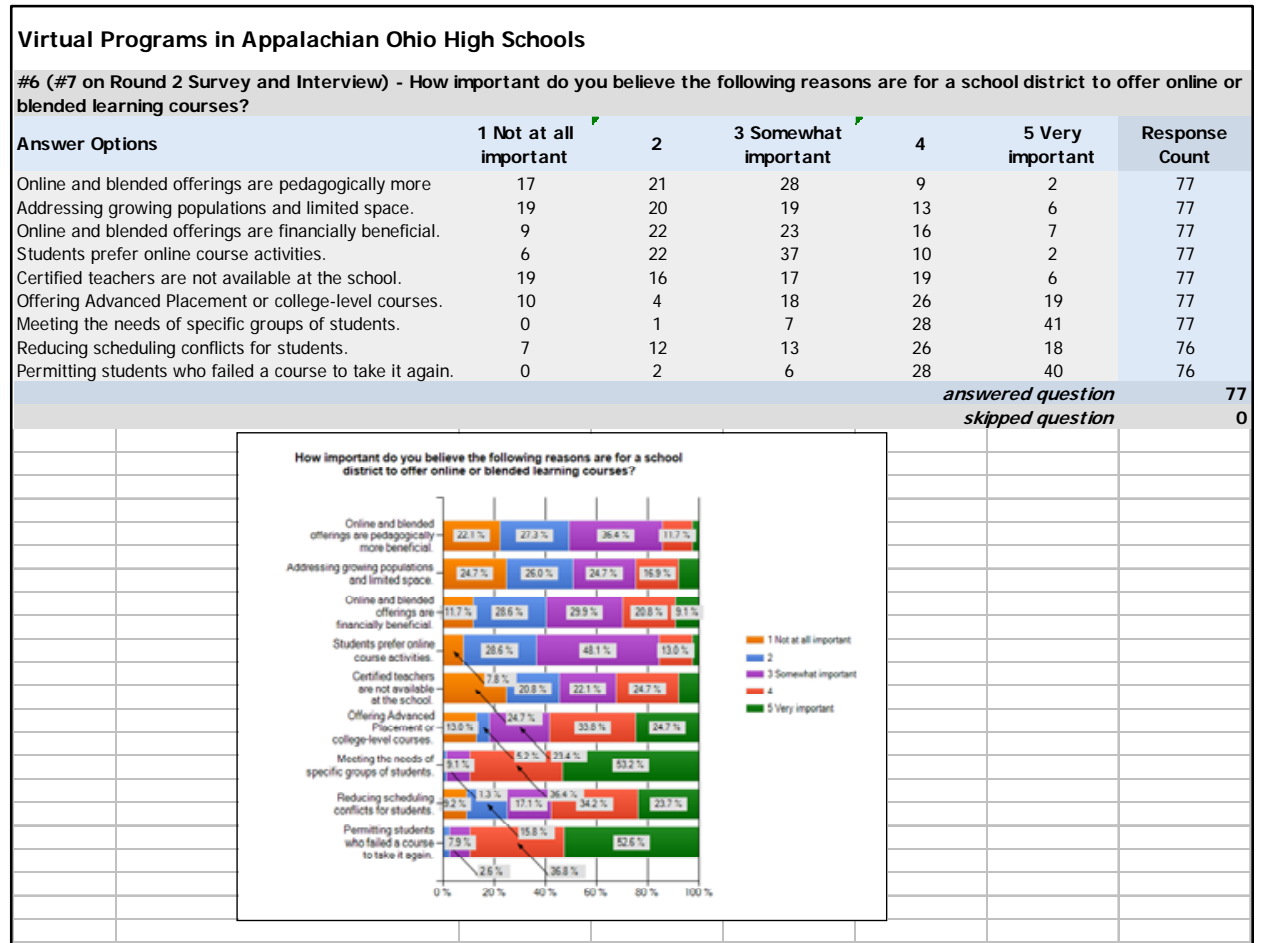

Table Q8

Pedagogical Feelings of Agreement/Disagreement

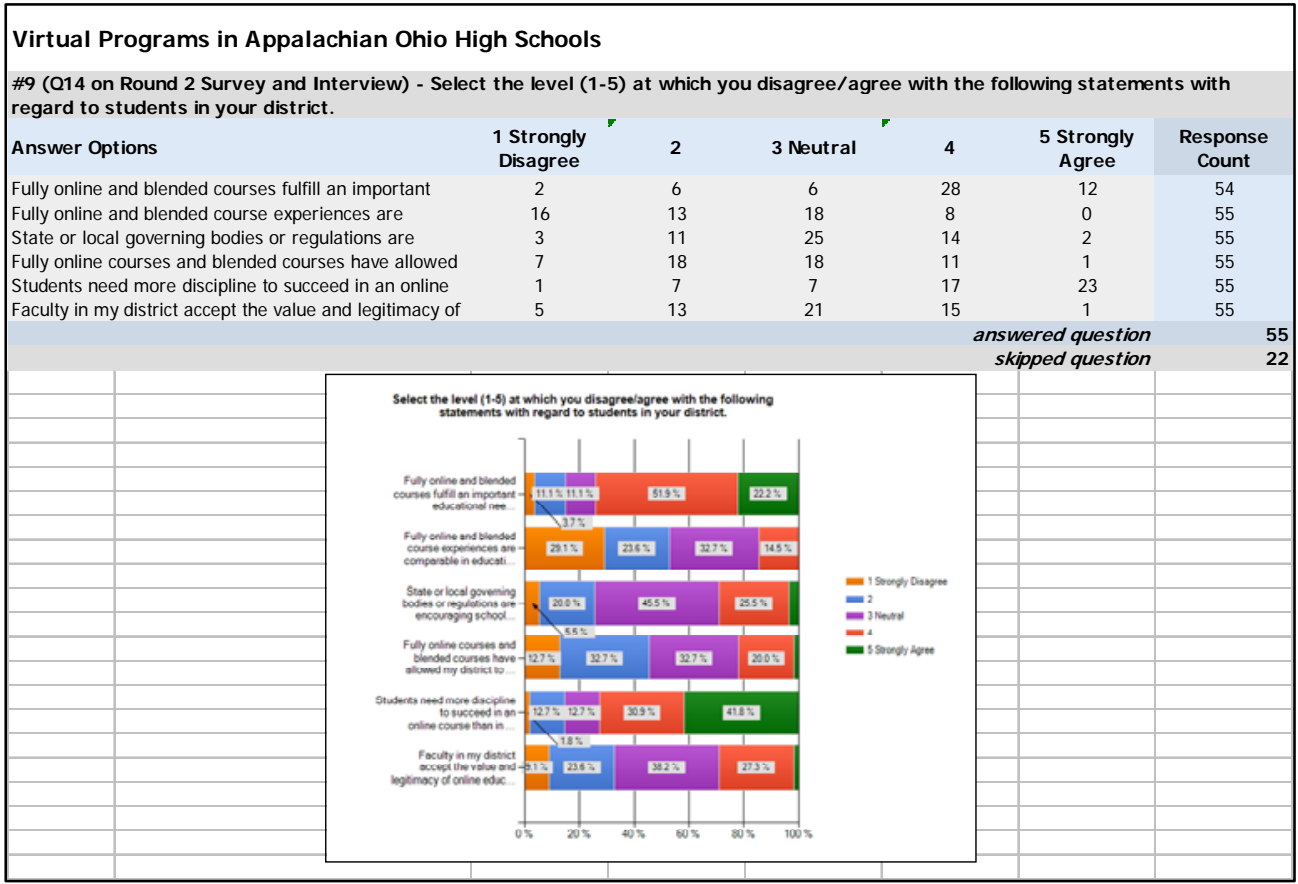


Table Q9

Nature of Enrollment Type

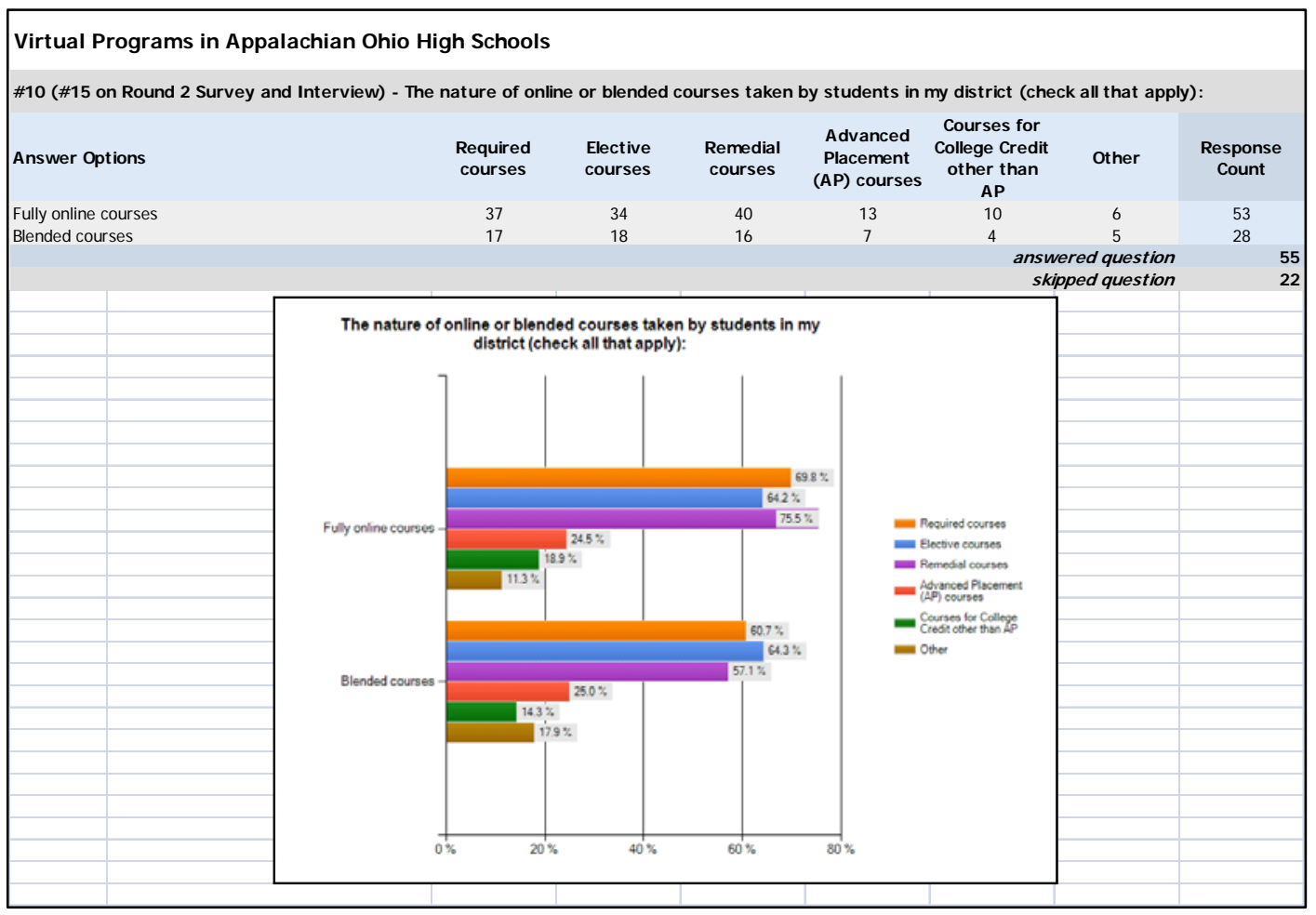

Table Q10

Growth of Virtual Programs

\begin{tabular}{|c|c|c|c|c|c|c|c|}
\hline \multicolumn{8}{|c|}{ Virtual Programs in Appalachian Ohio High Schools } \\
\hline \multicolumn{8}{|c|}{$\begin{array}{l}\text { \#11 (\#16 on Round } 2 \text { Survey and Interview) - What is your best estimate of the number of student enrollments (a student enrolled in more than one } \\
\text { course should be counted only once) between July } 1,2008 \text { and June 30, 2009? } \\
\text { Number of students taking at least one fully online course }\end{array}$} \\
\hline Answer Options & 0 & $1-10$ & $11-25$ & 26-50 & 50-99 & 100 or over & $\begin{array}{l}\text { Response } \\
\text { Count }\end{array}$ \\
\hline $\begin{array}{l}\text { Grades K-5 } \\
\text { Grades 6-8 }\end{array}$ & $\begin{array}{l}29 \\
20\end{array}$ & $\begin{array}{l}3 \\
14\end{array}$ & $\begin{array}{l}0 \\
1\end{array}$ & $\begin{array}{l}0 \\
0 \\
7\end{array}$ & $\begin{array}{l}0 \\
0\end{array}$ & $\begin{array}{l}0 \\
0\end{array}$ & $\begin{array}{l}32 \\
35\end{array}$ \\
\hline Grades 9-12 & 8 & 19 & 16 & 7 & 2 & 2 & 54 \\
\hline \multicolumn{8}{|c|}{ Number of students taking at least one blended course } \\
\hline Answer Options & $\mathbf{0}$ & 1-10 & 11-25 & 26-50 & 50-99 & 100 or over & $\begin{array}{l}\text { Response } \\
\text { Count }\end{array}$ \\
\hline $\begin{array}{l}\text { Grades K-5 } \\
\text { Grades 6-8 }\end{array}$ & $\begin{array}{l}30 \\
26\end{array}$ & $\begin{array}{l}1 \\
6\end{array}$ & $\begin{array}{l}0 \\
0\end{array}$ & $\begin{array}{l}0 \\
0\end{array}$ & $\begin{array}{l}0 \\
1\end{array}$ & $\begin{array}{l}1 \\
0\end{array}$ & $\begin{array}{l}32 \\
33\end{array}$ \\
\hline \multirow[t]{3}{*}{ Grades 9-12 } & 33 & 8 & 6 & 6 & 1 & 0 & 54 \\
\hline & & & & & & & $\begin{array}{l}\text { Question } \\
\text { Totals }\end{array}$ \\
\hline & & & & & \multicolumn{2}{|c|}{$\begin{array}{c}\text { answered question } \\
\text { skipped question }\end{array}$} & $\begin{array}{l}55 \\
22\end{array}$ \\
\hline
\end{tabular}




\section{Table Q11}

Growth of Fully Online Courses

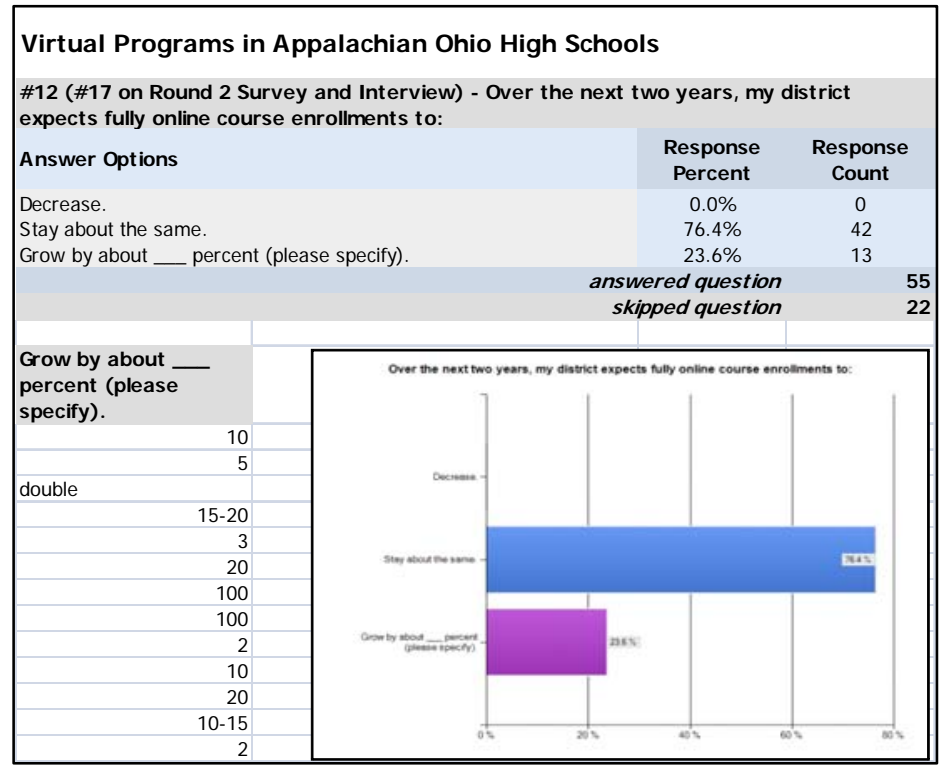

Table Q12

Growth of Blended Courses

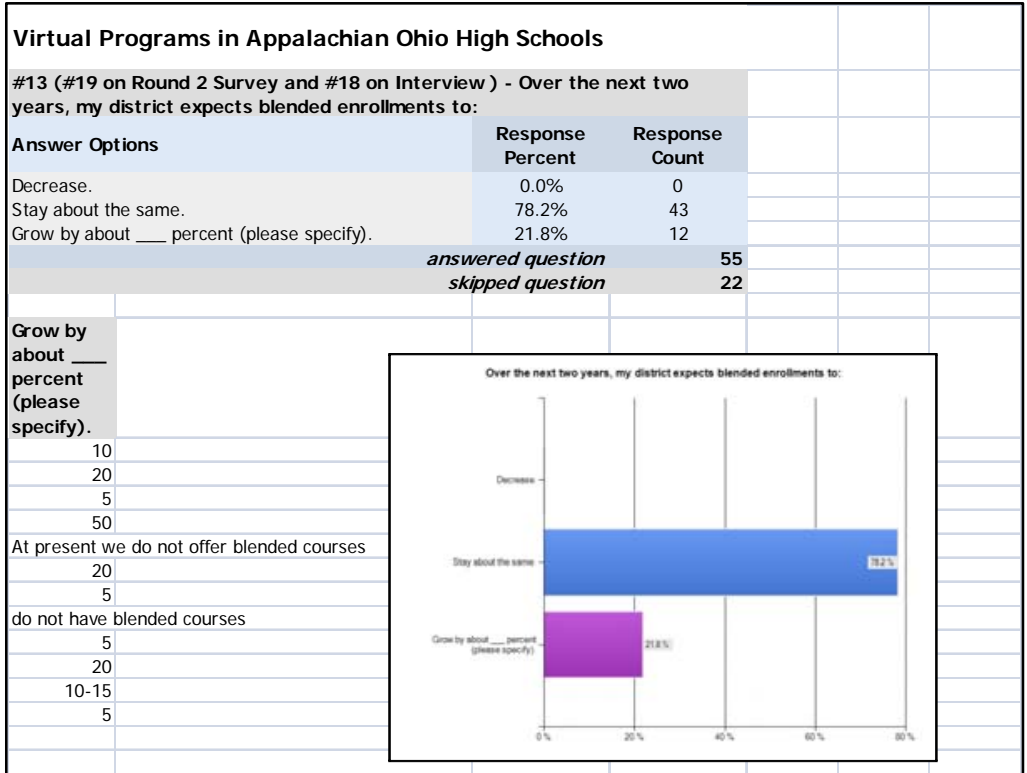


Table Q13

Providers of Virtual Programs

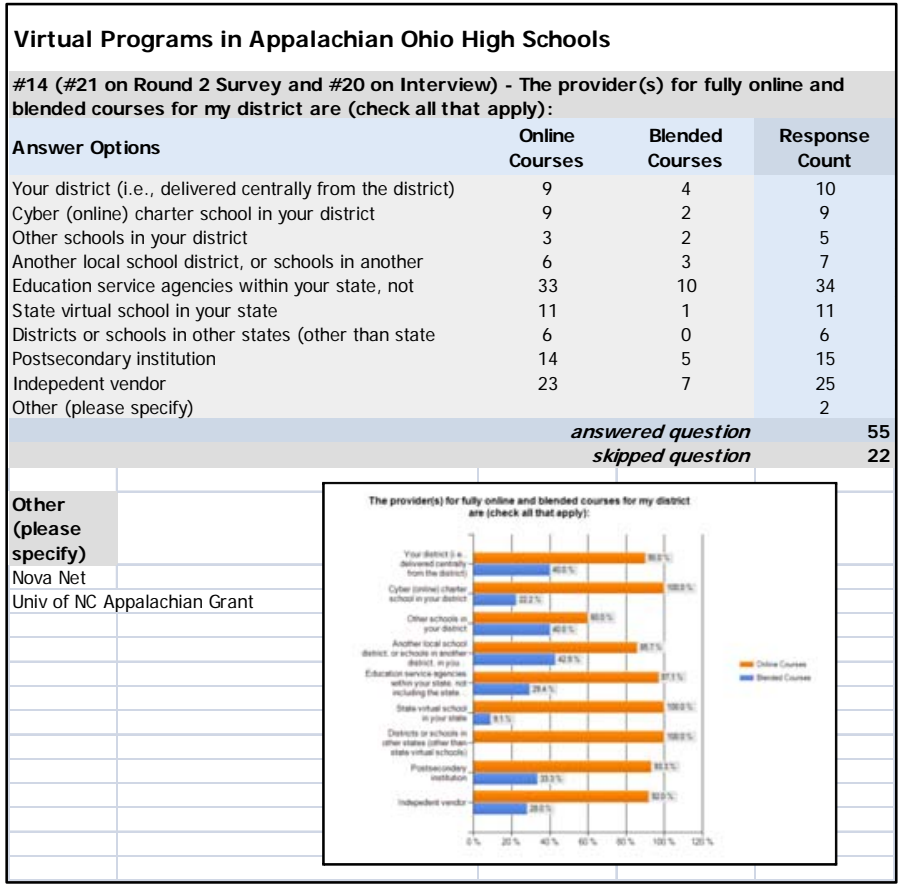


Appendix R

Round 2 Survey Questions

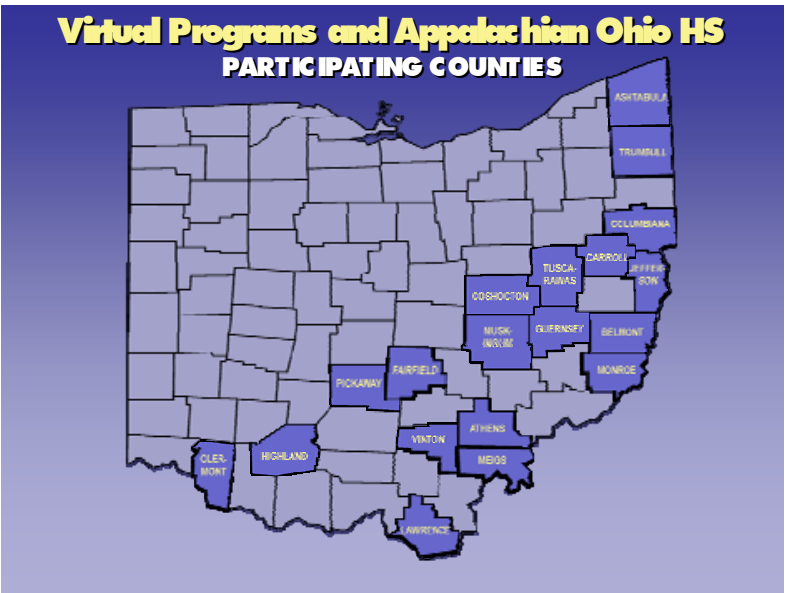

Figure R1. Participating Counties

Table R2

Position of Participants

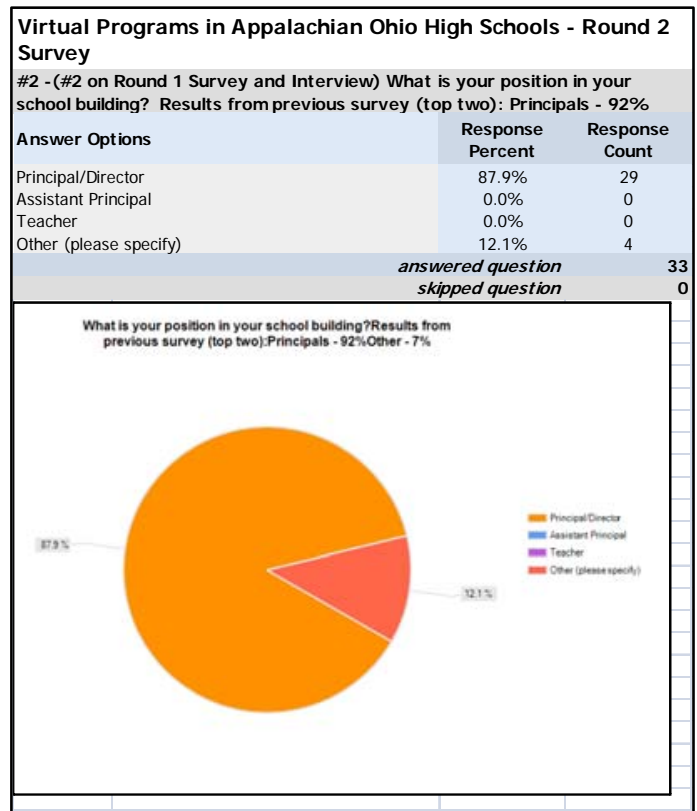


Table R3

\section{Length of Position}

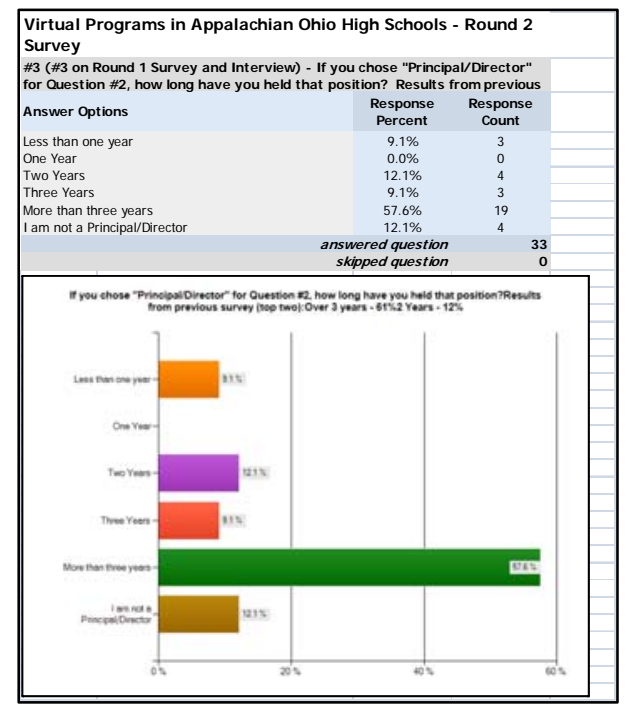

Table R4

Virtual Program Enrollment

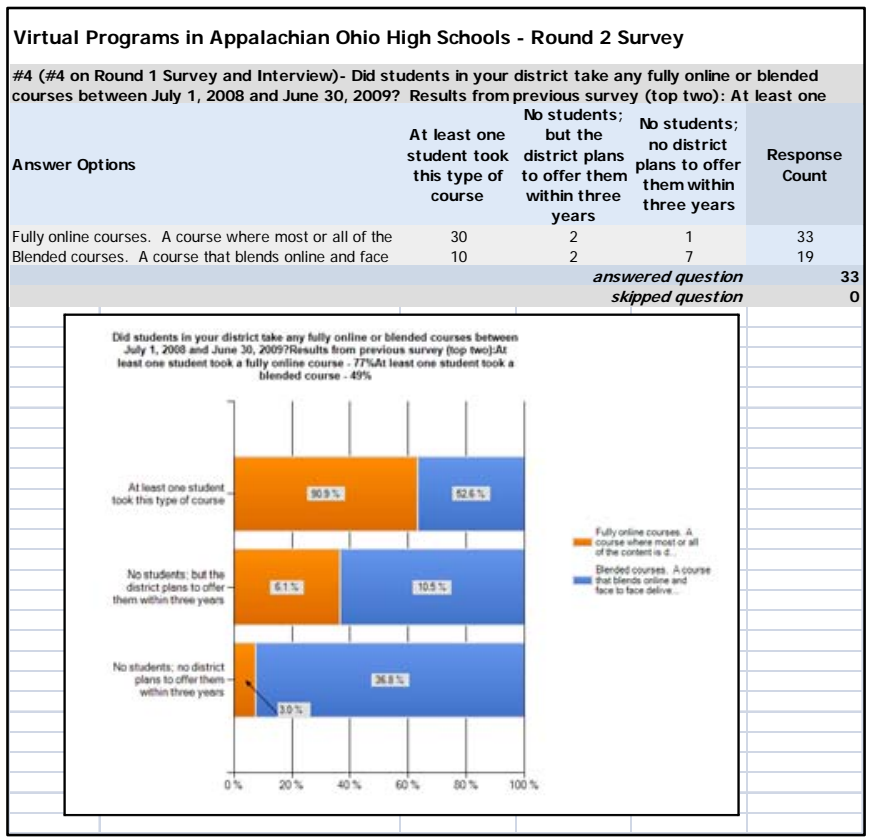


Table R5

\section{School Year of First Enrollment}

\begin{tabular}{|c|c|c|c|c|c|c|c|}
\hline \multicolumn{8}{|c|}{$\begin{array}{l}\# 13 \text { (\#8 on Round } 1 \text { Survey and \#13 on Interview) - In what school year did any student in your district first take a fully online or blended course? } \\
\text { Results from previous survey: Before } 2005-51 \% 2008-2009-18 \% \\
\text { School Year }\end{array}$} \\
\hline Answer Options & Before 2005 & 2005-2006 & 2006-2007 & 2007-2008 & 2008-2009 & 2009-2010 & $\begin{array}{l}\text { Response } \\
\text { Count }\end{array}$ \\
\hline \multirow[t]{3}{*}{ School Year } & 19 & 2 & 3 & 3 & 0 & 3 & 30 \\
\hline & & & & & & & $\begin{array}{c}\text { Question } \\
\text { Totals }\end{array}$ \\
\hline & & & & & & $\begin{array}{l}\text { ered question } \\
\text { oped question }\end{array}$ & $\begin{array}{r}30 \\
3 \\
\end{array}$ \\
\hline
\end{tabular}

Table R6

Virtual Program Barriers

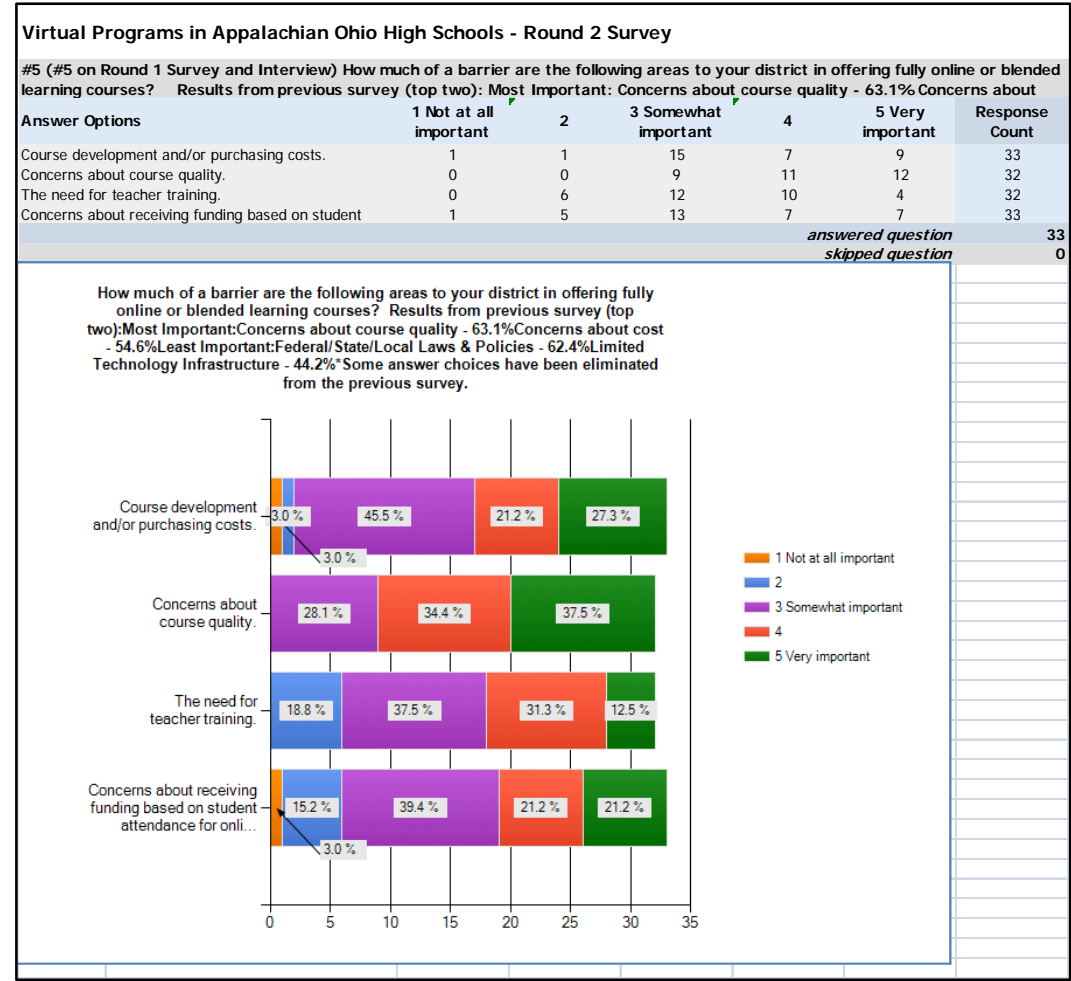


Table R7

Virtual Program Barriers - Ranked

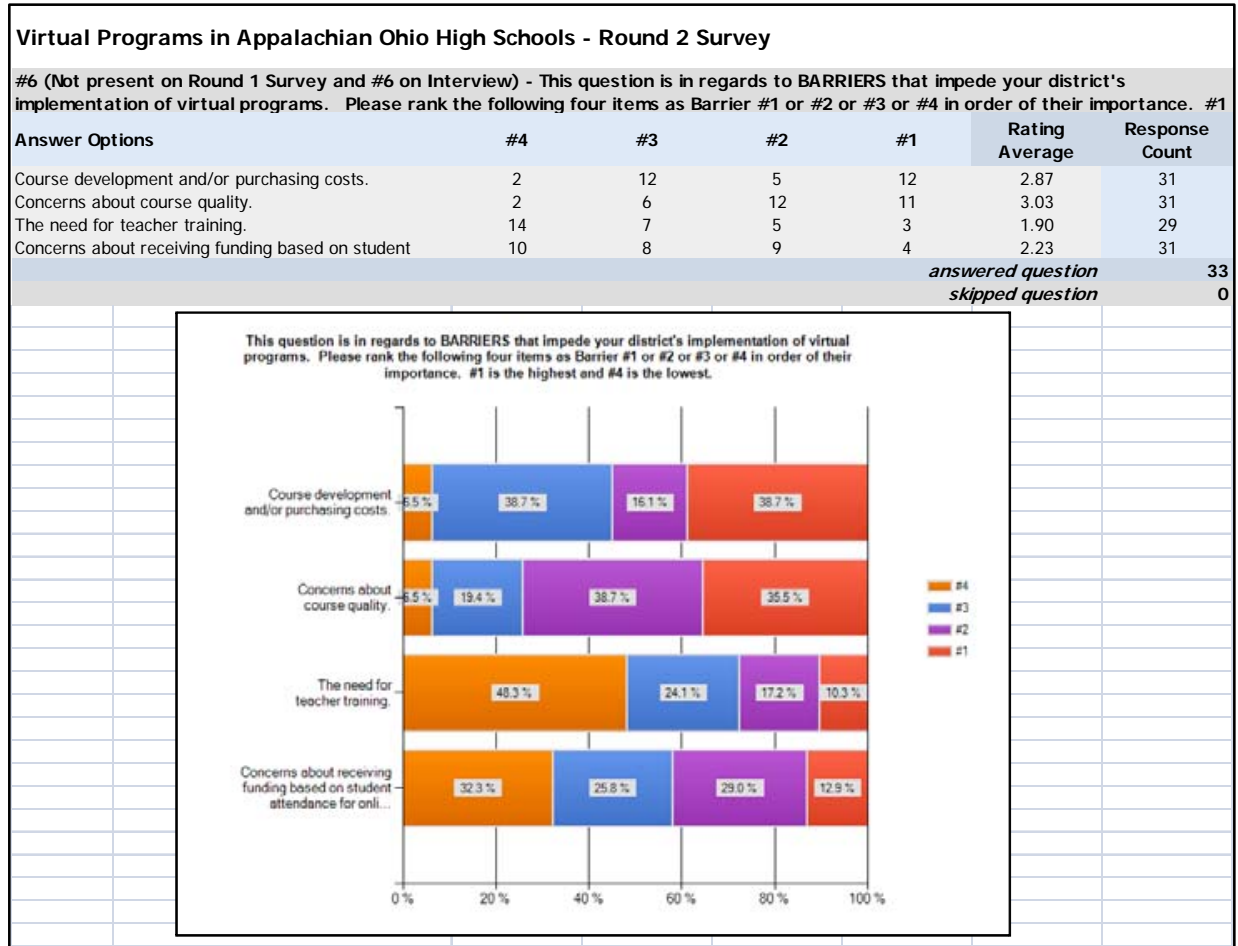

Table R8

Virtual Program Enrollment Reasons

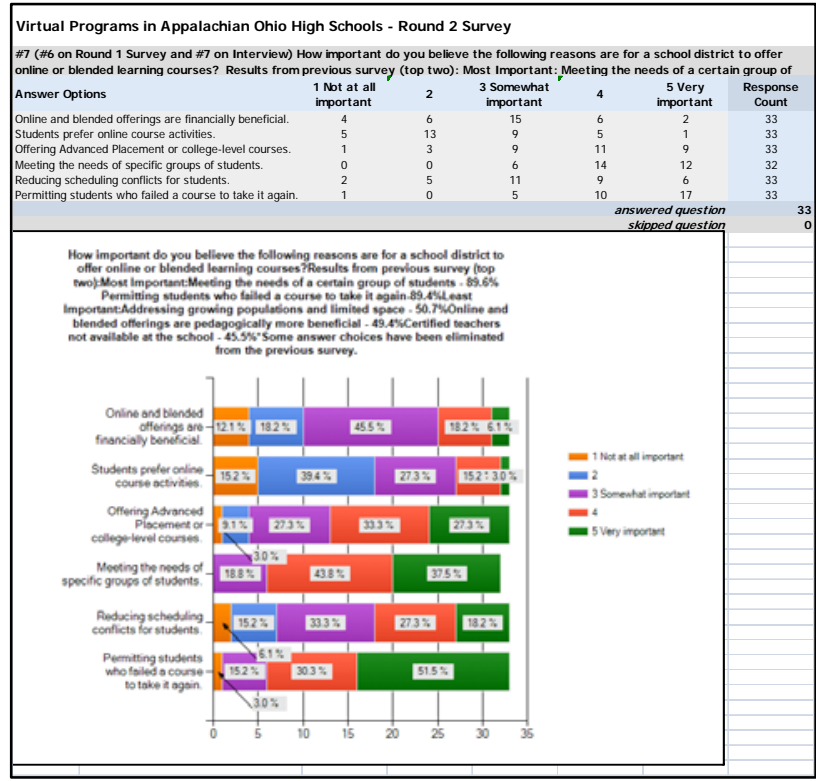


Table R9

Virtual Program Enrollment Reasons - Ranked

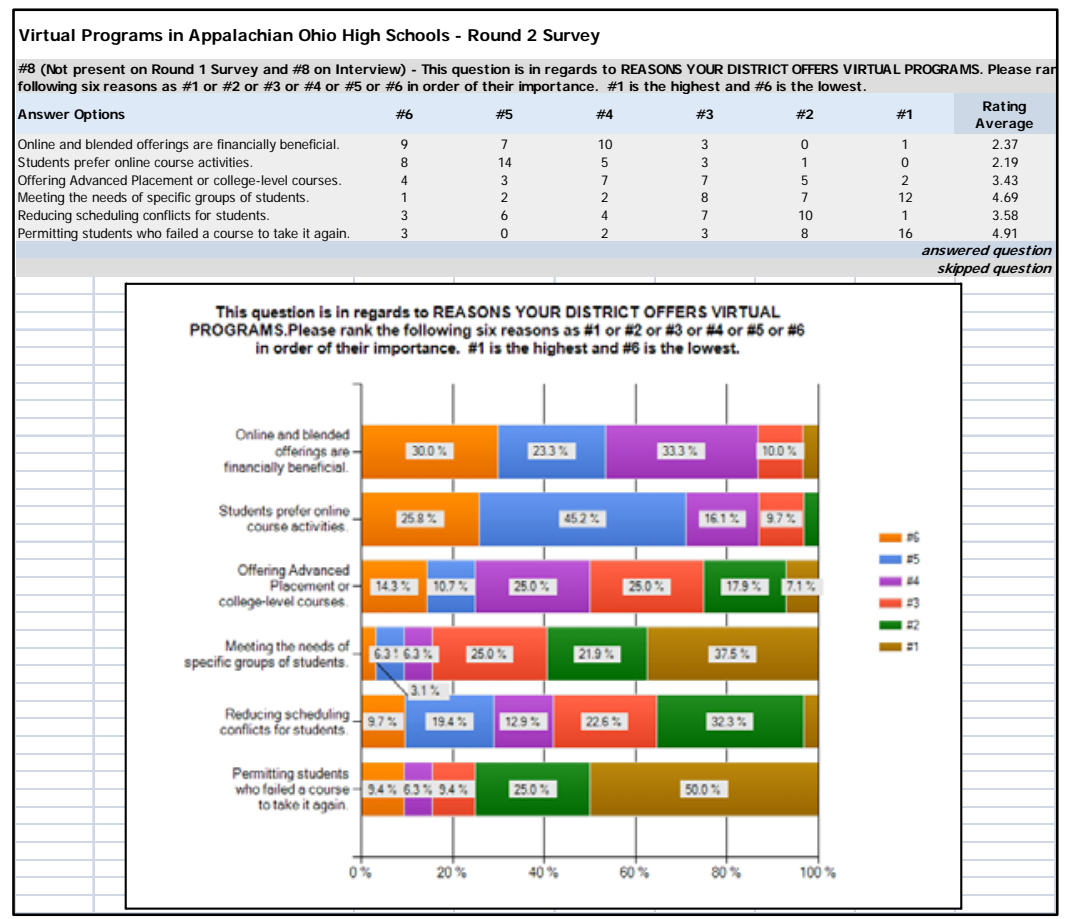

Table R10

Pedagogical Feelings - Alternative Uses of Virtual Programs

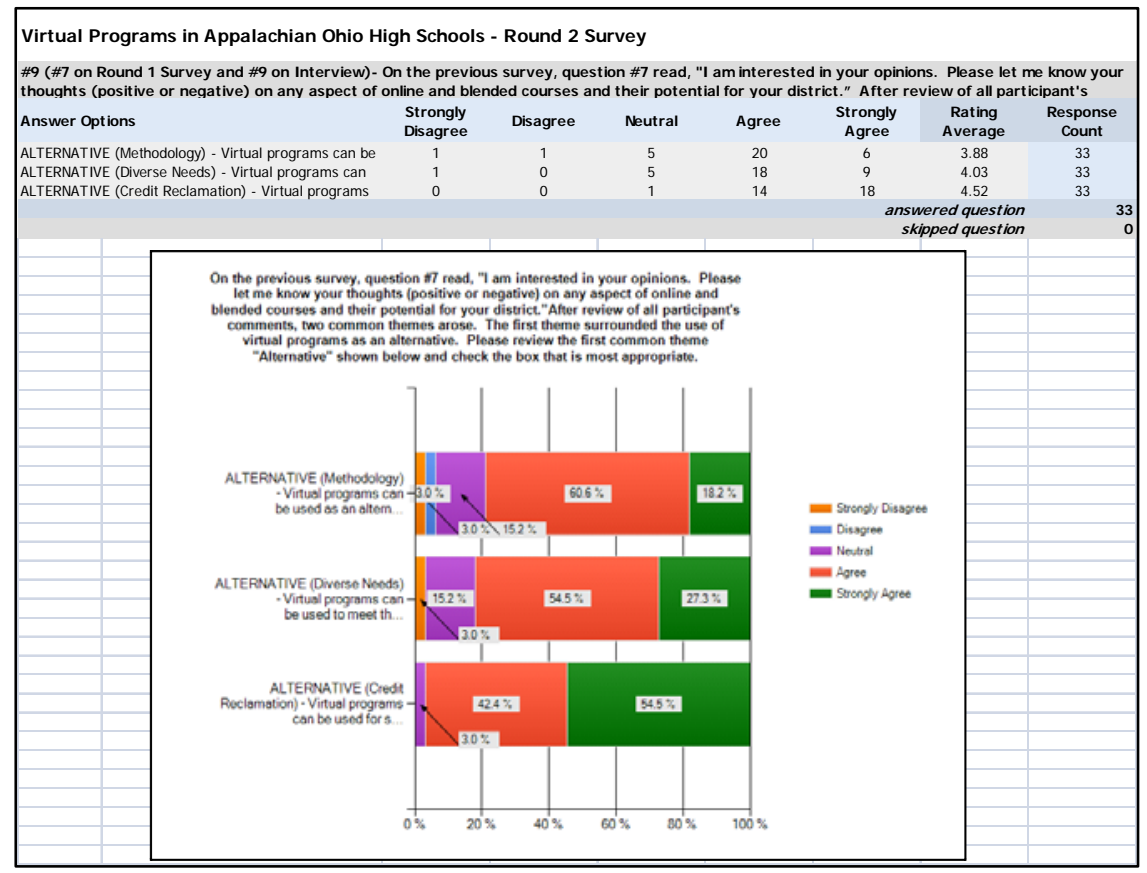


Table R11

Pedagogical Feelings - Alternative Uses of Virtual Programs - Ranked

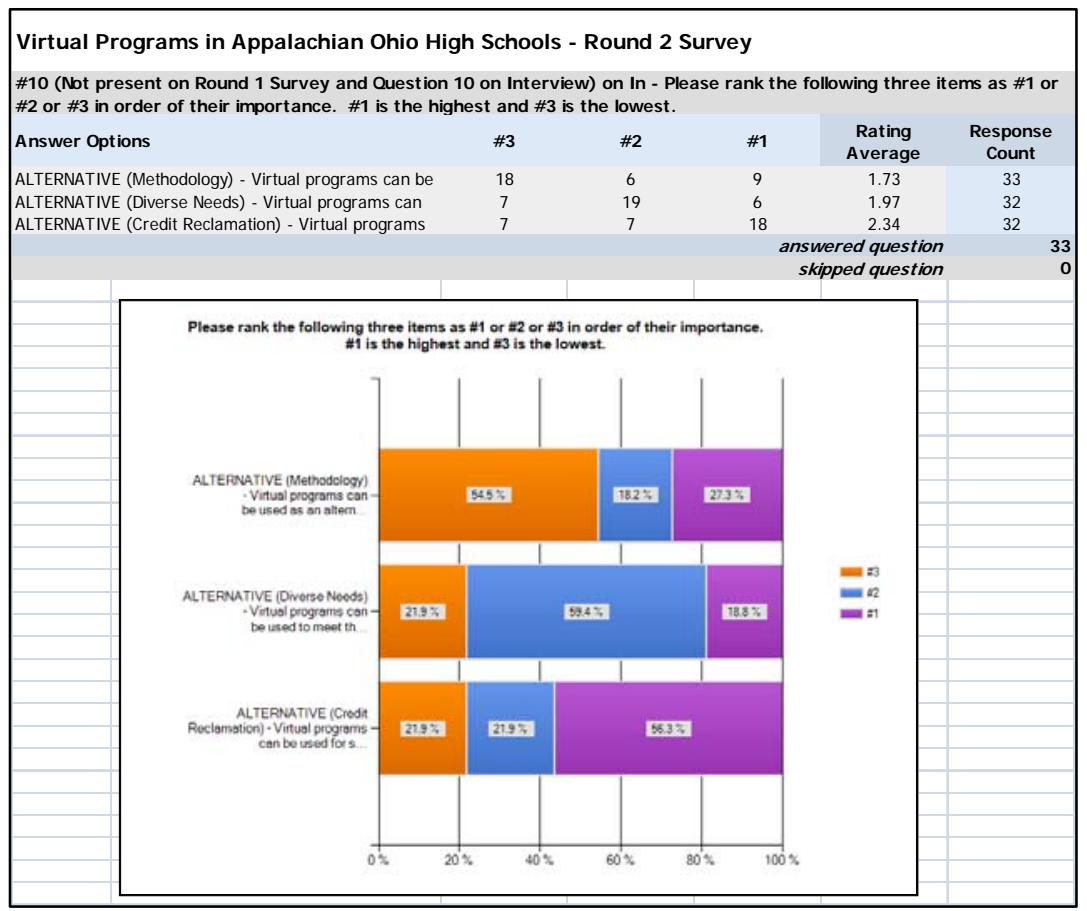

Table R12

Pedagogical Feelings - Apprehensions

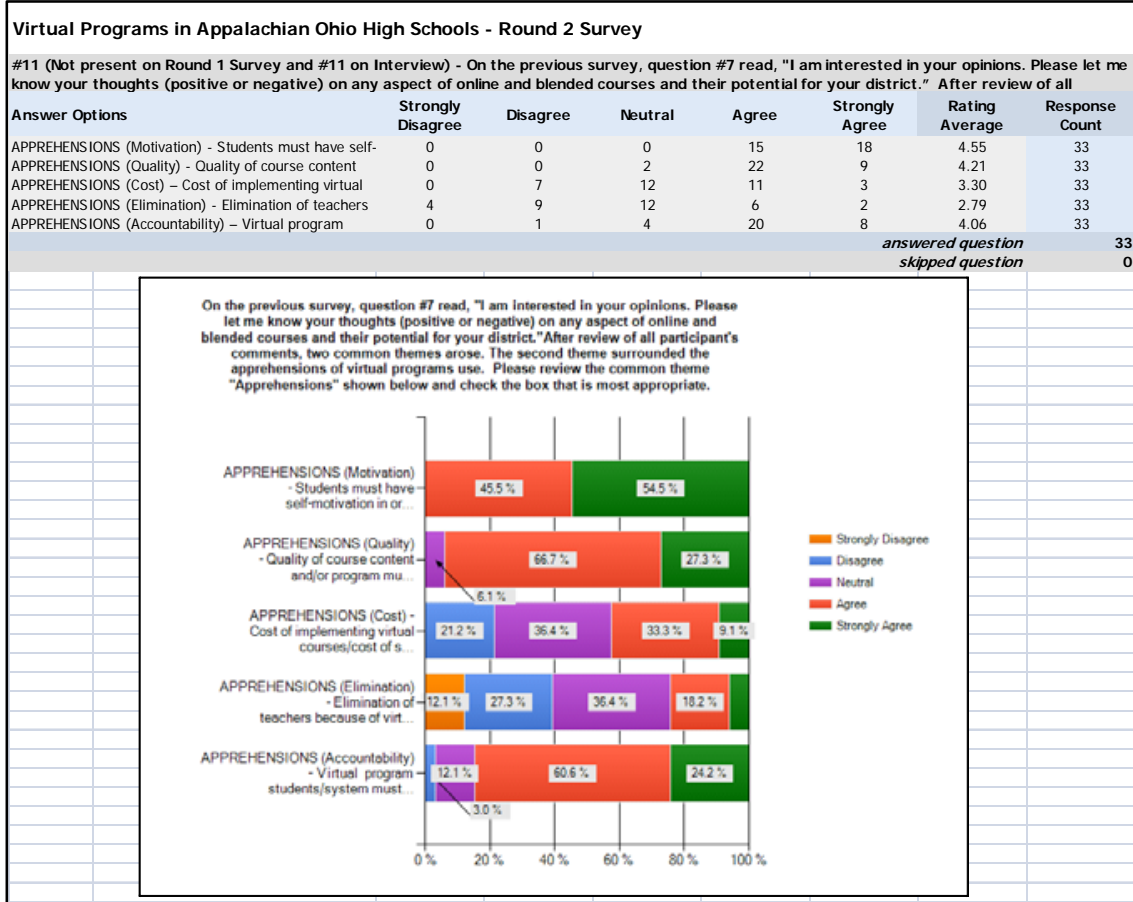


Table R13

Pedagogical Feelings - Apprehensions - Ranked

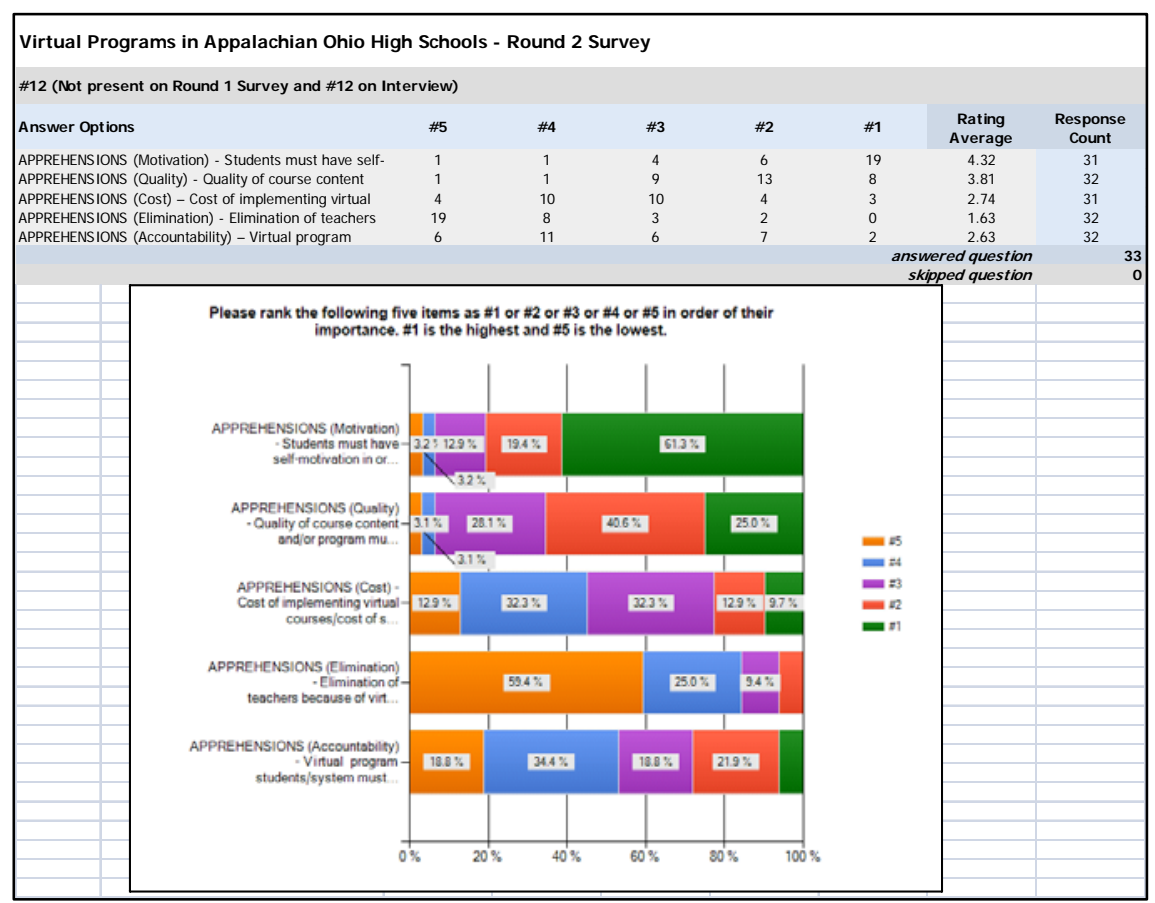

Table R14

Pedagogical Feelings of Agreement/Disagreement

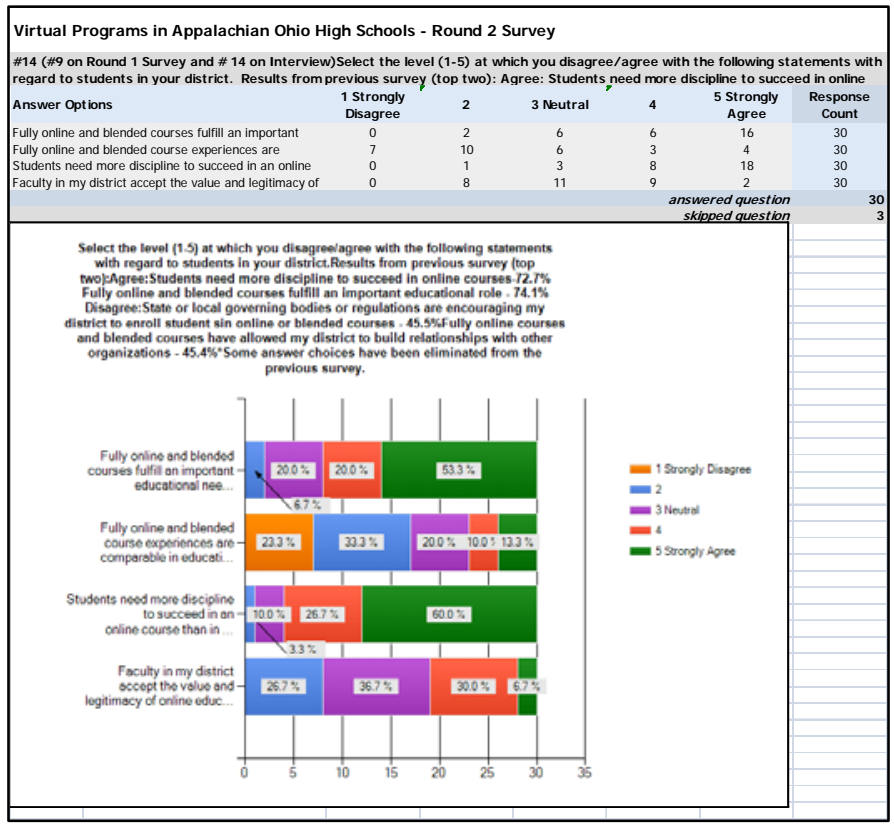


Table R15

Nature of Enrollment Type

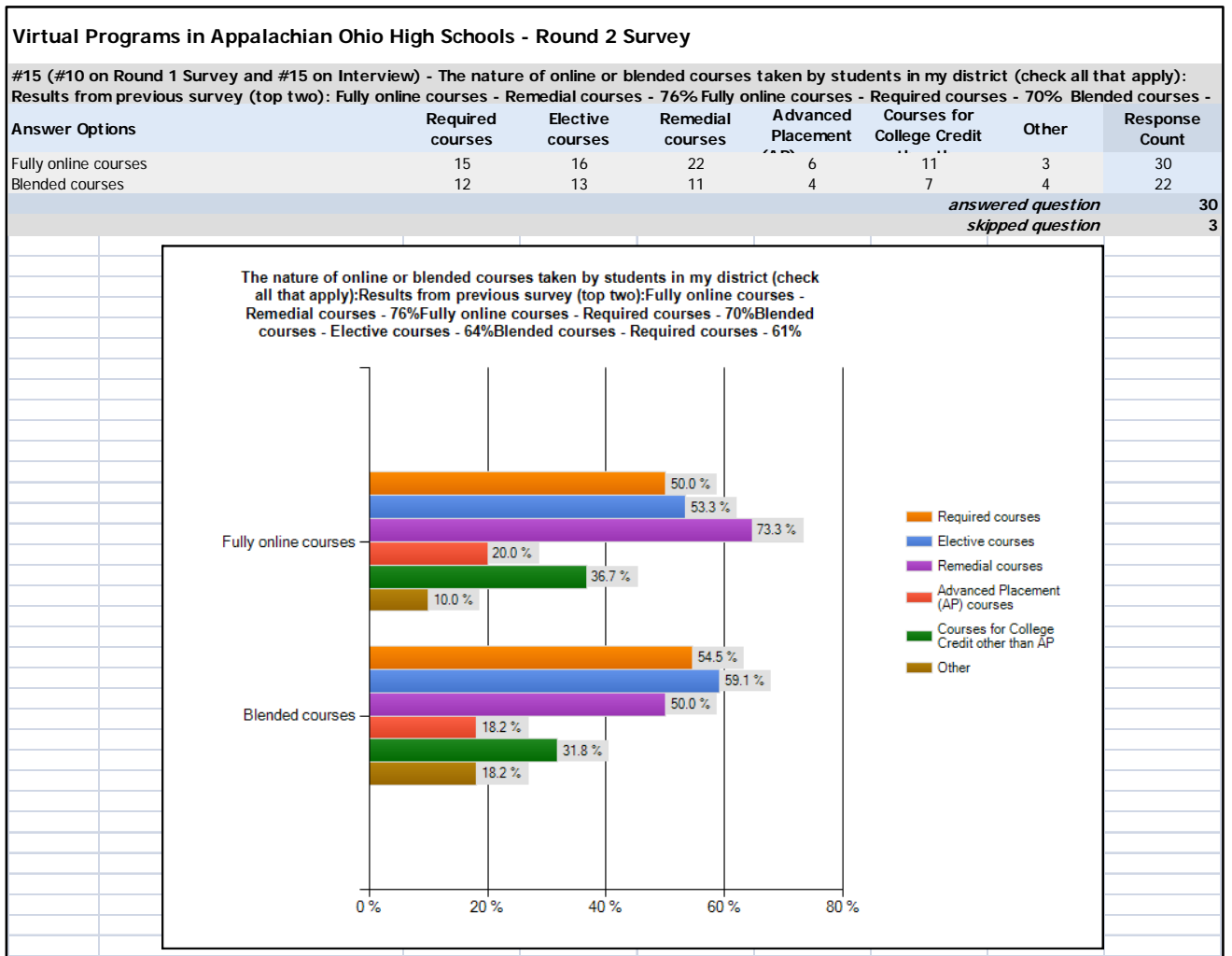

Table R16

Growth of Virtual Programs

\begin{tabular}{|c|c|c|c|c|c|c|c|}
\hline \multicolumn{8}{|c|}{$\begin{array}{l}\text { \#16 (\#11 on Round } 1 \text { Survey and \#16 on Interview) - What is your best estimate of the number of student enrollments (a student enrolled in more than } \\
\text { one course should be counted only once) between July 1, } 2008 \text { and J une 30, 2009? "Grades 9-12 Fully Online" (98\%) and "Grades 9-12 Blended courses" } \\
\text { Number of students taking at least one fully online course }\end{array}$} \\
\hline Answer Options & $\mathbf{0}$ & $1-10$ & $11-25$ & 26-50 & $50-99$ & 100 or over & $\begin{array}{l}\text { Response } \\
\text { Count }\end{array}$ \\
\hline Grades K-5 & 14 & 4 & 0 & 0 & 0 & 0 & 18 \\
\hline Grades 6-8 & 10 & 8 & 0 & 0 & 0 & 0 & 18 \\
\hline Grades 9-12 & 2 & 14 & 8 & 6 & 0 & 0 & 30 \\
\hline \multicolumn{8}{|c|}{ Number of students taking at least one blended course } \\
\hline Answer Options & 0 & $1-10$ & $11-25$ & $26-50$ & $50-99$ & 100 or over & $\begin{array}{l}\text { Response } \\
\text { Count }\end{array}$ \\
\hline Grades K-5 & 18 & 0 & 0 & 0 & 0 & 0 & 18 \\
\hline Grades 6-8 & 16 & 2 & 0 & 0 & 0 & 0 & 18 \\
\hline \multirow[t]{4}{*}{ Grades 9-12 } & 11 & 11 & 5 & 2 & 0 & 0 & 29 \\
\hline & & & & & & & \\
\hline & & & & & & & $\begin{array}{c}\text { Question } \\
\text { Totals }\end{array}$ \\
\hline & & & & & \multicolumn{2}{|c|}{$\begin{array}{c}\text { answered question } \\
\text { skipped question }\end{array}$} & $\begin{array}{r}30 \\
3\end{array}$ \\
\hline
\end{tabular}


Table R17

Growth of Fully Online Courses

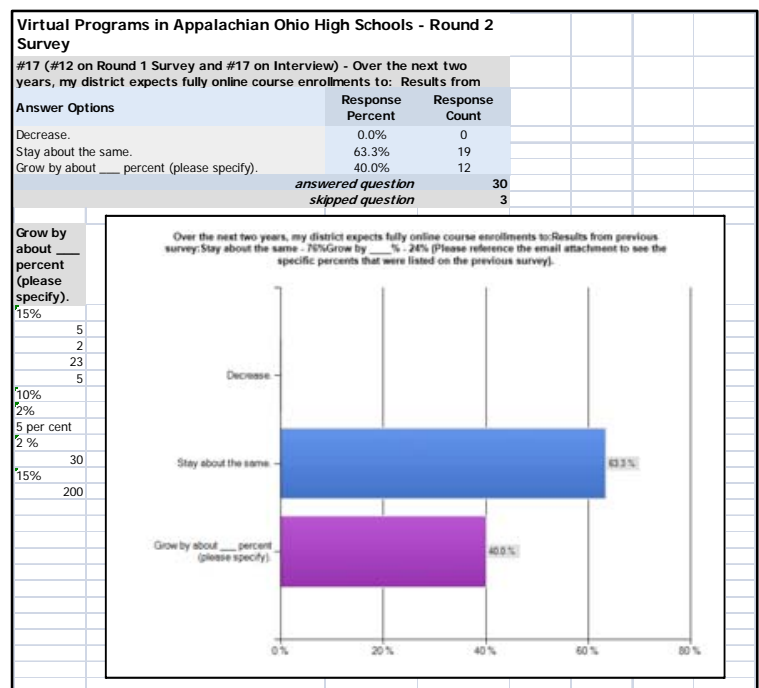

Table R18

Growth of Blended Courses

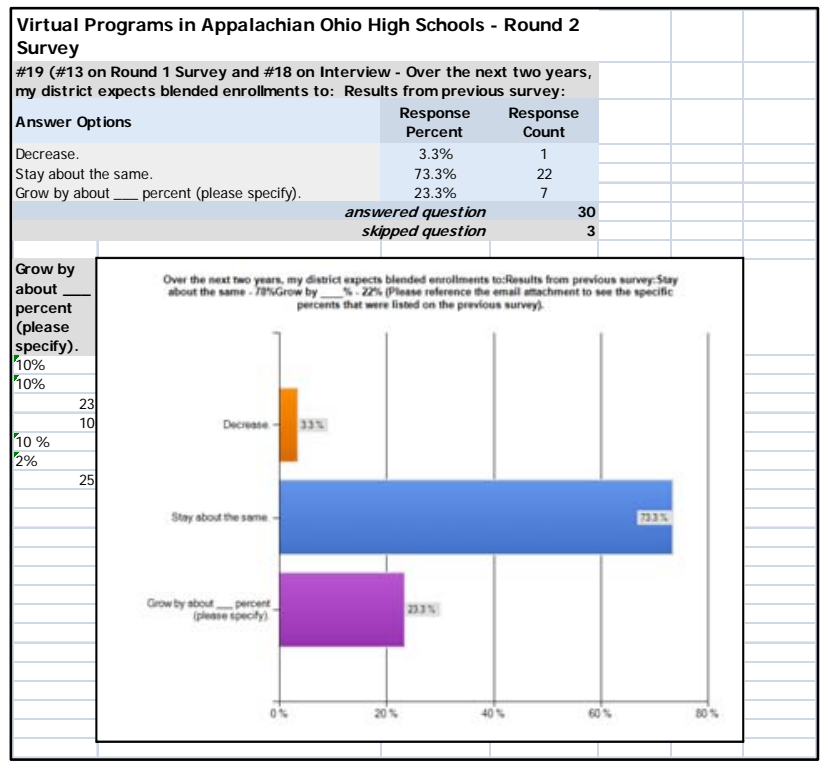


Table R19

Providers of Virtual Programs

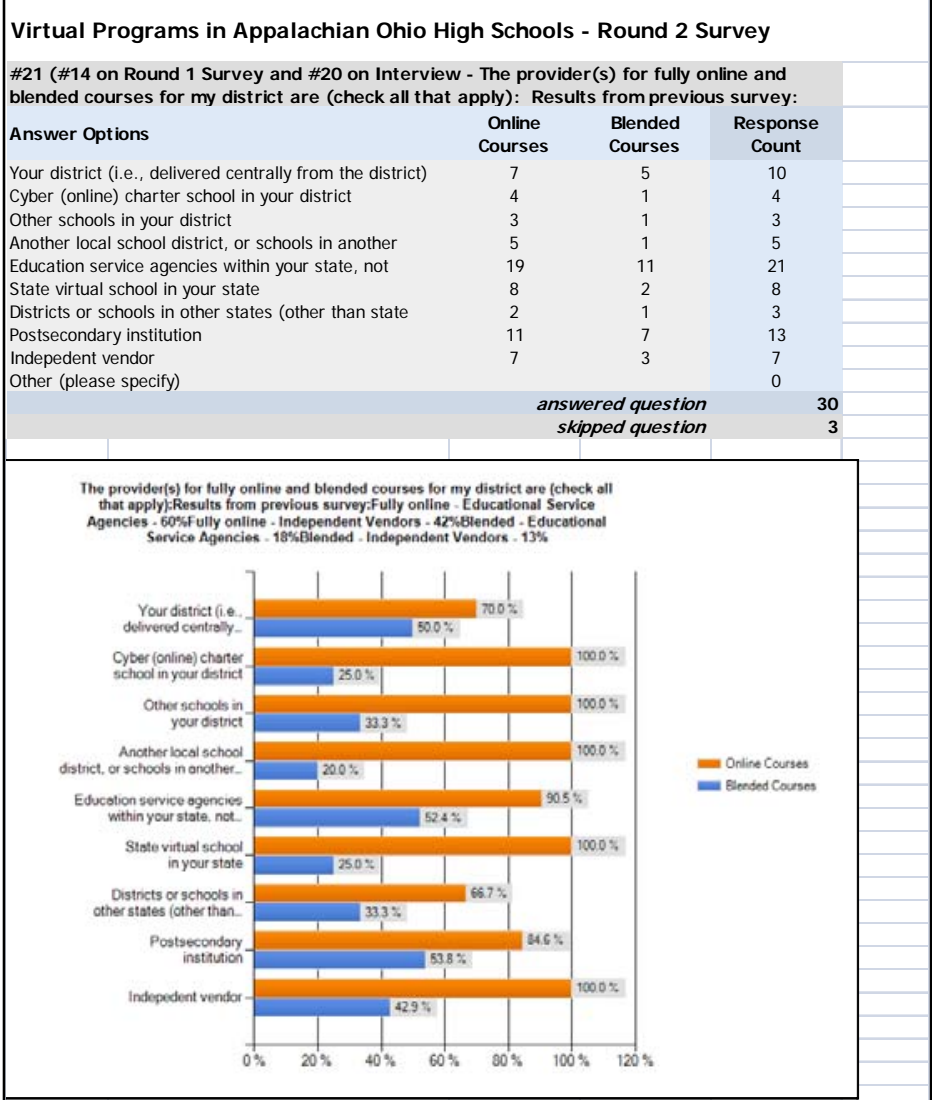


Appendix S

Interview Questions

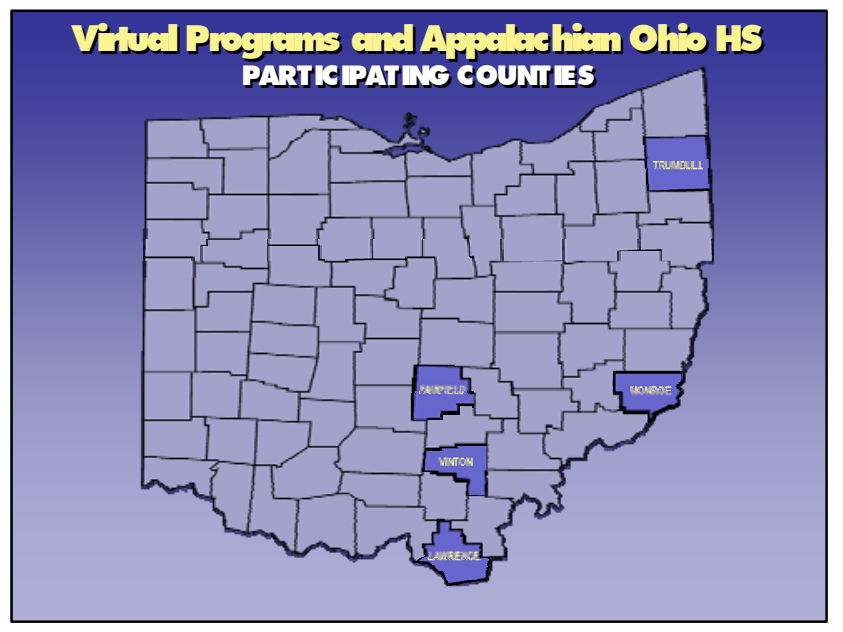

Figure S1. Participating Counties

Table S2

Position of Participants

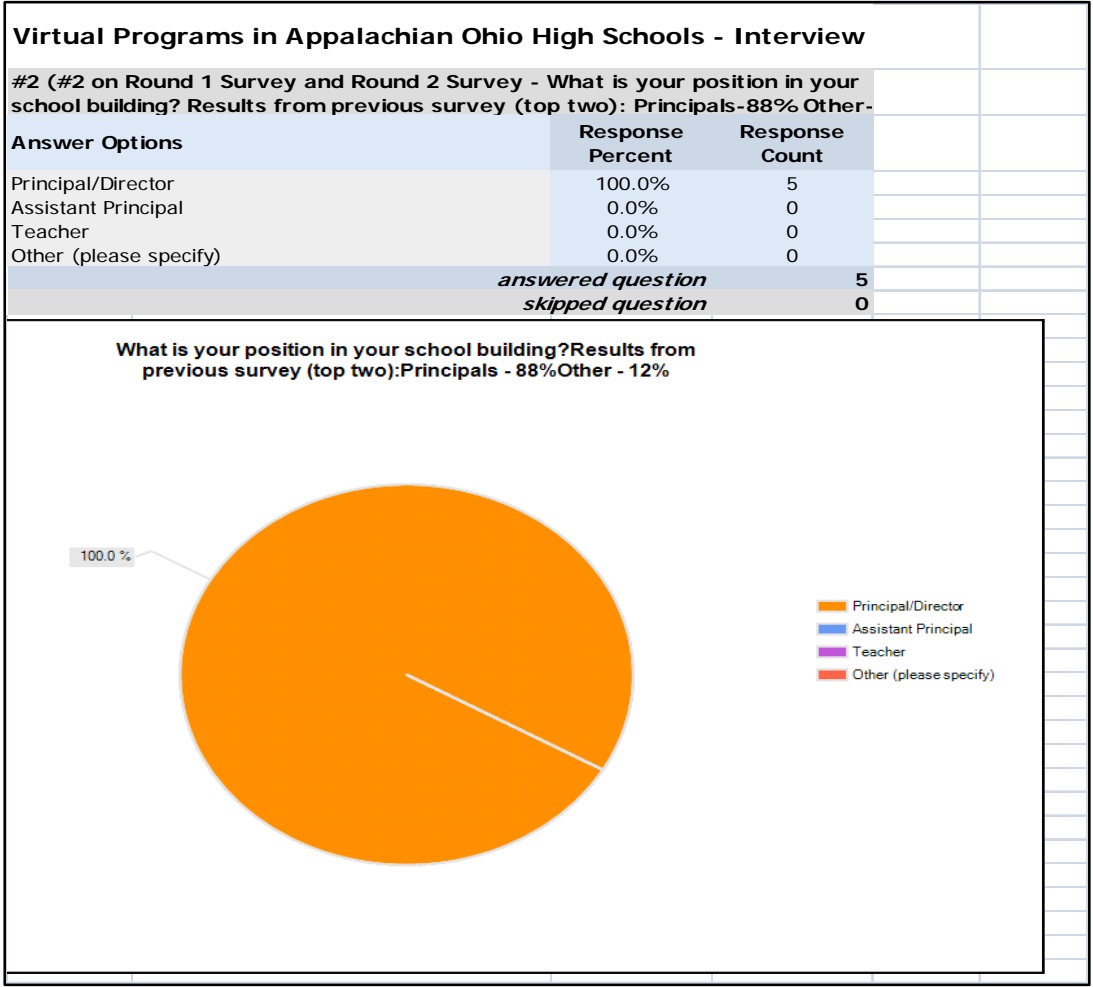


Table S3

Length of Position

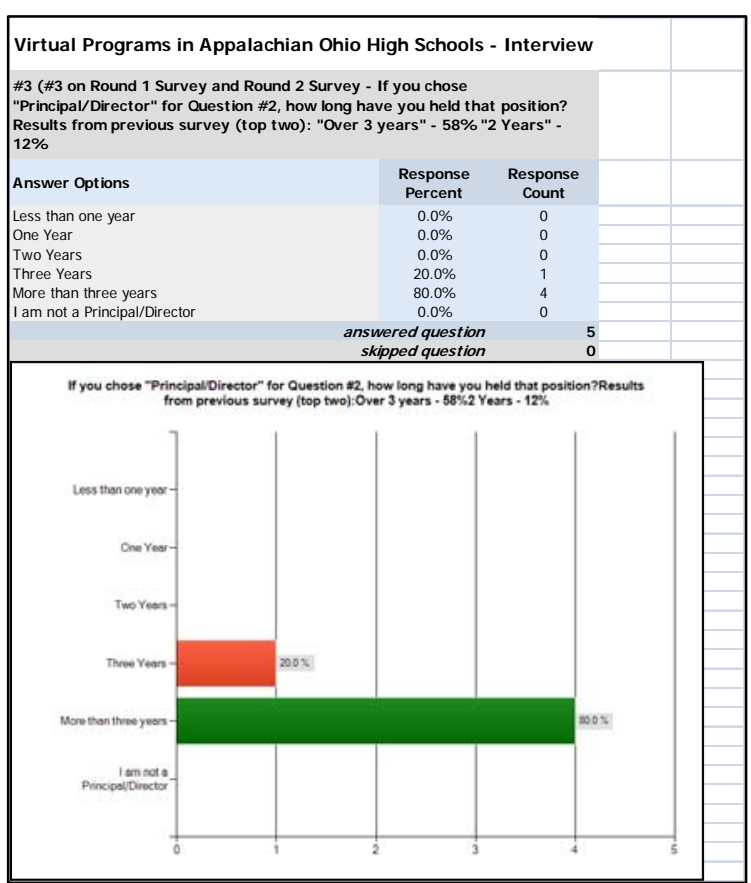

\section{Table S4}

\section{Virtual Program Enrollment}

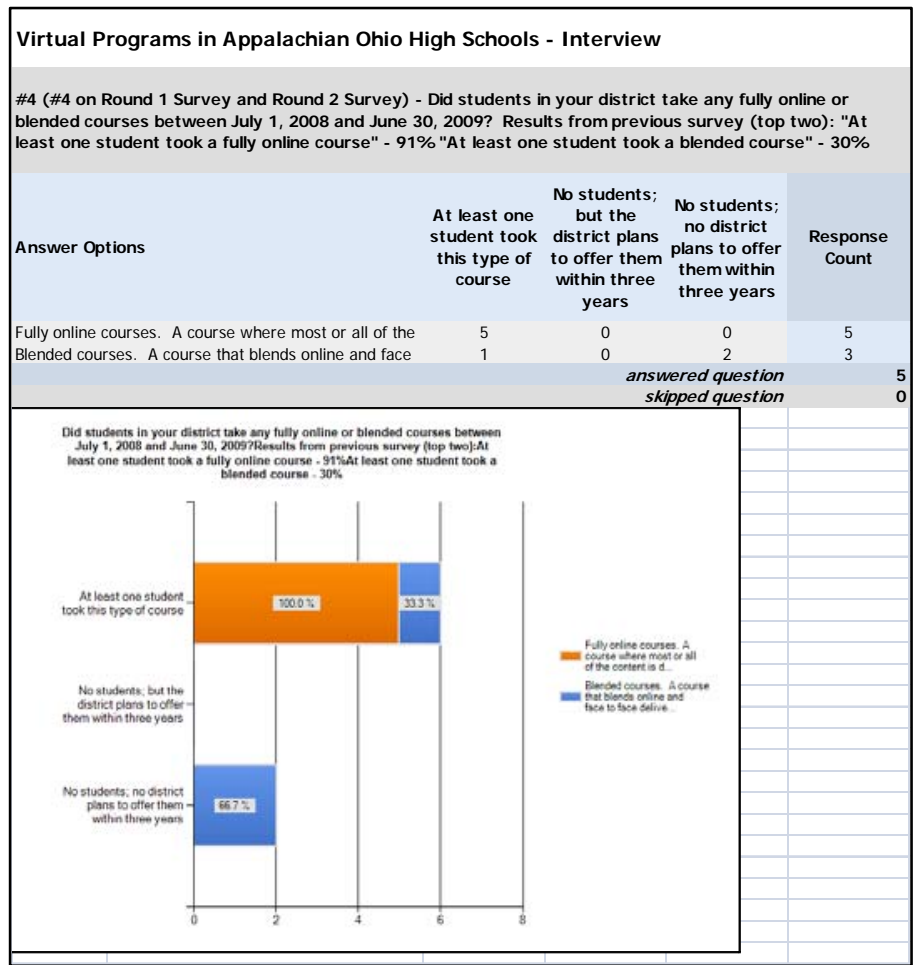




\section{Table S5}

\section{School Year of First Enrollment}

\section{Virtual Programs in Appalachian Ohio High Schools - Interview}

\#13 (\#8 on Round 1 Survey and \#13 on Round 2 Survey - In what school year did any student in your district first take a fully online or blended course? Results from previous survey: "Before 2005" - 58\% "2008-2009" - 0\% School Year

Answer Options

Before $2005 \quad 2005-2006$

School Year

$80 \%$
$0 \%$
2006-

1
2007-2008

0

$0 \%$
2008-

0
2009-2010

0

Table S6

\section{Virtual Program Barriers}

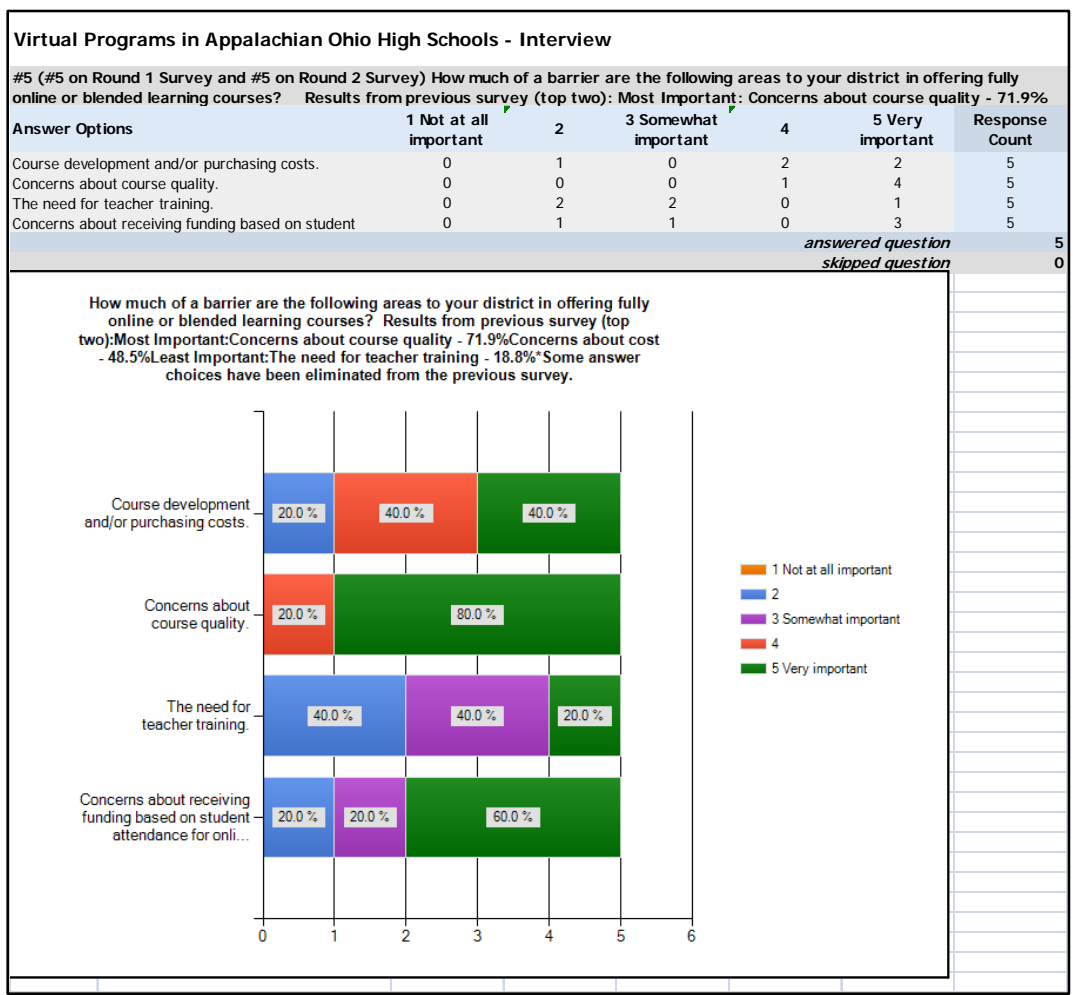


Table S7

Virtual Program Barriers Ranked

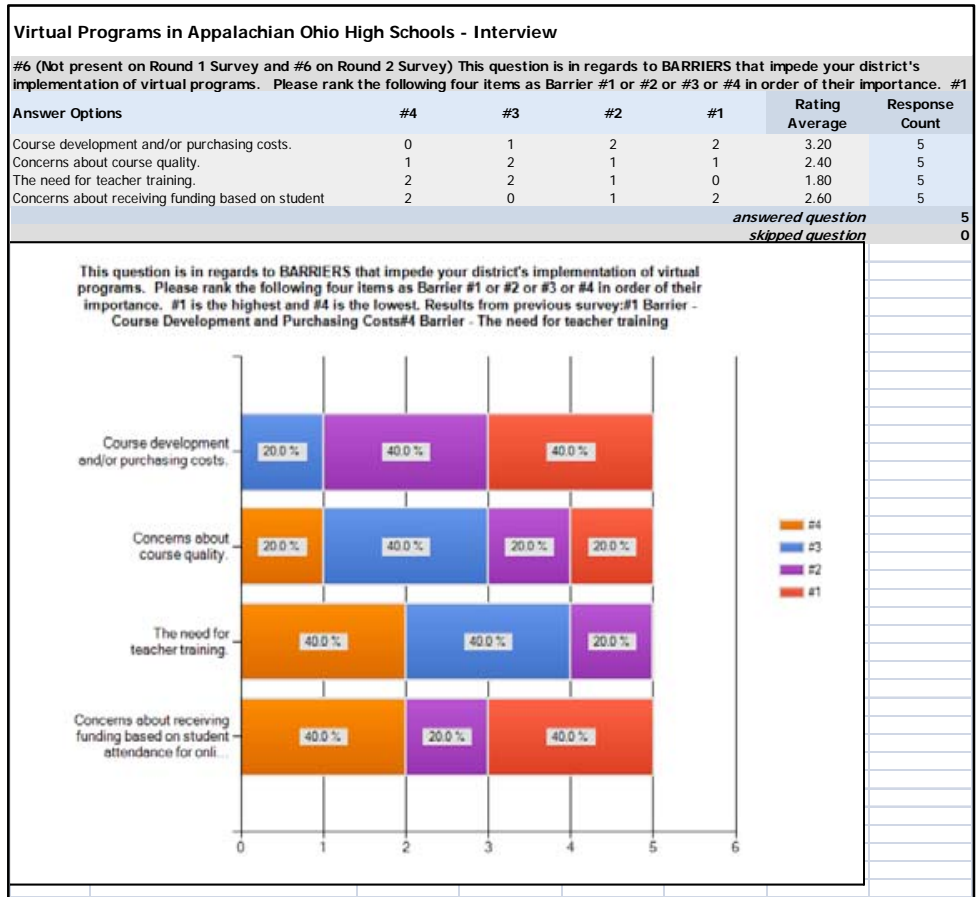

Table S8

Virtual Program Enrollment Reasons

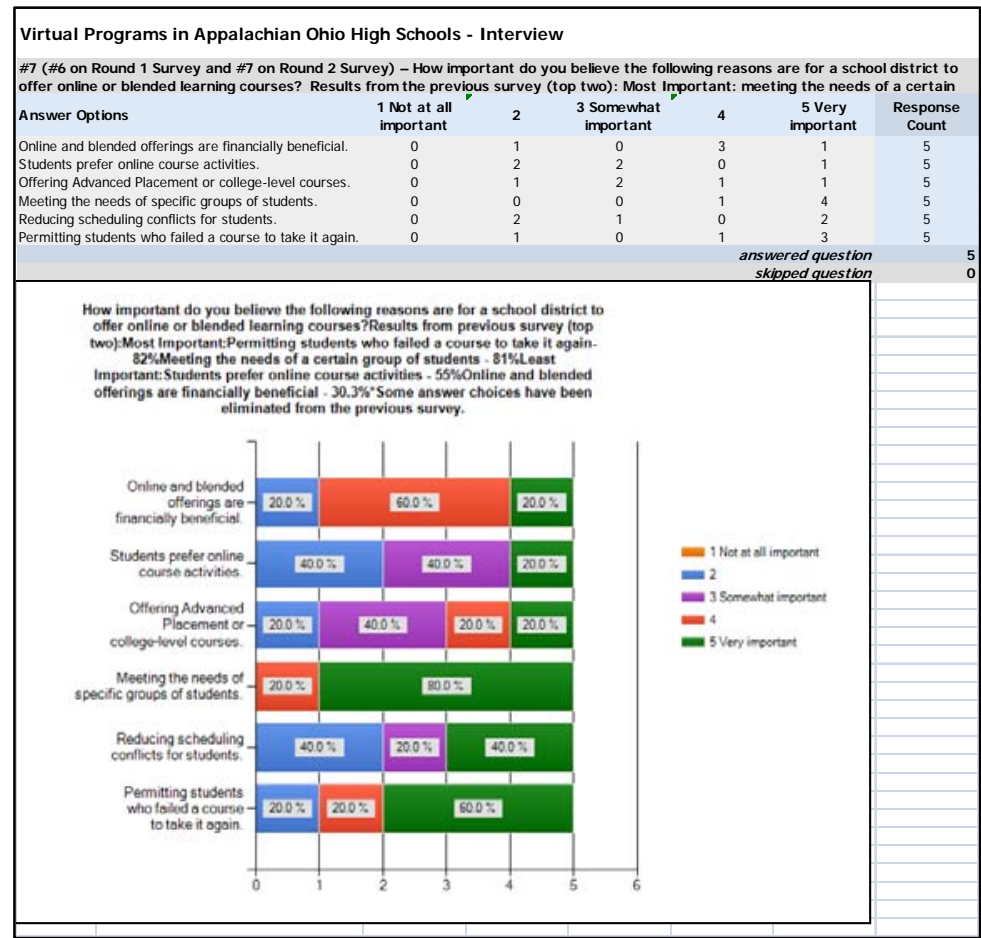


Table S9

Virtual Program Enrollment Reasons Ranked

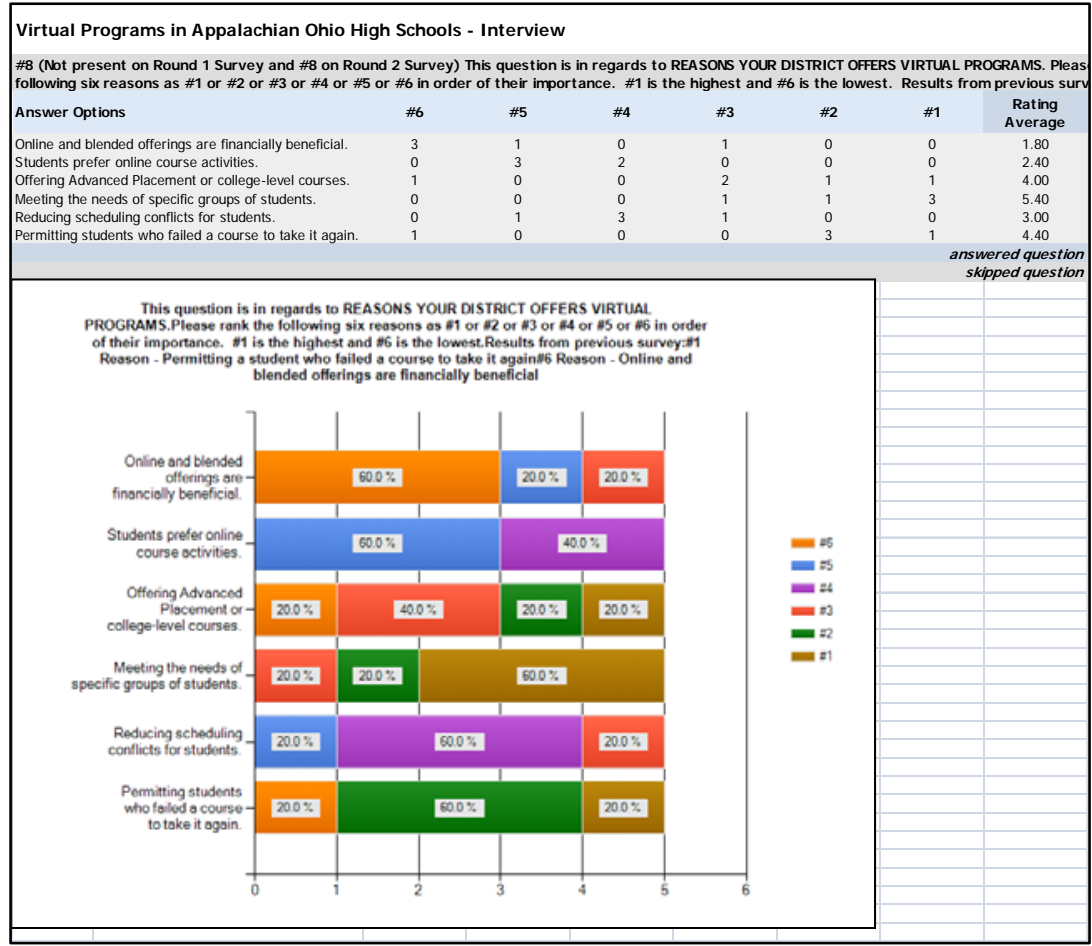

Table S10

Pedagogical Feelings - Alternative Uses of Virtual Programs

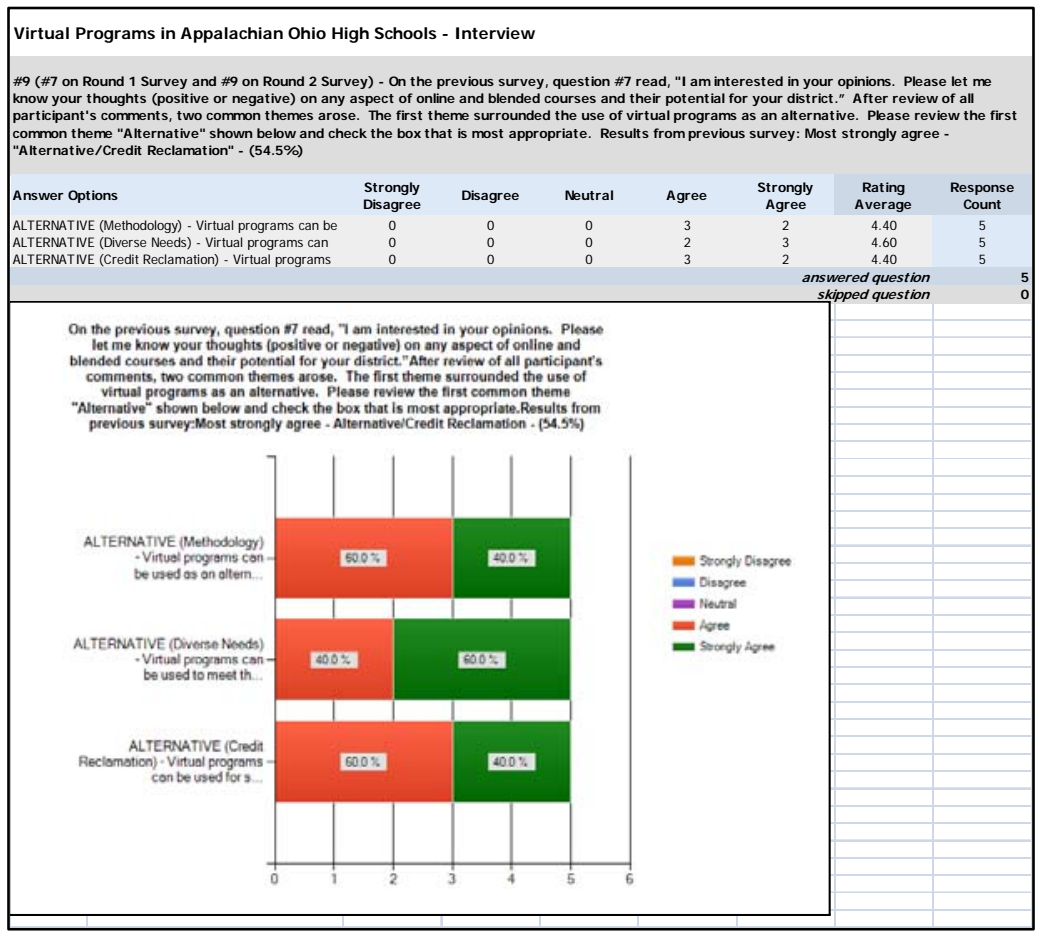


Table S1 1

Pedagogical Feelings - Alternative Uses of Virtual Programs Ranked

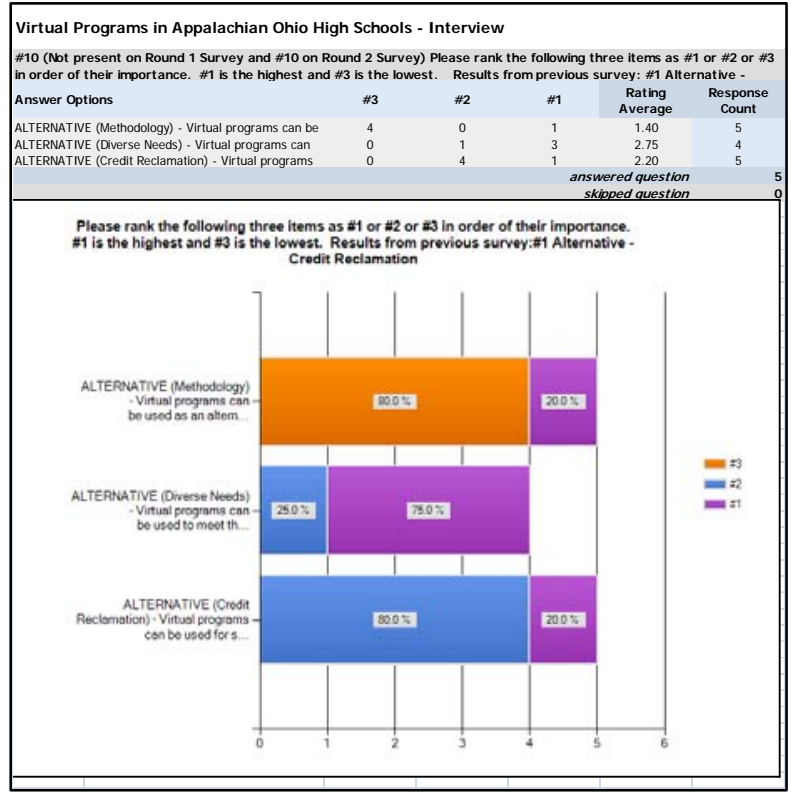

Table S12

Pedagogical Feelings - Apprehensions

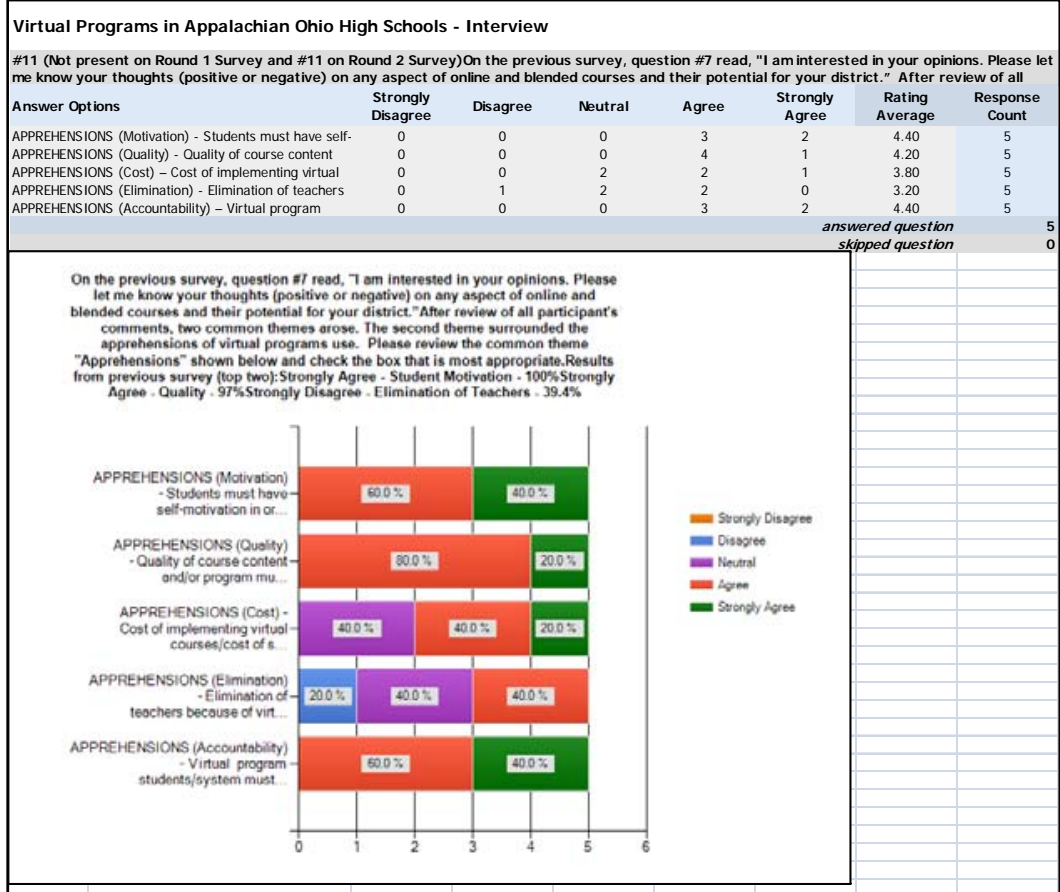


Table S13

Pedagogical Feelings - Apprehensions Ranked

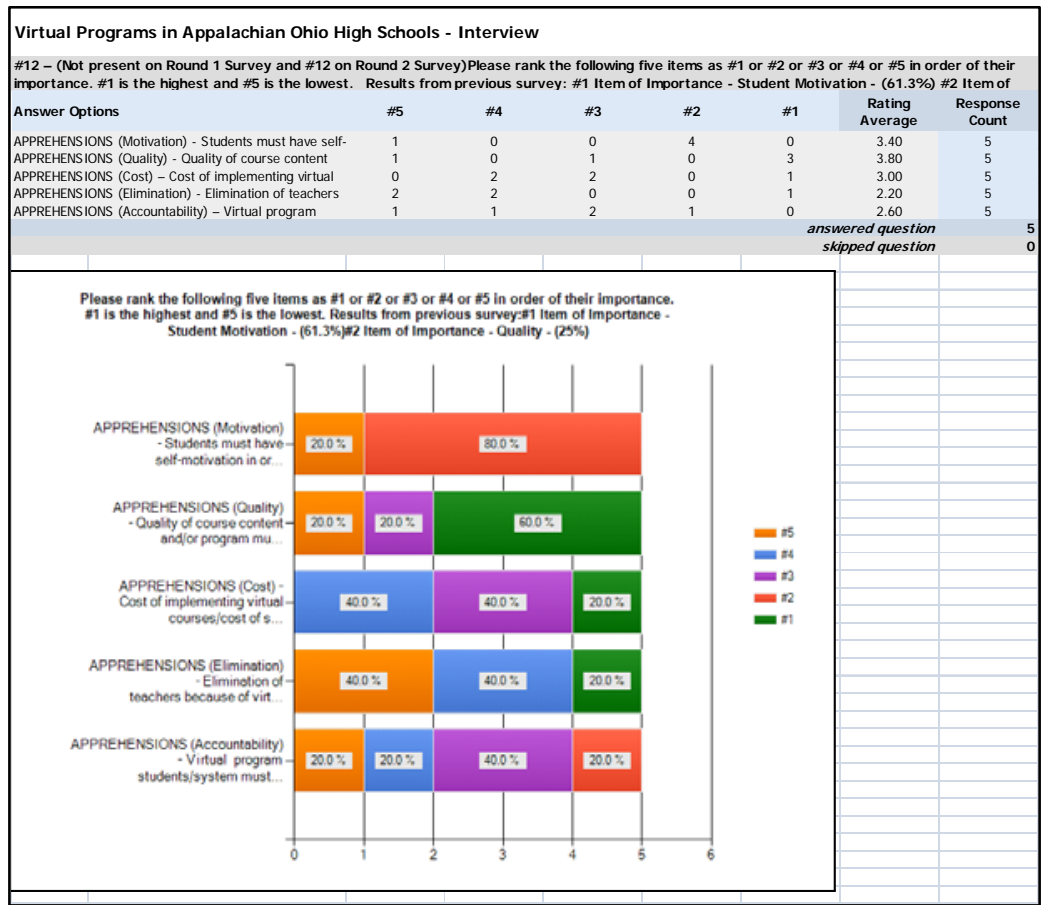

Table S14

Pedagogical Feelings of Agreement/Disagreement

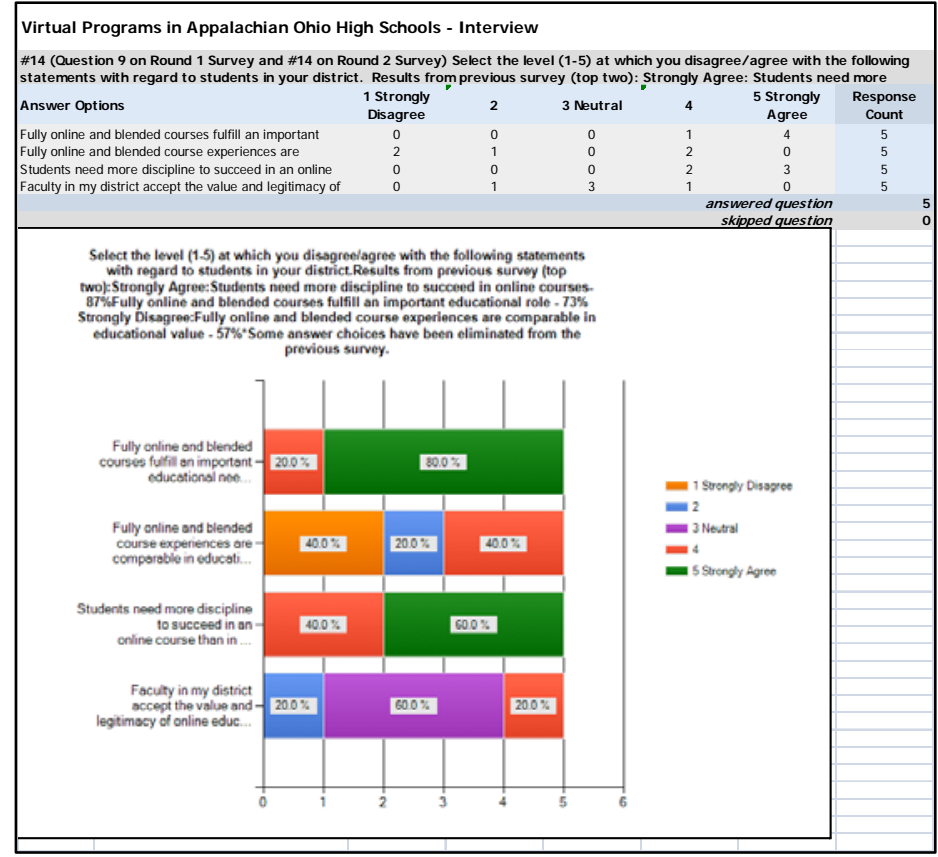


Table S15

Nature of Enrollment Type

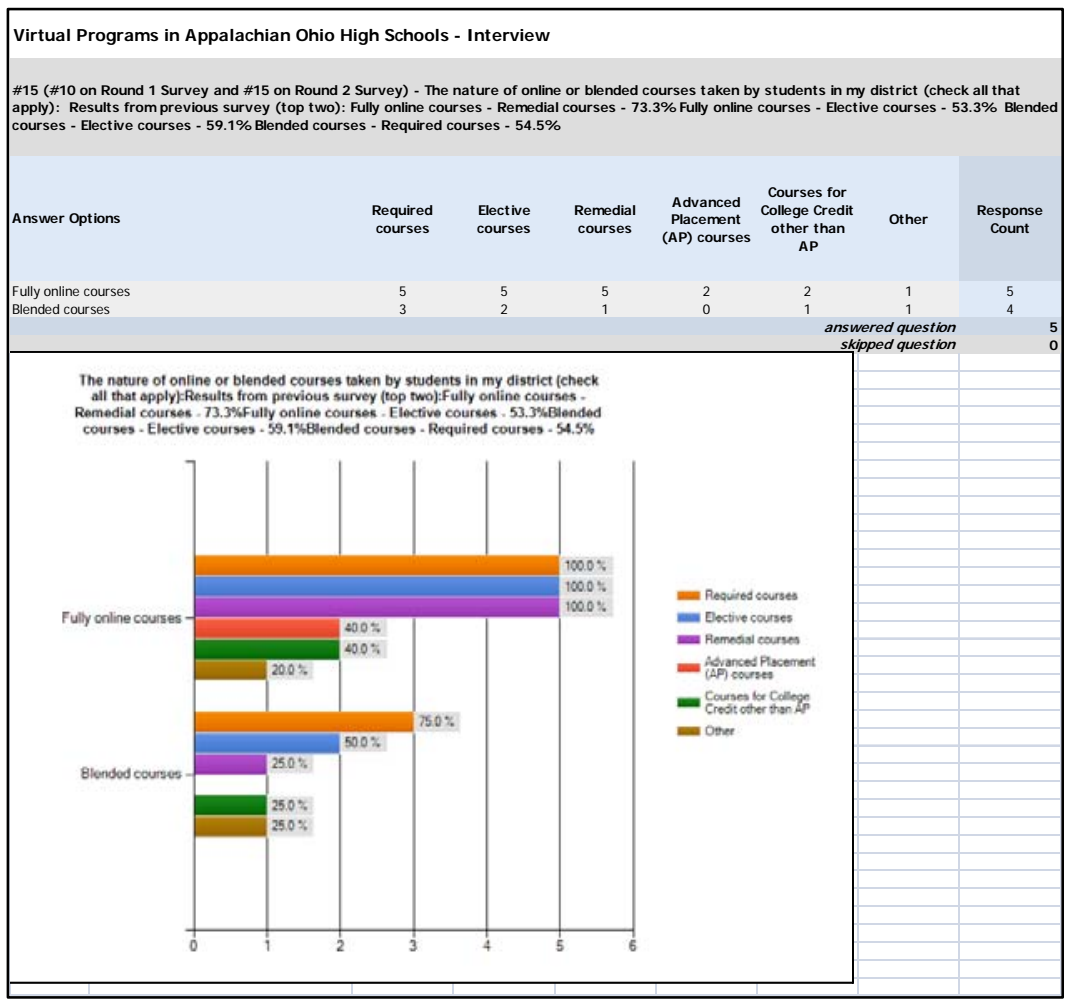

Table S16

\section{Growth of Virtual Programs}

\begin{tabular}{|c|c|c|c|c|c|c|c|}
\hline \multicolumn{8}{|c|}{ Virtual Programs in Appalachian Ohio High Schools - Interview } \\
\hline \multicolumn{8}{|c|}{$\begin{array}{l}\text { \#16 (\#11 on Round } 1 \text { Survey and \#16 on Round } 2 \text { Survey) - What is your best estimate of the number of student enrollments (a student enrolled in } \\
\text { more than one course should be counted only once) between July 1, } 2008 \text { and June 30, 2009? Results from previous survey: "Grades 9-12 Fully Online" } \\
\text { Number of students taking at least one fully online course }\end{array}$} \\
\hline Answer Options & 0 & 1-10 & $11-25$ & 26-50 & 51-99 & 100 or over & $\begin{array}{l}\text { Response } \\
\text { Count }\end{array}$ \\
\hline $\begin{array}{l}\text { Grades K-5 } \\
\text { Grades 6-8 }\end{array}$ & $\begin{array}{l}0 \\
0\end{array}$ & $\begin{array}{l}0 \\
1\end{array}$ & $\begin{array}{l}0 \\
0\end{array}$ & $\begin{array}{l}0 \\
0\end{array}$ & $\begin{array}{l}0 \\
0\end{array}$ & $\begin{array}{l}0 \\
0\end{array}$ & $\begin{array}{l}0 \\
1\end{array}$ \\
\hline Grades 9-12 & 0 & 0 & 5 & 0 & 0 & 0 & 5 \\
\hline \multicolumn{8}{|c|}{ Number of students taking at least one blended courses } \\
\hline Answer Options & 0 & $1-10$ & $11-25$ & $26-50$ & 51-99 & 100 or over & $\begin{array}{l}\text { Response } \\
\text { Count }\end{array}$ \\
\hline $\begin{array}{l}\text { Grades K-5 } \\
\text { Grades 6-8 }\end{array}$ & $\begin{array}{l}0 \\
0\end{array}$ & $\begin{array}{l}0 \\
0\end{array}$ & $\begin{array}{l}0 \\
0\end{array}$ & $\begin{array}{l}0 \\
0\end{array}$ & $\begin{array}{l}0 \\
0\end{array}$ & $\begin{array}{l}0 \\
0\end{array}$ & $\begin{array}{l}0 \\
0\end{array}$ \\
\hline \multirow[t]{3}{*}{ Grades 9-12 } & 0 & 0 & 3 & 0 & 0 & 0 & 3 \\
\hline & & & & & & & $\begin{array}{l}\text { Question } \\
\text { Totals }\end{array}$ \\
\hline & & & & & \multicolumn{2}{|c|}{$\begin{array}{l}\text { answered question } \\
\text { skipped question }\end{array}$} & $\begin{array}{l}5 \\
0\end{array}$ \\
\hline
\end{tabular}


Table S17

Growth of Fully Online Courses

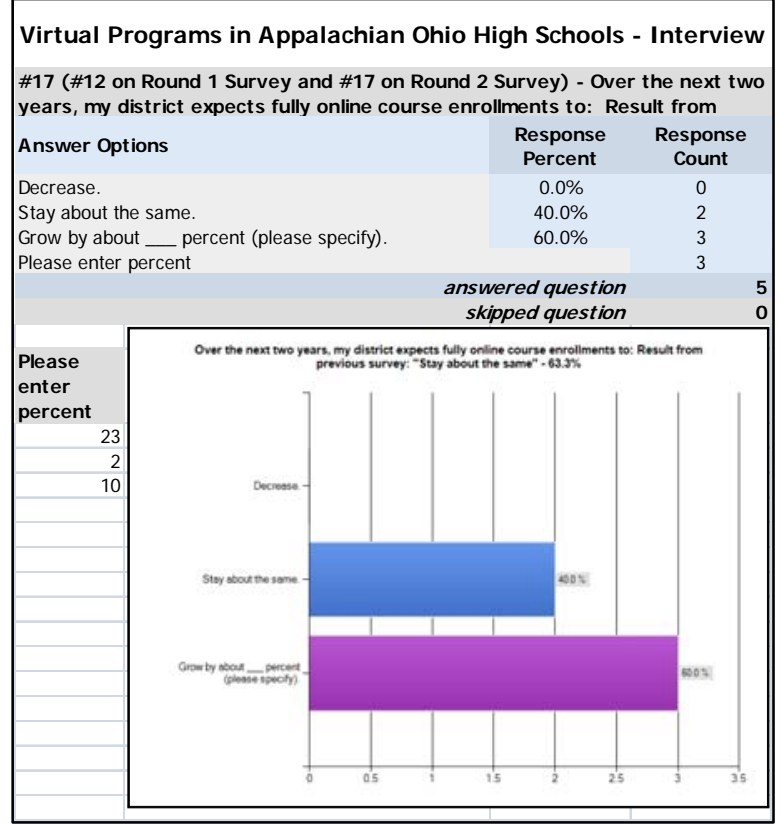

Table S18

Growth of Blended Courses

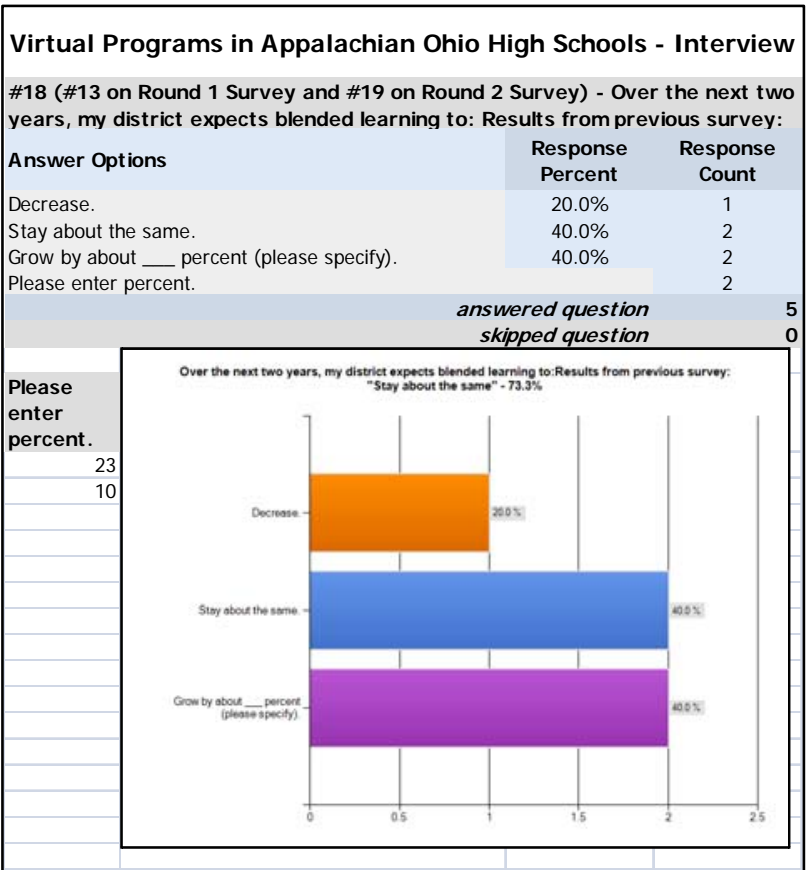


Table S19

Providers of Virtual Programs

\section{Virtual Programs in Appalachian Ohio High Schools - Interview}

\#20 (\#14 on Round 1 Survey and \#21 on Round 2 Survey) - The provider(s) for fully online and blended courses for my district are (check all that apply): Results from previous survey:

\section{Answer Options}

Your district (i.e., delivered centrally from one district) Cyber (online) charter school in your district Other schools in your district

Another local school district, or school in another

Education service agencies within your state

State virtual school in your state

Districts or schools in other states

Postsecondary institution

Independent vendor

Other (please specify)

\begin{tabular}{ccc}
$\begin{array}{c}\text { Online } \\
\text { Courses }\end{array}$ & $\begin{array}{c}\text { Blended } \\
\text { Courses }\end{array}$ & $\begin{array}{c}\text { Response } \\
\text { Count }\end{array}$ \\
1 & 1 & 1 \\
0 & 0 & 0 \\
1 & 0 & 1 \\
3 & 1 & 3 \\
5 & 2 & 5 \\
3 & 1 & 3 \\
0 & 1 & 1 \\
1 & 2 & 2 \\
0 & 0 & 0 \\
0 & 0 & 0 \\
\multicolumn{4}{c}{ answered question } & \\
skjpped question & $\mathbf{5}$ & $\mathbf{5}$
\end{tabular}

The provider(s) for fully online and blended courses for my district are (check all that apply):

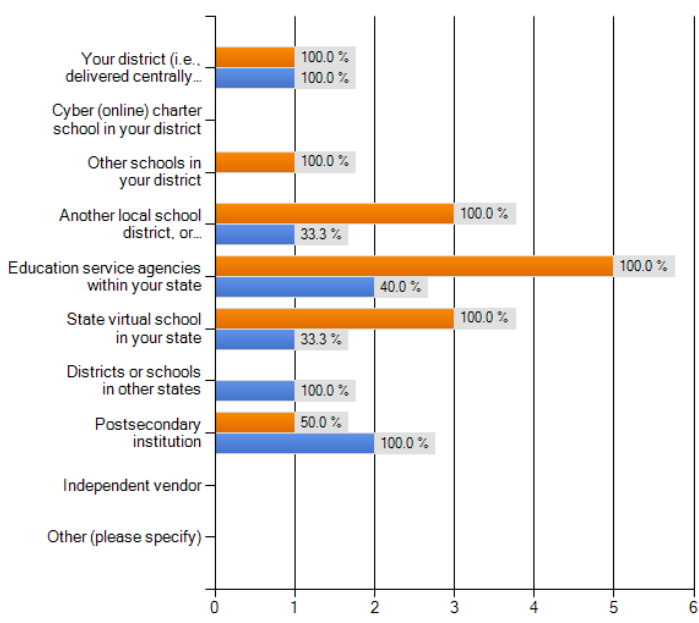

